

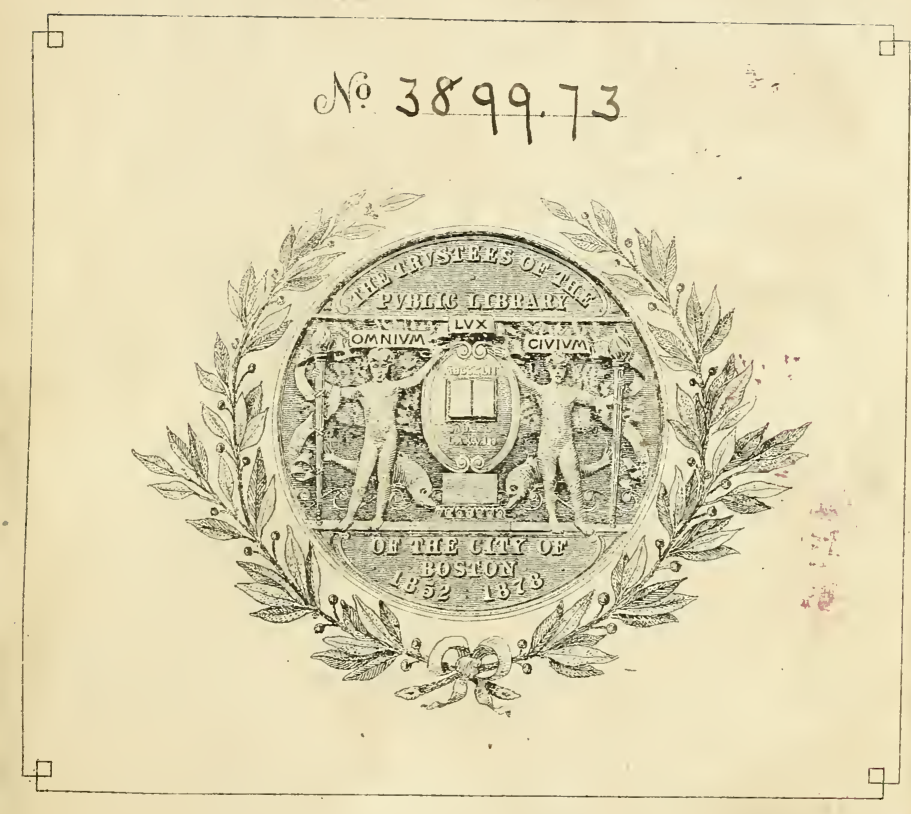




Digitized by the Internet Archive in 2011 with funding from Boston Public Library 



\section{THE HONEY-BEE:}

ITS NATURE, HOMES, AND PRODUCTS. 




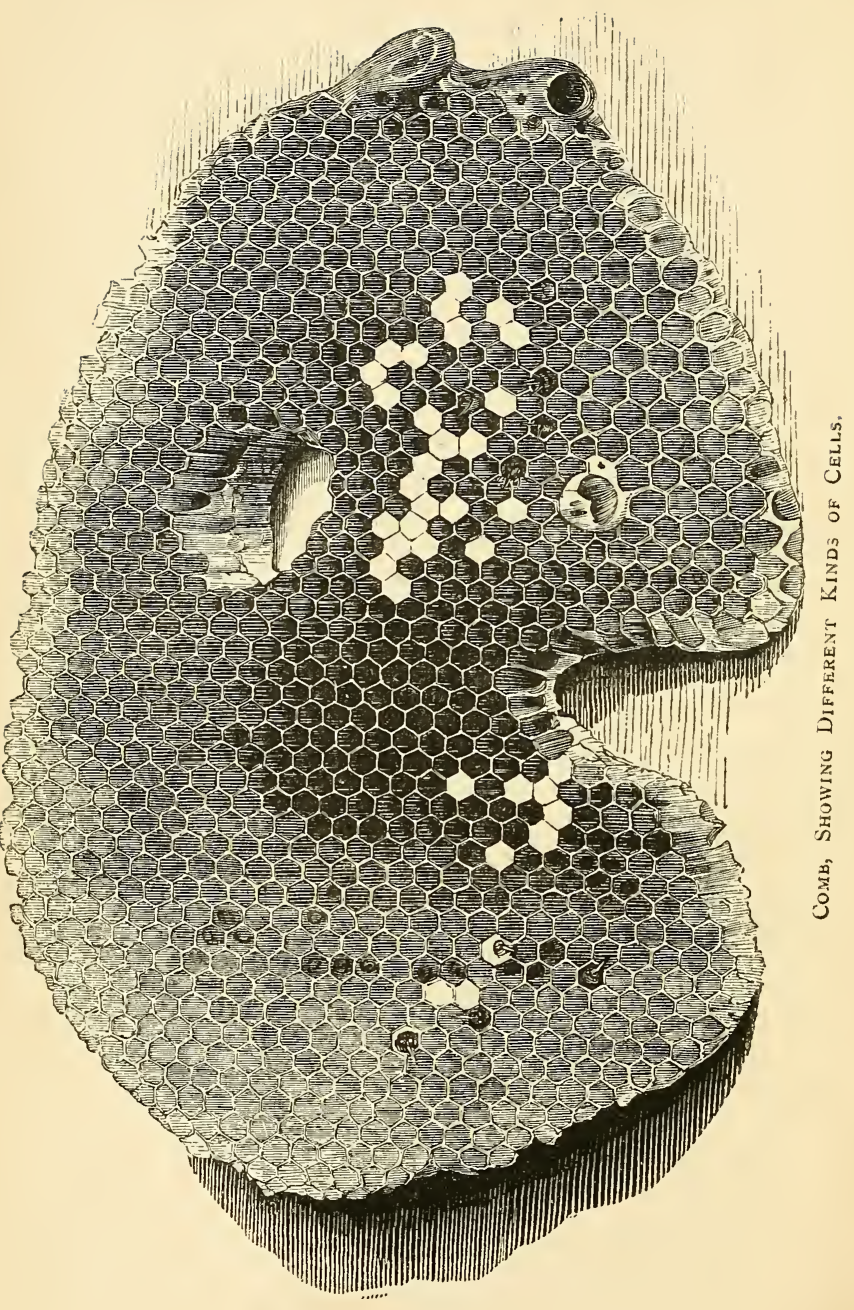




\title{
THE HONEY-BEE
}

\section{ITS NATURE, HOMES, AND PRODUCTS,}

\author{
EY \\ W. H. HARRIS, B.A., B.SC.
}

LONDON :

THE RELIGIOUS TRACT SOCIETY, 55, Paternoster Row; 65, St. Paul's Churchyard, AN I64, liccadilly. 

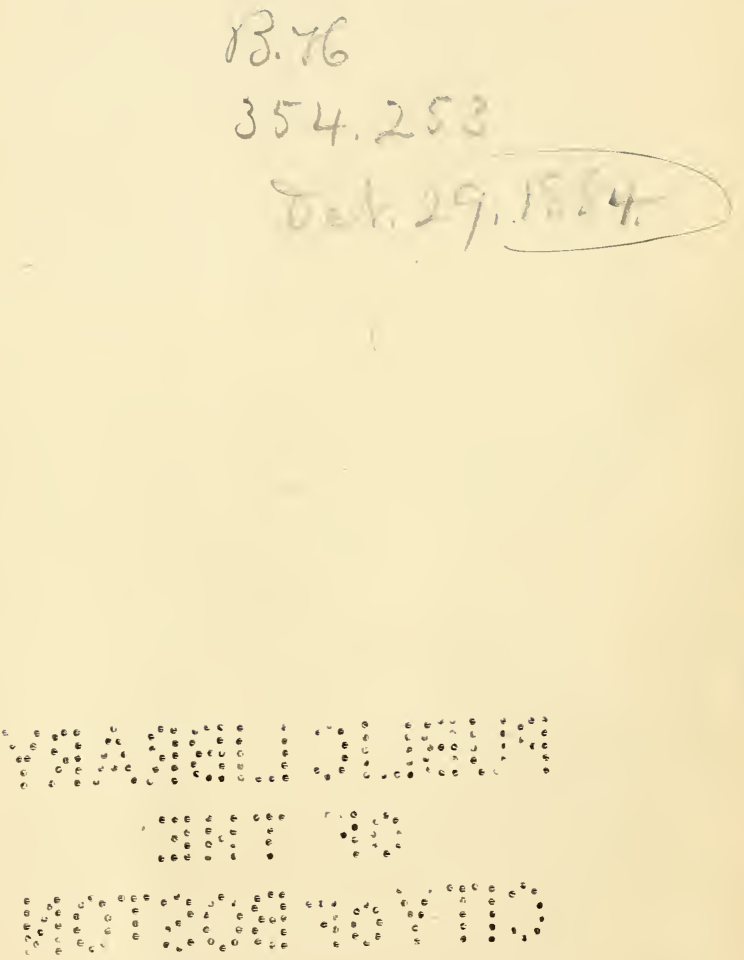

LONDON :

R. Clay, Sons, and Taylor, Printers, BREAD STREET HILL. 


\section{O N T E N T S.}

INTRODUCTION . . . . . . . . . . . . . . I-3

CHAPTER I.

HISTORIC SKETCH.

Holy Scriptures-Vedas-Egyptian Monuments-The KoranEtymological Considerations-Literature of Subject-Aristotle-Philiscus-Pliny-Vergil-Columella-Other Classical Authors-Shakespeare-Modern Writers . . . . . . . 4-9

\section{CHAPTER II.}

NATURAL HISTORY.

Orders of Insects-Stages of Development-Egg, Larva, Pupa, Imago or Perfect Insect-Three Classes of Bees: Queen, Drones, Workers ............ . . . . . . I6

\section{CHAPTER III.}

THE QUEEN-BEE.

Early Errors as to Sex-The "Mother Bee"-Distinguishing Characteristics-Functions-Attentions paid her-Effects of Loss; how Repaired by Bees-Enmity to Rivals-ILength of Life-Egg-laying ............. . . $77-28$ 


\section{CHAPTER IV.}

THE DRONES.

Distinguishing Characteristics-Time of Hatching-NumbersPAGES Purposes served by them-Destruction by Workers or other means-Unusual Survival . . . . . . . . 29-34

\section{H A P TER V. \\ THE WORKERS.}

Distinguishing Characteristics-Supposed Differences of Function among them-Sir John Lubbock's Experiments-Fertile Workers-Length of Life- "Black Bees"-Duties of Workers . . . . . . . . . . . 35-43

\section{CHAPTER VI.}

HONEY.

Origin-how Collected and Stored-Constitution-Poisonous Honey-Best, varieties of Honey-Distances traversed by Bees in search of Honey-Uses . . . . . . . . . .44-4S

\section{CHAPTER VII.}

MEAD.

Nature-Method of Manufacture-Metheglin and Mead-Estimation in former times-Queen Elizabeth's Recipe-Scandinavian liking for Mead . . . . . . . . . 49-52

\section{CHAPTER VIII.}

WAX.

Origin-Production-Chemical Constitution-Comb-Building-

Detailed Description-Amount of Wax in Hives-Commercial Value-Properties......... . . 53-7r

\section{CHAPTER IX.}

POLLEN, OR BEE-BREAD.

Origin-Collection-Conveyance-Deposition-Quantity Stored

-Uses-Artificial Substitutes . . . . . . . . . 72-75 


\title{
CHAPTER X.
}

PROPOLIS.

Derivation of Word-Sources-Nature-Purposes-Quantity ColPAGES lected-Adaptation of Materials to Wants of Bees . . . 76-79

\section{CHAPTER XI. \\ PHYSIOLOGY OF THE BEE.}

Nervous System-The Head-Eyes-Compound and SimpleUses and Powers-Sir John Lubbock's Experiments-The Antennæ-Structure and Uses-Mouth-Detailed Description . . . . . . . . . . . . . 80- Ico

\section{CHAPTER XII.}

\author{
HEARING, TASTE, AND SMELLING.
}

Hearing-Sir John Lubbock's Experiments-Sounds uttered by Queen-Effects produced by them-Smell-Organs-Purposes - Liking for, and Antipathy to, certain Effluvia-Discovery by Bees of Nectar and Honey . . . . . . . . . IOI-IOS

\section{CHAPTER XIII.}

THE THORAX.

Detailed Description-Legs-Wings-how used in FlightHooking together-Employed for Ventilating . . . . . I09-I I4

\section{CHAPTER XIV.}

THE ABDOMEN.

Respiratory Organs-Circulation of Nutritive Fluid-Digestion and Nutrition-Secretion of Wax-Reproductive OrgansDetailed description of Sting-Effects of Poison-Queen's Sting ................ I I $5-128$ 


\section{CHAPTER XV. \\ THE DISEASES OF BEES.}

Dysentery: How Produced-Indications - Treatment. FoulPAGES

Brood : two kinds-Nature-Propagation. Mr. Cheshire's Discoveries and Treatment-Fatal Effects of Disease-Detection-Vertigo-Analogy of Human and Bee Diseases. I29-I38

\section{CHAPTER XVI.}

THE ENEMIES OF BEES.

Birds-Mice-Moths-Braula Caca-Hornets and WaspsSpiders-Toads-"Robber Bees"--Prevention of robbing.

\section{CHAPTER XVII.}

HIVES.

Natural Abodes of Wild Bees-Taking Honey from Roof of House-Straw Skeps-Cottager's Hive-Supering-Nutt's Collateral Hive-Village Hive-Woodbury Hive-Abbott's Hives - Sectional Supering - Stewarton Hive - CarrStewarton Hive-Observatory Hives-Bee-houses . . I48-I 70

\section{CHAPTER XVIII.}

NATURAL SWARMING.

General Facts connected with Swarming-Reconnoitring-Settling-Hiving-Curious Incidents-Transferring Swarms to Bar-Frame Hives-Division of Swarms-Placing Swarm in Permanent Position-Number of Bees in Swarming"Casts" and Later Swarms-Prevention of SwarmingFeeding of Swarms .......... I7 I- I86

\section{CHAPTER XIX.}

ARTIFICIAL SWARMING.

Advantages-Driving: Close and Open-Transfer to Bar-Frame Hive-Conditions of Successful Driving-Various Methods of Artificial Swarming with Bar-Frame Hives . . . I87-I95 


\section{CHAPTER XX.}

QUEEN REAR ING.

Protection of Queen-cells-Nucleus Hives-Various Methods of Queen Rearing-American Plan-Introduction of Stranger Queens-Difficulties. . . . . . . . . I96-200

\section{CHAPTER XXI.}

FEEDING.

Troughs-Dangers of this Method--Bottle Feeders-Cheshire's Feeding Stage-Neighbour's Can Feeder-The "Roundfeeder"-Autumn Feeding-Spring Feeding-Uses of Precautions-Summer Feeding of Swarms-Flour-cake-Barleysugar or Sugar-cake-Mr. Hunter's Recipe . . . . 20I-2I3

\section{CHAPTER XXII.}

WI N T ERIN G B E E S.

False and True Hybernation-Temperature of Hive in Winter -Necessity for Quiet during Winter-Structure and Winterpacking of Bar-Frame Hives-Prevention of Draught and Condensation of Vapour-Supply of Water . . . . . 214-220

\section{CHAPTER XXIII.}

\section{BEE-STINGS.}

Gentleness necessary in Manipulation-Causes of Irritation of Bees-Examination of Stocks-Treatment of Stings-Remedies-Effects of Stings-Inoculation-Bee Dress-Smoke and its Uses .................. 22I-228

\section{CHAPTER XXIV.}

\section{PASSIONS AND EMOTIONS OF BEES.}

Affection for Queen and Brood-Recognition of Friends and Strangers-Fear-Anger-Covetousness-Benevolence-Remorse-Hope-Instinctive or Sense-action . . . . . 229-233 


\section{CHAPTER XXV. \\ INTELLECT AND INSTINCT IN BEES.}

Intellect in Man and Animals as Related to Immortality-Memory PAGES -Judgment-Instances of Attention-Prevision-Provision -Instinct-Manifestations-Bearing on Evolution . . . 234-243

\section{CHAPTER XXVI. \\ BEES IN RELATION TO FLOWERS.}

Connection of Plant-life and Insect-life-Reproduction of Flowers -Intervention of Insects-Hermaphrodite Flowers-Crossfertilisation-Cucumbers, Melons, \&c.-Poplars-FirsEpilobium or Willow Herb-Cincerarias-Darwin's Experiments-Nasturtium-Foxglove-Figwort-Salvia-Heath Strawberry, Raspberry, and Blackberry-Apple and PearAltruism of Bees . . . . . . . . . 244-258

\section{CHAPTER XXVII.}

SUPERSTITIONS CONNECTED WITH BEES.

Superstitions likely to gather around Bees-Unlucky to Buy Bees -Ill Omen for a Swarm to Settle on a Dry Stick-"Have the Bees been told?"-Turning Hives on the Death of the Owner-Probable Origin of these Errors . . . . 259-267

\section{CHAPTER XXVIII.}

THE PROFITS OF BEE-KEEPING.

Methods of Honey-taking-Straw Caps-Bell-Glasses-Sections -Frames-Extractors-Run Honey-Average Returns of Hives . . . . . . . . . . . . . 268-272 


\section{LIST OF ILLUSTRATIONS.}

FIG.

PAGE

Comb, Showing Different Kinds of Cells . Frontispiece

I. Eggs and Larva of Bees . . . . . . . . . . . . I I2

2. LARVA ..................... I I 3

3. Seated Cells . . . . . . . . . . . . . . I4

4. a, LARVA FUll GROWN, viewed sideways. b, LARVa

PREPARING FOR PUPA SIATE . . . . . . . . I5

5. Worker Larva and Pupa in Comb ... . . . . . . I6

6. The Queen of The Hive . . . . . . . . . . . . 19

7. Queen surrounded by Attendants . . . . . . 20

8. A Drone . . . . . . . . . . . . . . 29

9. A Worker BeE . . . . . . . . . . . . . . . 35

Io. A Worker Bee, Showing the Scales of Wax • • 53

II. Festoons of Bees Suspended from the Roof of the

Hrve . . . . . . . . . . . . . 55

12. Cluster of Bees .. . . . . . . . . . . 58

13. WaX-Worker Commencing A Comb . . . . . . 59

I4. Diagram of Cells . . . . . . . . . . . . 63

I5. Supposed Cikcular Cells. . . . . . . . . . . . 63

16. Arrangement of Cells . . . . . . . . . . . 64

I7. Diagram showing Slope of Cells . . . . . . . . 66

18. Arrangement of Combs in a Bell-Glass . . . . . 68

19. The Queen Cell . . . . . . . . . . . . . 69

20. Queen Cells in Situ.............. . . 70

2I. Hind-Leg of A BeE . . . . . . . . . . . . . 73

22. Nervous System of Privet Hawk Moth . . . . . 81 
FIG.

23. Nervous System of Larva of Bee.

PAGE:

24. Nervous System of Perfect Insect

25. Eyes of a Bee (GReatly magnified)

26. Facets of Eye of A BeE. 86

27. Head of Bee, with Antenne . . . . . . . . 98

28. Lower Segments of Hind-Leg of Bee, considerably ENLARGED . . . . . . . . . . . . . . I I IO

29. Complete Hind-Leg of Bee.......... . . ilo

30. Wing of BeE . . . . . . . . . . . . II I

3I. Hooklets of a Bee's Wing . . . . . . . . II3

32. Abdomen of Bee, showing Respiratory Organs . . il6

33. Air-Sacs of Worker ............ II I

34. $a$, Air-Sacs ; $b$, Ovaries, of The Queen . . . . . I I 8

35. $a$, Tracheæ; $b$, Elastic Spiral of Tracheæ . . . I I 9

36. Under Side of Abdomen, showing Wax Scales . . I I I

37. Bee, Showing the Wax Scales . . . . . . . I2I

38. Scales ..................... I2I

39. Ovaries and Spermatheca of Queen...... . I 23

40. Sting of a Bee (greatly Magnified) . . . . . . I 25

4I. Barbs of a Bee's Sting (Very highly magnified) . I i26

42. The Enemies of Bees ....... . . . . . I4I

43. Straw Skep............. . . . . I5O

44. Flat-topped Hive and Straw Super... . . . I5I

45. Neighbour's Improved Cottager's Hive . . . . I I52

46. ", " ", . . . . I53

47. Moinern Hives. Nutt's Collateral Hive in the Foreground . . . . . . . . . . . . . I55

48. The Woodbury Hive . . . . . . . . . . 157

49. Woodbury Straw Bar-Frame Hive... . . . . 157

50. Cheshire's Bar-Frame Hive . . . . . . . . . I59

5I. Cheshire's Bar-Frame Hive (sectional view). . . . i6o

52. Abbott's Standard Frame .......... I6I

53. $, ", \quad$ (TOP VIEW) . . . . I6I

54. Neighbour's Sectional Super (open) . . . . . . I62

55. Frame Super . . . . . . . . . . . . . . I62

56. Glass Frame Hive, with Super ... . . . . i63

57. Stewarton Hive ............... . . I65 
FIG.

58. The Carr-Stewarton Hive . . . . . . . . . . I67

59. Unicomb Observatory Hive . . . . . . . . . . i68

6o. A Swarm ................. . . I73

6I. "TANGING" . . . . . . . . . . . . . . I74

62. Hiving a Swarm . . . . . . . . . . . . . I79

63. SWARMING BoARD . . . . . . . . . . . . . . . I92

'4. Queen Cage over Sealed Cell. . . . . . . . . I97

Inserted Queen Cell . . . . . . . . . . . . I98

Bottle Feeder . . . . . . . . . . . . . 202

'. Cheshire's Feeding Stage .. . . . . . . . . 203

i. CAN Feeder . . . . . . . . . . . . . . . 205

). Round Tin Feeder . . . . . . . . . . . . . . 205

o. Epilobium Angustifolium. (Young Bloom). . . . $24 \mathrm{~S}$

II.,,$\quad$ (OLD BloOM) . . . . 248

72. Cineraria (Magnified) . . . . . . . . . . 250

73. Tropcelum Majus. (Young Bloom) . . . . . . . . 252

74. $\quad,, \quad$ (OLD BloOM) . . . . . . . 252

75. Section of Scrophularia Nodosa . . . . . . . . 254

76. Scrophularia Nodosa. (Y'oung Bloom) . . . . . . . 254

7. $\quad$, , (OLD BlOOM) . . . . . . 254

8. Salvia Officinalis. (New Bloom) ....... . 255

19. , , $\quad$ (Oln Bloom) ........ 255

8o. a, Erica Tetralix. b, Anther of Tetralix . . . 255

8i. Section of Strawberry Bloom . . . . . . . . . 256

82. Section of Apple Bloom ............ . 257 



\section{THE HONEY-BEE :}

ITS NATURE, HOMES, AND PRODUCTS.

\section{INTRODUCTION.}

In these days of intense business-pressure, it is a good thing for men to cultivate hobbies. We say this, notwithstanding the fact that men with hobbies are likely to become bores, from thinking and talking too incessantly of their pet occupations, or are apt to run into extravagant expenditure of time and money, which could be better utilised. Now, in recommending apiculture, or bee-keeping, as a recreation from more serious pursuits, we feel that we incur little risk of increasing the number of bores in society, or of inducing an undue outlay of hours or pounds on the part of those who follow our suggestions. For, on the one hand, the facts likely to be spoken of by enthusiastic apiarians to casual hearers could not fail to interest ; while the practical results of bee-keeping will certainly, to say the least, repay in hard cash all 
reasonable outlay on the part of any one who is possessed of ordinary good sense, and who learns to manage his hives according to modern methods.

In the following pages we hope to make good both these statements. We are sure that comparatively few people know what marvellous creatures bees are; what constant pleasure may be found in watching their work; what opportunities for skilful use of brain and hand are afforded by an apiary; what a wide field of study and information is displayed by these domesticated insects : and though we shall not hold out dazzling prospects of a large return of money from the pursuit we are commending, we shall show by facts that, in ordinary seasons, the yield of honey should amply cover the cost of the bees, their homes, and their requirements.

Nor would we be understood to limit our recommendation of bee-keeping to men alone. It is an occupation eminently suited to women. It has none of the manifest drawbacks of poultry or rabbitrearing. The needs of the hives are usually not so pressing as to involve a disregard of weather or important engagements. Many operations in apiculture call for female dexterity of hand and finger. It is true that a little courage, in which few ladies are deficient, is necessary in making a beginning of skilful beemanagement. But, duly protected by veil and gloves, even the timid need have no fear of being stung or seriously incommoded.

Intelligent boys and girls of fifteen years and upwards will find a hive or two of bees quite within their power of management, and the clever and industrious insects will afford them a surprising amount 
of interest, and, it may be, some not unimportant moral lessons.

In the hope of enlarging popular knowledge of these wonderful insects, and so of increasing apiculture, we have written this bock. It does not profess to go exhaustively into the practical part of bee-keeping; but enough information is given for ordinary apiarian purposes. The excellent publications of Langstroth, Cowan, Neighbour, Cheshire, Hunter, Taylor, and Wood, will supply all details intentionally omitted from the present treatise. 


\section{CHAPTER I.}

HISTORIC SKETCH.

Holy Scriptures-Vedas-Egyptian Monuments-The Koran-Etymological Considerations-Literature of Subject-Aristotle-Philiscus -Pliny-Vergil-Columella-Other Classical Authors-Shakespeare-Modern Writers.

FAR back in historic time there are records that man had learnt the value of the bee. The book of Job-probably the oldest of our sacred Scripturescontains a reference to honey. The Pentateuch, the Chronicles of the Israelites, the Psalms, the works of Solomon, and nearly all the later books of the Old Testament, speak of these wonderful insects or their produce. They are referred to in the Vedas of Hindostan, the monuments of Egypt, the poems of Homer and Euripides, and the narrative of Xenophon's expedition into Persia.

Throughout the ancient civilised world the virtues of honey were celebrated, and the habits of the bee served to point a moral for human conduct. It is remarkable that in the Koran we find Mahomet representing the Almighty as addressing this insect alone of all the creatures He had made: "The Lord spake by inspiration unto the bee, saying, 'Provide 
thee houses in the mountains and in the trees, and of those materials wherewith men build hives for thee; then eat of every kind of fruit, and walk in the beaten paths of thy Lord.' There proceedeth from their bellies a liquor of various colours, wherein is a medicine for men. Verily, herein is a sign unto people who consider."

The ancient Egyptians must have known much of the domestic economy of the hive, for they took the figure of the insect to symbolise a people governed by a sovereign, and this so far back as the twelfth dynasty, or 2080 - I920 B.C.

It has been argued on etymological grounds that in a much remoter period still, the human race had domesticated the bee; for in Sanskrit ma means honey, madluupa honey drinker, and madhukara honey maker. Madlut is evidently the origin of our word mead. Again, mil or mat, in Chinese, signifies honey; and it can hardly be a mere coincidence which has brought about so close a resemblance between the Turanian and the Indo-European terms above mentioned. We have rather the indication of the survival of a name in two branches of a still older language than either of the Asiatic tongues, from which so large a proportion of modern speech has flowed, thus carrying us back to an enormously remote period in the history of man. The Latin mel, and French miel, both meaning honey, are, of course, the offspring of the Greek; and all the above words, according to some authorities, point to the circumstance of the constructive power of the insect having impressed the minds of men emphatically.

In the Teutonic languages biene, bee, \&c., are 
evidently connected with $b y$-a termination met with in many English towns, and signifying "a dwelling”; and so we see that it was not so much the sweet liquid procured and stored by the insects, as the skill and beauty with which they fashioned their combs, which struck their human observers ; and though we cannot with certainty affirm that men domesticated them in these remote times, it seems probable that races who, before the historic period, had learnt to make use of most of the animals now under immediate subjection to the wants and purposes of man, saw the convenience and wisdom of turning to account the nectar-collecting habits of the bee. Jacob, seventeen centuries before Christ, told his sons to take "a little honey" among their presents to the lord of Egypt. Again, the land of Canaan was pictured by God to Moses as "a land flowing with milk and honey." We should, therefore, probably be justified in inferring that, as the one liquid was derived from herds under the people's control, so, too, the other came from domesticated insects. It may be that no hives were used at so early a period as the sixteenth century before Christ, and the reference in Ps. Ixxxi. I6- "with honey out of the rock should I have satisfied thee"-would seem to indicate that, at a much later date, the bees were left at large in their native haunts. Still, the numerous references of the earlier Scriptures make it plain that honey was an article of common use, and was obtainable at the discretion of those in Palestine who wished for it.

With regard to the ancient literature of our subject, the first treatise on the bee now extant is that of Aristotle in his History of Animals, written about 
330 B.C. Observations of a scientific kind had, however, been made with regard to these insects by a philosopher of Asia Minor, who is said to have devoted a long lifetime to watching their habits. Unfortunately, the records of his studies in this department of entomology have not survived to our day. We have also to regret that later ages lost the benefit of the labours of Philiscus of Thasos, who is said to have abandoned the abodes of men for a forest life, that he might learn all that was possible of the nature and work of these creatures, which seemed to him so marvellous in their structure and their doings. It is Pliny the Elder-the well-known Roman man of science, who lived near the beginning of the Christian era-to whom we are indebted for notices of the workers in natural history just mentioned, while he himself devotes some considerable space in his own book to a description of the bee.

Nearly a century earlier, Vergil, the poet of rural life, as well as of loftier themes, wrote a charming book-his Fourth Georgic-on the subject of these our winged friends. We may smile at his wondrous plan for securing a prodigious swarm, and modern methods may claim far more reasonableness and success than those he advocates in apiculture; but we may rejoice to see how bewitching was the pursuit of bee-keeping nearly two millenniums ago, and how true it has been through all the centuries, as the French writer Gelieu says, "Beaucoup de gens aiment les abeilles; je n'ai ou personne qui les aima médiocrement: on se passionne pour elles."

The orator Cicero makes frequent reference to them in his charming treatise on Old Age, 
and other classical writers allude not unfrequently to these insects.

Columella, who lived in the first century of the Christian era, gave, in his work De re rusticâ, many directions for apiarians; and though, of course, abounding, like Vergil's work, in errors on certain points, his book shows a decided advance beyond the knowledge of preceding writers.

We might speak of Theophrastus, Celsus, and Varro as contributing to the literature of bee-lore, but it would be beyond the scope of our design to detail what they have written on the subject. Coming, however, down to much more recent times, and to our own country, we cannot resist the temptation to quote the well-known lines of our most marvellous poet Shakespeare, whose comprehensive intellect almost rivalled that of Solomon, for "he spake of trees, from the cedar-tree that is in Lebanon, even unto the hyssop that springeth out of the wall : he spake also of beasts and of fowl and of creeping things and of fishes." The passage to which we now especially refer is to be found in his play of Henry $V$., act i. sc. 2 :-

"Therefore doth heaven divide The state of man in divers functions, Setting endeavour in continual motion ; To which is fixed, as an aim or butt, Obedience : for so work the honey-bees ; Creatures, that, by a rule in nature, teach The act of order to a peopled kingdom. They have a king and officers of sorts : Where some, like magistrates, correct at home :

Others, like merchants, venture trade abroad;

Others, like soldiers, armèd in their stings

Make boot upon the summer's velvet buds; 
Which pillage, they, with merry march, bring home

To the tent-royal of their emperor :

Who, busied in his majesty, surveys

The singing masons building roofs of gold;

The civil citizens kneading up the honey;

The poor mechanic-porters crowding in

Their heavy burdens at his narrow gate ;

The sad-eyed justice, with his surly hum,

Delivering o'er to executors pale

The lazy yawning drone.".

Of more recent writers we may mention the French Réaumur ; the Swiss, Bonnet; and Huber, of Geneva, who, with his assistant Burnens, gave the world so many wondrous details of bee-life and habits. In our own country, Dr. John Hunter, Dr. John Evans, who has been called the "poet-laureate of bees," Shuckard, Sir John Lubbock, Cowan, John Hunter, Taylor, Cheshire, Alfred Neighbour, Pettigrew, Abbott, and many writers in the British Bee Joumal, have largely added to our apiarian knowledge. Not only in America, but universally, the Rev. L. L. Langstroth, of Ohio, has a well-earned reputation for his researches and his practical instructions with regard to apiculture. In Germany, Dr. Dzierzon of Carlsmarkt, in Silesia, and Baron von Berlepsch, of Coburg, stand at the very head of authorities on all that relates to bees and bee-keeping. 


\section{CHAPTER II.}

NATURAL HISTORY.

Orders of Insects-Stages of Development-Egg, Larva, Pupa, Imago or Perfect Insect-Three Classes of Bees : Queen, Drones, Workers.

IT will be observed from the title of this book that it deals with the honey-bee. The necessity of this restriction will become immediately evident when we mention the fact that in Great Britain there are no less than twenty-seven genera and I77 species of native bees, none of which have been successfully domesticated except Apis mellifica, or the ordinary hive-bee.

The term "insect" has unfortunately been loosely employed in popular parlance to include such diverse beings as coral-polyps and house-flies. As the name itself indicates, it is properly applicable only to such animals as are more or less distinctly divided into segments. All true insects, in fact, are plainly divisible in their perfect state into three portions, the head, thorax, and abdomen. The most important classes in this portion of the animal kingdom are distinguished by the characteristics of their wings, and are- 
I. Coleoptera, or those possessing crustaceous sheathing wing-covers, including all the beetles.

II. Orthoptera, having the wings when at rest in straight longitudinal folds, comprising such families as the earwigs, cockroaches, grasshoppers, and locusts.

III. Neuroptera, nerve-winged, characterised by four naked, strongly reticulated organs of flight, as seen in dragon-flies, may-flies, and white ants.

IV. Hymenoptera, membrane-winged, resembling the Neuroptera in some respects, but with fewer reticulations, and their organs of flight when in use are hooked together along the margins, so as to expose a continuous surface. Another distinguishing character is the appendage at the tail, in the form of either a sting or an ovipositor. The chief representative families are the bees, wasps, gad-flies, ants, and ichneumons.

V. Lepidoptera, having the wings covered with a scale-like powder, set like the tiles of a house. The butterflies and moths all belong to this order.

VI. Diptera, or two-winged insects, embracing the gnats, "daddy-long-legs," blow-flies, and house-flies.

Less important are the Homoptera, which have the wings of the same consistence throughout, as the aphides or blight-insects.

The Heteroptera, having the fore-wings coriaceous (or leathery) at the base and membranous towards the extremity. These comprise the bug tribe; while fleas belong to the Aptera, or wingless insects.

Insects pass through four stages during their lifetime: the egg, the larra, the pupa, and the imago conditions. The honey-bee exists in each of these states. 
The egg.-All the eggs of the community are laid by the queen. The cells in which they are deposited vary in size and in shape, according to whether queens, drones, or workers are to be developed in them. In length the eggs are about one-twelfth of an inch; in shape, oblong, but a little broader at the

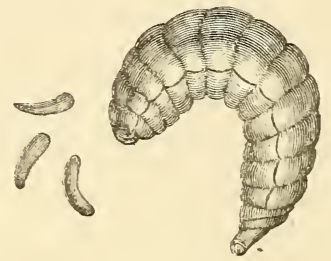

Fig. 1.-Eggs and Larva of BeEs.

upper than at the lower end, and slightly curved; in colour they are white, with a bluish tinge. Their external coat is slightly glutinous when they are first laid, and thus they adhere to the bottom of the cell in which they are deposited.

The larva.-Under the genial influence of the heat of the hive, ranging from $66^{\circ}$ to $70^{\circ}$ Fahr., the formation of the larva from the egg-contents immediately begins; and, in the course of three days, a tiny worm or grub has been developed, and makes its way out of its delicate shell. It now lies curled round, still at the base of its dwelling, and, fed by the nurse-bees on a jelly-like mixture of pollen and honey, it rapidly grows. Its food supply is made strictly correspondent to its wants, and by the time the larva is ready for its next change not a drop of the jelly is unconsumed. The fleshy white grub is in shape at first slightly, and afterwards strongly 
curved, and a little pointed at each end. The future segments of the insect now become gradually visible, fifteen in number, and ten of them are furnished each with a minute aperture on opposite sides of the body, and connected with air-tubes, or spiracles, by which respiration is carried on. The segments have also a series of minute tubercles, whose office seems to be to aid in the motions of the grub, which motions doubtless contribute to the assimilation of food, and so to growth. The head of the larva is small, is smooth above, and is furnished with two little projecting horns, from which will be developed the future antennæ.

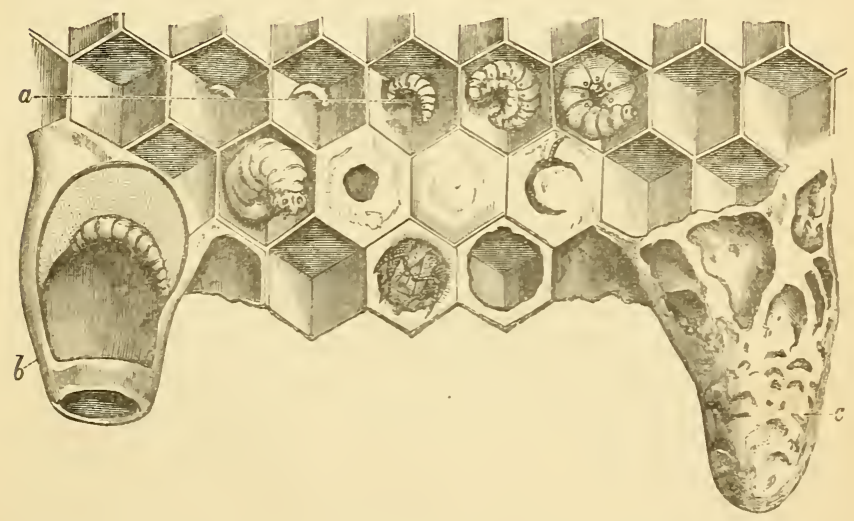

FIG. 2.-LARVE.

a. Worker larvæ. b. Queen larva. c. Queen cell sealed.

The jaws are small, and articulate below a narrow lip. They are constantly in motion, probably to reduce the pollen-grains existing in the so-called bee-bread, which, with honey, as already mentioned, constitute their food. Beneath the jaws, and centrally between them, is a fleshy protuberance, which 
has a perforation at its extremity, through which the larva emits a sticky fluid, similar to that from which spider's-web or silk is made. With this the grub spins for itself a cocoon, in which a further and important transformation takes place in the structure of the insect.

The time occupied in making this silken dress is, for drone- and worker-larvæ, thirty-six hours. Princesses, who trouble themselves to make only halfcocoons, finish theirs in twenty-four hours. So soon as the grubs are ready for this process, the nurse-bees

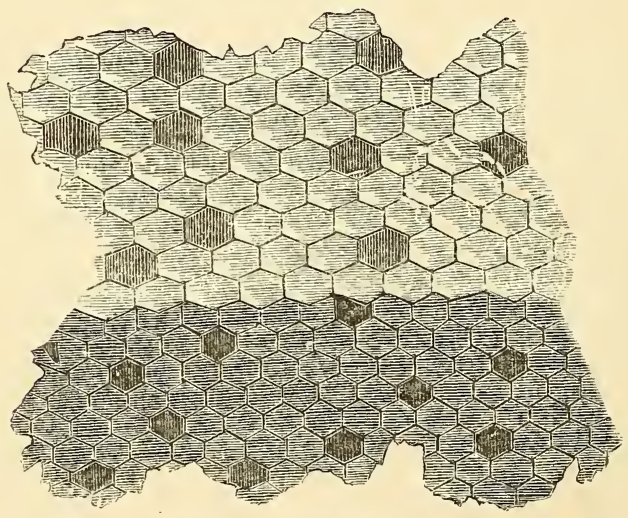

Fig. 3.-Sealed Cells.

form over the entrance to each cell a lid made of wax and a sticky substance called propolis, leaving, however, minute perforations for the admission of air. These coverings are darker than the caps of the honey-cells. They are also somewhat convex over worker-larvæ, and over drone-grubs they stand out almost hemispherically. Hence it is easy to distinguish the look of brood cells from that of those 


\section{CHAPTER III.}

\section{THE Q U E E N-BEE}

Early Errors as to Sex-The "Mother Bee"-Distinguishing Characteristics-Functions-Attentions paid her-Effects of Loss; how Repaired by Bees-Enmity to Rivals-Length of Life-Egg-laying.

ONE of the earliest facts ascertained in the study of bees was that there existed in each colony one individual differing considerably from all the rest in appearance and in functions. Early observers, it is true, mistook even the sex of the one so distinguished. Vergil says :

" Et circa regem atque ipsa ad prætoria densæ Miscentur."

And, again,

"Rege incolumi mens omnibus una est."

Shakespeare, in the passage quoted in a previous chapter, talks of "a king," and other writers were equally ignorant of the true state of the case. The headship of the hive is, in fact, held by a solitary female, to whom the name of "queen " has been given, both on account of the respect she receives, and the controlling influence she appears to exercise over the other inmates of her domain. The Germans, on perfectly safe grounds, call her "the mother-bee"; and it is, doubtless, owing to the all-important 
circumstance of the continued existence of the race depending upon her, that she is the object of such intense affection, attention, and devotion.

This is corroborated by the circumstance that it is only after she has been fertilised, and begins to lay, that she is much honoured. As princess merely, not the slightest respect is paid to her. She is not even fed by the workers, but has to help herself, and in doing so must scramble over the busy crowd in her way, not one of whom will trouble to move out of her path.

Two or three prominent characteristics serve readily to distinguish the queen from the rest of the bees. In the first place, her body is much longer and more tapering towards its lower extremity. Her wings are shorter in comparison with her length. The upper surface of her body is of a darker and more glossy hue than that of her subjects. Her movements are slower and less anxious in appearance than those of the workers, except at swarming time, when excitement quickens her steps, and gives her an air of purposeless solicitude; though, in reality, her anxiety is caused by the desire to slay a royal and rival daughter, whose co-existence in the hive she cannot tolerate.

A closer examination reveals several other points of difference. In our English species, of which we are now especially speaking, her colour is yellowish underneath; her head is rounder, her legs are longer, her tongue is more slender and not so extensile as that of the other bees; and her sting is curved instead of being straight, like the formidable weapon of the workers. It is asserted by some writers that she 
has a peculiar odour readily distinguishable, and so powerfully attractive to her people, that they will alight on the finger of any one who has been handling their queen.

Several characteristics of a negative kind may also be noted. Her proboscis is not fitted for extracting the nectar of flowers, and she can only lap food, or take it from the tongues of her attendants. She, moreover, has no expansion of the gullet for a honey-bag, since she never requires to collect and carry home the sweet liquid. She possesses no cysts for the elaboration of wax, as she takes no part in contributing to the materials of her dwelling. The last

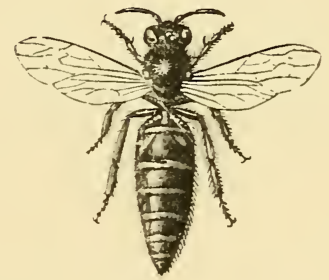

Fig. 6.-The Queen of The Hive.

pair of legs are convex on the outside, containing no pocket for carrying pollen or propolis ; and the other legs are without the brushes of the workers, which enable them to clear their bodies of the powdery discharge of the anthers of flowers, for she never visits plants. All her wants in the way of nourishment are supplied by her subjects.

She mates once in her life, when she is a few days old, with a single drone, and on the wing. That is the only occasion of her leaving the hive, except when she leads forth a swarm. Her grand function 
is to lay eggs, and every part of her structure and every power she has is more or less related to this all-important duty. She is, as we have implied, freed from every other office. The hatching, the tending, the rearing, the instruction of her progeny, are entirely taken out of her hands, and it is doubtful whether she has any affection for her children. She is constantly attended by a retinue of ten or twelve

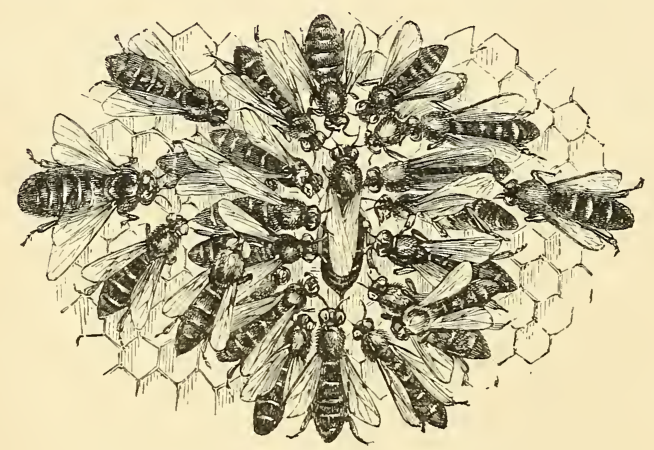

Fig. 7.-QueEn surrounded by Attendants.

The Queen, or Mother-Bee, as in nature, surrounded by her ladies-in-waiting, and exhibited in a glass hive to the royal visitors at the British Bee-Keepers' Association Show at Kilburn, 1879, by Abbott Bros., Southall.

"maids of honour," who all keep their heads turned towards her, clear the way for her, prevent all crowding round her, and supply her with the most nutritious food, previously half digested by themselves. They caress her with their antennæ, and seem to find a real joy in mere proximity to their monarch. Should she, by more rapid movements than usual, outstrip her retiring attendants, the bees with whom she thus unexpectedly comes in contact appear excited and alarmed, and move 
hastily from her path. So long as she remains sound and well in the hive, all the varied works go on peacefully and incessantly. Should she die or be removed, immediate consternation is manifested. Her subjects rush about in excitement and distress. They buzz around the neighbourhood of the hive, but all active and productive work ceases. They know that unless the disastrous loss can be repaired, their community must perish for lack of new progeny, and when despair seizes them, they seem to act upon the motto, "Let us eat and drink, for to-morrow we die."

But the skilled bee-keeper comes to the rescue when he has ascertained the death or loss of a queen, and introduces another monarch to the distressed community. Care and caution, however, have to be exercised in this operation; for, until convinced that there is no hope of the restoration of their rightful sovereign, the workers will not tolerate a substitute for her. Even when their hopes are extinguished, it is much safer to cage the new queen, for thirty-six or forty-eight hours, on a comb, so that a gradual acquaintance with one another may be formed before free intercourse is allowed. Otherwise, it will frequently happen that the introduced mother-bee will come to grief by stings or by suffocation. Cases, indeed, have occurred in which it has been found impossible to induce a hive to receive a stranger queen, and it has become necessary to amalgamate such a community with another already possessed of a monarch.

But, under certain circumstances, the bees will, in a marvellous way, provide themselves with a sovereign. If at the time of discovering their loss 
there are worker-eggs in the hive, and these are only two or three days old, a cell containing one such egg is selected, and enlarged by breaking down the surrounding partitions. The shape and direction of the cell are also altered, being made pyriform, or like a pear, and with its open end downwards. The royal cradle, in fact, is made to look like a small acorn-cup inverted. In this abode is deposited a certain amount of so-called "royal jelly," a more pungent and stimulating food than that supplied to other larvæ, and consisting of a mixture of honey and partially digested pollen. Under the influence of this nourishment, the grub, instead of becoming a worker-bee, as it would have done in the usual course of events, undergoes all thase important modifications which distinguish the queen from her ordinary offspring; and, moreover, the necessary transformations from the larval to the perfect condition of the insect are so expedited as to take only sixteen, instead of twenty-one, days. We have said that, if newly-laid eggs exist, these are preferred by the workers for their purpose of queen manufacture; but they will, if shut up to the necessity, thus transform worker-larvæ, if not full grown. Usually, when prompted in this way to provide themselves with a hive-mother, they begin, not one only, but several, apparently to secure themselves against all danger of failure. But the first which comes to maturity assumes the sovereignty, and, unless the condition of the stock requires the speedy emission of a swarm, she will be allowed to gratify her instinctive enmity to rivals, and will destroy them as they are ready to emerge from their cells.

This hatred of equals is an extraordinary fact, 
when we consider that the queen knowingly lays eggs under conditions in which they will, in the ordinary course of events, become princesses. Then another circumstance of peculiar significance, and very marvellous, is that, notwithstanding the absolute authority possessed by the queen under other conditions, and in spite of the usual subjection and subservience of the workers, they will not allow their monarch complete liberty in the destruction of her royal progeny. If the crowded state of their dwelling makes it evident that the emission of a colony is necessary, the workers-in-waiting forcibly restrain their sovereign from indulging in her strong desire to slay her fully-developed daughters. She resents the interference, but no assumption of her dignity and authority will avail, and her absolutism is in this direction distinctly limited. Incensed at length beyond endurance, she, quits the hive at the head of a swarm of her faithful subjects, and establishes a community where again she will have sole sway. If, on the other hand, circumstances do not necessitate a division of the population, the old queen is allowed to destroy the young ones as they issue from the pupa state.

It is said that the only other condition in which the workers rebel against their monarch is when she is growing worn out with age, and seems likely to fail in power of egg-laying. Then she is believed, in some instances, to be supplanted; but it is not known with certainty whether natural death may not account for her removal, or whether she is slain by her subjects, or by a young queen preserved by their intervention. 
Should the loss of the queen take place when there is no brood-comb in the hive, from the season of the year, or from other circumstances, such as the cessation of egg-laying, the bees often manifest a series of almost frantic efforts to repair their loss. Sometimes they will try to develop a female from drone eggs. They have been known even to take a lump of pollen and surround it with a queen cell, in the absurd hope of getting a monarch so. It sometimes happens that one of the workers develops the power of laying eggs, all of which turn to dronesa marvellous fact in parthenogenesis-and the workers treat some of these to a royal abode and royal jelly, in the futile hope of thus raising a sovereign. In fact, as has been wittily but truly said, "when bees have lost their queen they lose their head." This close connection of queen and people is reciprocal, for the sovereign who is forcibly separated from her ubjects refuses food, pines away, and speedily dies.

It is only in very rare instances (such as those we have mentioned when speaking of the introduction of a stranger-queen) that the workers attack and kill royalty. Queens, on the other hand, are never known to use their stings against their subjects. They reserve them for combats with their equals, thus realising the salutary arrangement, which might have such practically important political consequences if adopted in human affairs, "Let those who make the quarrels be the only ones to fight."

The queen, though developed more rapidly than the drones and the workers, enjoys a much longer life than her subjects. In some instances this period has been known to extend to five or even six years; 
but her fecundity is said to diminish after her second year, or, if it continues, she will in her old age lay a majority of drone eggs, to the serious weakening of the community. The skilled apiarian, therefore, takes care that every hive shall have a queen of an age when her fertility is greatest.

The process of egg-laying begins from two to four days after the flight for mating, depending somewhat on the preparation of cells for that purpose. The queen, on finding comb adapted to her needs, thrusts her head into a cell, apparently to ascertain if it is empty, and of the right depth and size for one of the two different kinds of eggs-those for workers, and those to become drones. Satisfied on these points, she withdraws her head, and, curving herself downwards, inserts her abdomen, and giving the lower part of her body a half-turn towards the thorax, she expels an egg from her oviduct, and then retires in search of other cells in which to make similar deposits. She rarely, and only by mistake, lays more than one egg in a cell. If she falls into the error, the worker-bees immediately remove all but one.

The examination of each cell by the queen to ascertain its fitness for the two kinds of eggs is an essential point; for, in the first place, the nature of drone-eggs is radically different from that of those which will produce workers; and the size of the cells in which the former are hatched is considerably greater than that in which the latter will be developed, nineteen ends of the larger covering a square inch of surface, while twenty-seven of the smaller will occupy the same space.

It seems an indisputable fact that the queen has 
the power of laying which of the two kinds of eggs she pleases. The essential difference between the two seems to be, that those which will become drones are not fertilised by spermatozoa just previous to leaving the oviduct, while the worker-eggs are thus specially vivified, and the operation appears to be under volitional control.

A further remarkable circumstance is that the rate of egg-laying is also a matter of determination, and not of necessity, on the part of the queen ; for when a transfer has been made from a weak to a strong hive, the number of eggs deposited has been known to vary, within two days, from none to two thousand in twenty-four hours. In the one case the motherbee knew her colony was not strong enough to keep up the requisite warmth for hatching and developing her progeny; in the other, she proceeded vigorously with her functions, the further progress of the young being secured by the abundance of the population sufficing to keep up the proper temperature, and to render all needed attention to the larvæ in their further development.

The ordinary rate of laying, under favourable conditions, varies from 600 to 800 eggs a day; but, under pressure of specially suitable conditions, from I,000 to $\mathrm{I}, 200$ are not unfrequently deposited. Langstroth and Von Berlepsch have seen six laid in a minute; and the latter observer, on supplying a queen with some new empty comb, found after twenty-four hours more than 3,000 eggs had been laid. If this queen on the average got rid of five eggs per minute, the total number just mentioned would have been deposited in ten hours, so that she 
would have had fourteen hours for rest. The queen kept up her rate for twenty days, in which time she had filled 57,000 cells, and, what is very remarkable, her fecundity is said to have continued for five years, during which period she must have laid nearly a million and a-half of eggs. Dzierzon says, "Most queens, in spacious hives, and in a favourable season, lay 60,000 in a month, and a specially fertile queen, in the four years which she on an average lives, lays over a million eggs." These numbers will give some idea of the immense expenditure of life that is continually going on.

To keep up these very great productive energies, it is evident that large quantities of food must be consumed by the mother-bee, and, as we should expect, the amount taken varies in the ratio of the vigour of egg-laying.

It sometimes happens that, in the very height of her duties, sufficient cells are not forthcoming as places of deposit for eggs; and, in that case, the queen leaves some on the combs, or at the bottom of the hive. Strange to say, the worker-bees greedily devour such waifs and strays. In this respect we observe a great difference between ants and bees. Amorig the latter we do not find that passionate love and care for the eggs and larvæ which so strongly mark the former. Other circumstances of a similar kind, to be noted later on, show, on the part of bees, an intense regard for stores rather than progeny, notwithstanding their affection and devotion to the mother-bee, whose functions they thus acknowledge as all-important to the race.

The egg-laying of the queen goes on more or less 
for nine or ten months of the year, under favouring conditions; but the season of greatest activity is during April, May, and June. Various circumstances after that time cause a diminution of the number of eggs, till in November, December, and January, as a rule, the queen ceases her motherly functions. 


\section{H A P TER IV.}

THE DRONES.

Distinguishing Characteristics-Time of Hatching-Numbers-Purposes served by them-Destruction by Workers or other meansUnusual Survival.

THE drones are the male population of the beecommunity. In general form they are more cylindrical than the queens or workers. They are shorter than the former, but larger and more robust than the latter. Their colour is of a deeper brown, and they

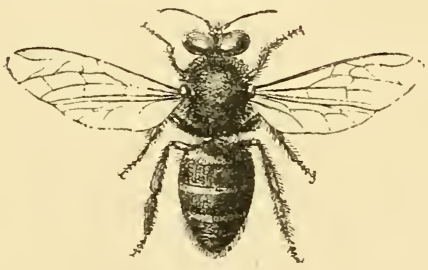

FIG. 8.-A DRONE.

are much more hairy, especially at the lower extremity. Their wings are strong, and greater in proportion to the length of their bodies than those of the females or neuters, reaching, indeed, to the full extent of their abdomen. The posterior expansion 
of the lower pair gives a broad backward sweep, and enables the heavy body of the drone to fly with great rapidity, and to rise very freely in the air. Another peculiarity of structure is the vertical enlargement of the compound eyes. By the meeting of these eyes over the brow, the drone is able more readily to see the virgin queen when she issues for her one bridal excursion. Drones have a strong odour, which becomes very perceptible when several are confined together in a box. Their proboscis is not fit for the collection of honey; moreover they have no receptacle for carrying the liquid, and, in fact, show no inclination even to feed themselves from flowers. They take their nourishment from what is stored in the cells. As Evans accurately and concisely says of them, they

$$
\text { "wheel around }
$$

On heavier wing, and hum a deeper sound. No sharpened sting they boast; yet, buzzing loud, Before the hive, in threatening circles, crowd The unwieldy drones. Their short proboscis sips No luscious nectar from the wild thyme's lips; From the lime's leaf no amber drops they steal, Nor bear their grooveless thighs the foodful meal ; On others' toils, in pampered leisure, thrive The lazy fathers of the industrious hive."

This inability to feed themselves from Nature's sources makes them almost unique among the fully developed creatures of the animal world. Their consumption of the stores of the hive is not resented by the workers till the swarming season is over, and what is further remarkable is, that they are permitted to enter without molestation communities other than that in which they were bred, though neuters would be strictly prohibited from such trespassing. 
The first drones of the season appear generally about the middle of April, but they are most numerously hatched in May and June. The actual number in a hive varies from 500 to 2,000 . Only one or two of these will become the mates of as many young queens, and the question is often asked, What can be the use of such an immense superfluity of males? The best answer that can be given is, that it is extremely important, considering the dangers to which a virgin queen is exposed in her flight from the hive, that there should be no difficulty for her in meeting with a spouse. When drones are scarce, and a very early swarm has issued from a hive, it happens sometimes that the young queen remaining at the head of the stock has to make several flights before finding a mate. As she is liable to be snapped up by birds, or driven away by gusts of wind, or lost through not knowing her own hive, it is manifestly far safer for the supply of drones to be large enough to insure a meeting on the first occasion of her flying.

It has been suggested by some bee-keepers that the eggs are fertilised in the cells by the drones, after the manner of the ova of fishes; but this theory is utterly untenable in view of the fact that much brood is found in the hives at seasons when, as a rule, no drones exist, i.e. in the early spring and late autumn.

From a reference to drones in the Troades of Euripides (lines I9I-I95), it would almost seem that the ancient Greeks, five centuries before Christ, had an idea that the male bees were the door-keepers of the hives, and the guardians of the young. We know, however, that this is not the case. 
Again, certain Polish writers have asserted that the drones are the water-carriers of the community; but this notion is as fanciful and groundless as the preceding idea.

A more sensible supposition is that by their numbers the warmth of the hive necessary for the hatching and development of the larvæ is promoted, and that, in consequence, more of the workers are freed for honey-getting and pollen-gathering. One objection to this theory has been made on the score that, when there is most need for the heat of the hive to be maintained, viz., in the winter, all the drones are dead; but the reply to this is, that at that season there are no stores to be collected, and therefore no need for the workers to be liberated from indoor duties.

It is certain that bee-keepers who have taken the trouble to catch or to destroy hundreds of drones from their hives, have not found themselves rewarded by a greater amount of produce or by stronger stocks through saving what the murdered drones would have eaten. At the same time, where a honeyharvest is desired, there is little doubt it is well for some control to be exercised over the number of drones hatched in the hive. This can be governed, to a considerable extent, by furnishing the bees with "foundation comb," the rudimentary cells of which are of the size adapted only for workers. Still, there is no doubt of the practical importance of having a good supply of males in the hives during the swarming time. When they are no longer of use, the workers expel them. By many it has been asserted that the drones are stung to death; but any one who 
takes the trouble to watch what goes on in July and August, will see that, for the most part, the neuters seize their brethren by the wing, and drag them from the entrance of the home. If much resistance is made, they will perseven in trying to keep them away; but, at last, when patience is exhausted, they will bite the wings underneath, and so render them almost powerless. Harassed in these ways, and prevented from taking food from the cells, the drones die of starvation in large numbers. A few may be stung to death. Many will creep to unfrequented parts of the comb, in hope of escaping notice ; and if a side box, or unoccupied back of a wooden hive, be opened for them, they will congregate there. Mr. Henry Taylor mentions in his Bee-Keeper's Manual, that, on one occasion, he found as many as 2,200 which had thus clustered in an empty side box. He took them away, and the other bees went to work with more vigour after having been thus relieved of their useless population, as if they were glad to be rid of those who were consumers, but non-producers.

In many instances, especially when food-supplies are running short, and are not easily replaceable, the workers will drag out the just emerging drones from their cells, together with pupæ and larvæ, and will cast them forth to die.

If no necessity for swarming occurs, through there being plenty of room in the hive for the extension of the colony, or for any other reason, either no royal cells will be made, or the young princesses will be destroyed as they approach maturity. In this case, an unusually early destruction of the males will occur, as the workers instinctively know there is little 
use in permitting them to continue alive. Still, some will be allowed to exist, for the sake of other communities, as it is now maintained, with much show of reason, that a young queen selects for her consort a drone not belonging to her own hive. The importance of this crossing of breed, for keeping up the vigour of the race, is one of the best ascertained facts in natural history. While, then, we cannot suppose the bees to be aware of the benefits to be derived from this "selection before marriage," we see in it one more circumstance indicating the marvellous capabilities of so-called "instinct"-we would prefer very much to say one more proof of the all-pervading superintendence of a Divine Mind, which works throughout what we call Nature. We might, indeed, expect that $\mathrm{He}$, without whose supervision not a sparrow alights on the ground in search of its food, would show to our intelligent inquiries equally plain evidence of $\mathrm{His}$ universal working, and of His infinitely wise determination of all that has to do with the welfare and the permanence of the various classes of the animal and vegetable worlds. 


\section{CHAPTER V.}

THE WORKERS.

Distinguishing Characteristics-Supposed Differences of Function among them-Sir John Lubbock's Experiments-Fertile WorkersLength of Life- "Black Bees"-Duties of Workers.

THE workers are by far the most numerous, and, in some sense, the most important party in the commonwealth of bees. They are smaller in size than either queens or drones. Microscopic examination,

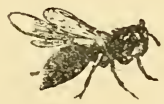

a.

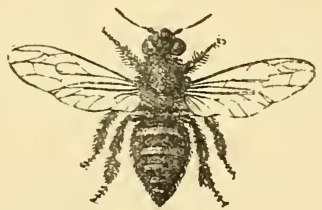

b.

Fig. 9.-A Worker BeE.

a. Natural size.

b. Maguified.

and the fact of their occasionally developing the power of laying eggs, prove that they are really undeveloped females. It is hardly correct, therefore, to call them, as has been so often done, neuters. The chief structural differences to be noted in them, as compared with the other two classes in the hive, 
are, the possession of a long proboscis for gathering honey, of receptacles for carrying pollen, of a very formidable straight and barbed sting, and brushes on the legs for clearing different parts of the body from the farina of flowers or from dust.

The worker-eggs are deposited by the queen in the smaller-sized cells of the combs, and are the first laid in a new colony, or in the spring of the year.

Certain observers have thought they noticed differences in the size of the full-grown workers, and supposed that these variations were connected with diversity of occupations and duties. But as all have their several organs and their whole structure precisely alike, and as little direct evidence of special functions has been adduced, it is tolerably certain that any peculiarities in regard to size must be otherwise explained. Nor is it difficult to discover how these may have been brought about. For, since each pupa leaves behind it some portion of the silken cocoon it had spun, it is clear that after a succession of young bees from the same cells, these must become sensibly contracted in extent, so that the later progeny will not have had as much space in which to grow as their elder-born sisters had, and hence are, at least when they emerge, smaller in size.

Huber, without reference to the above-mentioned fact, supposed that separate duties were undertaken by special bees, at least so far as the gathering of stores and the care of the young were concerned. Subsequent observations, however, tend to show that the latter office is undertaken by the most recently born young, till they themselves have become strong enough to fly abroad in search of honey and pollen. 
It is said they also see to the making of wax, the building of comb, and the cleansing of the hive, during the first two or three weeks of their life. Some corroboration of this idea is given by the circumstance that, if there be not sufficient room for the extension of a very strong population in their abode, and the conditions for swarming are not satisfactory, the older bees will remain idle in clusters, often outside the hive, leaving to the younger ones the execution of the internal work.

Sir John Lubbock has recorded a series of observations which seem to indicate that certain individuals are stationed near the entrances as sentinels. In his most interesting work on Ants, Bees, and Wasps, he says :-

"On October 5 th I called out the bees by placing some eau-de-Cologne in the entrance, and marked the first three bees that came out. At 5 P.M. I called them out again. About twenty came, including the three marked ones. I marked three more.

"October 6.-Called them out again. Out of the first twelve, five were marked ones. I marked three more.

"October 7.-Called them out at 7.30 A.M. as before. Out of the first nine seven were marked ones. At 5.3O P.Mr. called them out again. Out of six, five were marked ones.

"October 8.-Called them out at 7.I5. Six came out, all marked ones.

"October 9.-Called them out at 6.40. Out of the first ten, eight were marked ones. Called them out at II.3O A.M. Out of six, three were marked. I marked other three. Called them out at I.3O P.M. 
Out of ten, six were marked. Called them out at 4.30. Out of ten, seven were marked.

"October 10.-Called them out at 6.5 A.M. Out of six, five were marked. Shortly afterwards I did the same again, when out of eleven, seven were marked ones. 5.30 P.M. called them out again. Out of seven, five were marked.

"October 1I.-6.30 A.M. called them out again. Out of nine, seven were marked. 5 P.M. called them out again. Out of seven, five were marked. After this they took hardly any notice of the scents.

"Thus in these nine experiments, out of the ninetyseven bees which came out first, no less than seventyone were marked ones."

Many interesting questions connected with the workers remain for future investigation: such, for instance, as whether the same bee returns to the same part of the hive after each foraging expedition; whether the same bees go out in search of stores day after day, or sometimes take holidays or rest from out-door fatigues, by applying themselves to some of the internal labours of the hive; whether those who become more or less exhausted from long-continued flights die, for the most part, on their journeys, or come back home to end their lives.

One point not known to general readers is, that a bee on each separate going out for stores confines herself to one particular kind of flower for that expedition. That is to say, a worker who begins on violets, will not visit any other flowers than violets before returning to the hive. If lime blossoms are chosen, they will be adhered to. If a bee searching white-clover heads be watched, she will be seen to go 
only to similar sources of supply. This fact may be verified by any one who will take the trouble to notice in field or garden the customs of the hive-bee. It does not seem to be the habit of wild bees thus to confine themselves to particular flowers for each journey they make. The importance of this circumstance in the case of our domesticated species, and its influence on the vegetable world, will be noted in a later chapter, when we discuss the relation of bees to flowers.

We have before alluded to the very remarkable phenomenon occasionally occurring to the great annoyance of the bee-keeper, namely, the development in a worker of the power of laying eggs, which eggs will produce nothing but drones, so that the population of the hive dwindles, and becomes extinct. Various suggestions have been made as to the reason of this faculty appearing. A very plausible idea is that some of the "royal jelly" is occasionally, and possibly by mistake, given to a larva in the neighbourhood of a queen-cell, and this stimulating food produces a partial development of laying power. A second possibility is that sometimes a worker-larva in too forward a condition is transferred to a queencell, and owing to the difference of treatment not having been begun early enough, an imperfect and nondescript kind of bee results. Some corroboration of this may perhaps be found in a curious fact, which has been several times noted, and published in the British Bee-Joumal, viz., the finding of workers hatched in queen-cells. It would be difficult to imaginc such an abnormal event, unless unusual. circumstances had occurred to the young larva. 
The birth of a fertile worker in a hive is a great misfortune; for, not merely will the population diminish, and at length altogether fail, from the production of drone-brood only, but, as it is impossible to distinguish the offending worker, it is difficult to get rid of her. It has been recommended, on the discovery that she exists, to amalgamate the stock with another having a queen. This may answer, but there is a danger that when the battle comes to be fought between the actual sovereign and the fertile worker, who will try to maintain her prerogative, the latter, as the more active, and as possessed of a more formidable sting, may prove victorious. A safer plan, therefore, is to turn out the whole stock from their hive, comb by comb, if the bar-frame system is used, and allow them to return to the old place where the cleared combs may be put to receive them. The fertile worker, never having left the colony, will not know her way back, and so will be happily got rid of, and will probably perish. Her place must, of course, be supplied by an introduced queen, or the stock must be united with another.

The age to which the workers live varies according to the amount of labour they undergo. During the winter and the early spring, when little or no work is done, there is small drain on their vital force, and they may live for six or seven months. In the height of summer, when long days and abundant supplies invite them to many hours of continuous toil, the industrious insects are believed to exhaust themselves very rapidly, and to perish, as if prematurely old, in about five or six weeks. It is quite 
evident that the mortality during the middle of the year must be very great, seeing that egg-laying and hatching go on at the rate of several hundreds a day, and during weeks and months in succession: and yet it frequently happens, where room sufficient for the growing stores is provided, no swarm will be thrown off, from which we infer that a period is reached when the birth-rate and death-rate pretty closely approach each other.

The older workers are distinguishable from the younger by their deeper and more glossy colour. The grey bloom of youth has been worn off, and frequently their wings, notched or broken in places, betray the veterans in the battle of life, who, amidst rains, hail, and wind, have suffered more or less severely.

Some observers have called attention to certain individuals in the community, which have been spoken of as "black bees," 1 and which have been supposed to possess special functions. Von Berlepsch ascertained from his countryman Leuckart that no anatomical differences existed between these and ordinary workers ; and, from subsequent experiments, came to the conclusion that the difference in colour was due to the accidental absence or the loss of the hairs or down with which bees are ordinarily covered. This loss may have occurred through getting smeared with honey, or from stifling, or fright, or creeping constantly through apertures too small to admit their bodies readily. Dzierzon, another great authority, corroborates the above explanation, and

1 This term is also used for all English bees, in distinction from the Ligurian, Cyprian, and other varieties with yellow bands. 
further adds, " as a rule, the glossy black bees are robbers, which have been pursuing their trade for some time."

A similar difference in size and colour has been often noticed in the case of drones; and the explanation of their occurrence seems to be that such smaller individuals have been hatched in the cells intermediate between the normal drone and worker varieties, a tier or two of such intermediate cclls being frequently made, to shade off the difference of size between the two kinds.

The duties undertaken by the workers constitute a series of operations indicating marvellous skill and apparent reasoning power. It is true that what we call "instinct"-a word which merely covers our ignorance-seems to play a large part in the direction of the doings of bees; but the readiness with which they adapt themselves to circumstances, the expedients they adopt to remedy defects in their dwellings or surroundings, the efforts they make to repair losses and to provide for the continuance of the race, appear to transcend the limits of a power actuated by blind impulse alone.

We have spoken of the brooding over and feeding of the larvæ, the sealing of the pupæ, the cleansing of the newly-hatched young, as the special duties of the workers. All these offices are performed by the most juvenile members of the family, who thus become gradually initiated into the responsibilities of bee-life, and daily gather strength for the next and more extended duties of citizenship. These consist of the gathering of supplies of honey, pollen, and propolis, the elaboration of wax, the making of the 
combs, the storing and sealing up of produce, the cleansing and ventilation of the hive, the guarding of the entrance, and the driving off or slaughter of intruders of various kinds.

These various operations are worthy of separate notice, and we will proceed to give some details relating to each. 


\section{CHAPTER VI.}

\section{HON E Y.}

Origin-how Collected and Stored-Constitution-Poisonous HoneyBest varieties of Honey-Distances traversed by Bees in search of Honey-Uses.

HoNey is mainly derived from the nectar of flowers, We say mainly, because bees are able to make use of many sweet liquids, such as the juices of ripe fruits, the substances constituting what is called "honeydew," the syrup of sugar, and the solid material of sweetmeats. Still, by far the larger proportion of honey is derived from flowers. By means of its long flexible tongue the bee sucks from the nectaries of various plants the sweet liquid they contain. In an expansion of the gullet, which somewhat resembles the crop of birds, some slight, but important, chemical changes appear to take place, and while a portion of the fluid passes into the true stomach for the nourishment of the insect, the rest is regurgitated into a cell of one of the combs. At first the honey thus deposited is very thin, but by evaporation under the warmth of the hive, a portion of the water passes off, and a process of what apiarians call "ripening". 
goes on, after which the remaining liquid is less liable to fermentation, when extracted from the comb.

Honey appears to consist mainly of two kinds of sugar, one of which is closely allied to that contained in the grape, and which by spontaneous change is apt to crystallise in contact with air. The other is uncrystallisable, like the purest treacle, and mingled with it are slight quantities of colouring matter and mucilage. These sugars are somewhat apt to undergo a vinous fermentation, of which advantage has been taken in the manufacture of mead-a drink much used by the inhabitants of these islands in ancient times as a stimulant, and even intoxicant.

The taste of honey varies according to the flowers or other sources from which it has been chiefly derived. That procured from flowers, especially those of the labiate family-from the clovers, the limeblossoms, and the heaths - is most esteemed. That which has been derived from sugar-syrup differs but slightly from the liquid of its origin. That procured from what is called honey-dew, or the secretion of various sorts of aphides, is very worthless in quality, though bees are extremely fond of the liquid.

It is a remarkable and unfortunate fact, that the honey collected from certain flowers is, though innocuous to bees, more or less injurious to the human body. Xenophon tells us in his Anabasis that his soldiers found many hives in the neighbourhood of Trebizonde, and, after eating of the contents, the men were seized with violent purging and vomiting, stupefaction, and inability to stand. Those who ate little became like men very drunk, and those who ate much, like madmen, and some like dying persons. 
In this condition great numbers lay upon the ground, as if there had been a defeat. None of them died, and in about twenty-four hours they recovered consciousness. On the third or fourth day after the seizure they got up, but were like men who had taken powerful physic.

Tournefort, when travelling in Asia Minor, recollecting these historical circumstances, made careful investigations as to the probabilities of the case. Two kinds of shrubs were pointed out to him as bearing flowers, the honey from which was deleterious, and the very odour of which is still said to produce headache. These plants were the rhododendron Ponticum, and azalea Pontica, nearly allied species, growing abundantly in that part of the world. Father Lamberti corroborates Xenophon's description, by stating that similar effects have been produced by the honey of Colchis, where these shrubs are common.

We learn from an account published by Dr. Barton in the American Philosophical Transactions, that, in the autumn of I790, several fatal cases occurred near Philadelphia, from eating honey collected in the neighbourhood. An official investigation into the circumstances led to the conviction that the source of the mischief lay in the flowers of the kalmia latifolia Still more recently, some persons in New York lost their lives from, as it was supposed, eating honey derived from the flowers of a species of dwarf laurel, common in the vicinity. A further instance of the influence of the kalmia tribe of flowers is given in the fact that honey drawn chiefly from the species latifolia, in New Jersey, is unsaleable, from its intoxicating 
qualities, though the bees themselves thrive prodigiously upon it.

Sometimes the colour is said to indicate the nature of the liquid, that which is mischievous being distinguished by a reddish or brown tinge; but this is by no means a sure indication of quality, for, in Florida and Carolina, the wild honey having harmful properties is so like in appearance that which is perfectly wholesome, that the hunters at first eat very sparingly of their newly-found treasures, till they have proved, by experimenting on themselves, what its properties are. Again, some "blood-red honey," found in Abyssinia, is said to be quite free from objectionable elements; and Linnæus tells us that the Swedish honey from the heath-flowers is of a reddish hue, but excellent in quality. That obtained in the Highlands of Scotland is occasionally observed to have a brownish tinge, but no ill effects are found to result from the use of it, though some have asserted that it has a soporific influence.

There is little doubt that the colours of honey from different localities vary according to the prevalence of flowers most frequently visited by the bees. Its aroma and taste are influenced, as we might suppose, by the same circumstances. As a natural result, we find also that the excellence of the liquid depends much on the season at which it is collected. The primest is the produce of the early summer. That which is stored in spring excels what is gleaned in autumn. The produce of the earlier part of the harvest is better than that which is stored when flowers grow scarce and fruits are ripening.

The distances to which bees will travel in search of 
their food-supplies are very astonishing. They have been proved to fly four or five miles to favourite pasturage. A gentleman, wishing to test this fact, dusted with fine flour his bees as they emerged from a hive. Then driving to a heath five miles distant, which he knew to be much frequented by the insects, he soon found many of those which he had sprinkled at home. Their instinct, indeed, appears to lead them considerably afield, and hence it is of slight use to plant, as recommended by some writers, particular flowers: near an apiary. Moreover, unless such flowers are grown for seed purposes, or in very large quantities, the amount of nutriment they will afford is almost inappreciable.

Fields where the white or Dutch clover abounds, and heath districts, are, perhaps, the finest sources of honey-supply. Our fruit blossoms of almost all kinds also furnish abundant stores to the busy insects.

The uses of honey hardly require to be pointed out. Besides being an agreeable addition to the breakfast or tea-table, as a substitute for butter, it is often very serviceable as a laxative, when taken in moderate quantity. It is frequently employed in medical confections, as a vehicle for the administration of certain drugs; and its generally wholesome properties have been thoroughly ascertained. Its use for the manufacture of metheglin, or mead, is not now extensive, but in earlier periods of British history this beverage was held in high esteem. 


\section{CHAPTER VII.}

MEAD.

Nature-Method of Manufacture-Metheglin and Mead-Estimation in former times-Queen Elizabeth's Recipe-Scandinavian liking for Mead.

THE sugar of various vegetables is susceptible of alcoholic fermentation; so from the sugar of malt we get beer, from that of the grape, wine. Honey is, as we have said, a substance containing sugar, which may also be made to yield a vinous liquor. Usually only the washings of drained combs are used up for the manufacture of mead. The saccharine extract is skimmed, strained, and boiled. Then a certain proportion of raisins is added, together with a little ground ginger, and a few bay or laurel leaves for flavouring. A small quantity of brewer's yeast sets up the necessary fermentation, and after the liquor has been put into a barrel, and allowed to "work" for two or three days, it is bunged up, and at the end of six months may be bottled, and soon afterwards will be fit for use. Of course, run honey may be used for the purpose, but its employment is a more expensive mode of manufacture. 
Properly speaking, the word "metheglin" was applied to the superior sorts of mead, the two beverages being related mucin in the same way as effervescing bottled cider and the ordinary draught cider.

Mead-making seems anciently to have been considered a matter of great interest and importance, and we are told by old authors that the Court brewer of this beverage for Princes of Wales was the physician of the household, and ranked eleventh in point of dignity. Athelstan, King of Kent in the tenth century, on paying a visit to his relative Ethelfleda, expressed his satisfaction that there was no stint of mead. According to an antique rule of the Welsh Court, there were "three things which must be communicated to the king before they were imparted to any other person. First, every sentence of the judge; second, every new song; and third, every cask of mead."

Queen Elizabeth was so fond of this beverage as to have it made regularly every year; and her recipe has been preserved to our own day. It may interest our readers to give it entire: "Take of sweetbriar leaves and thyme each one bushel, rosemary half a bushel, bay leaves one peck. Seethe these ingredients in a furnace full of water [containing probably not less than 120 gallons], boil for half an hour; pour the whole into a vat, and when cooled to a proper temperature [about $75^{\circ}$ Fahr.], strain. Add to every six gallons of the strained liquor a gallon of fine honey, and work the mixture together for half an hour. Repeat the stirring occasionally for two days; then boil the liquor afresh, skim it till it becomes 
clear, and return it to the vat to cool. When reduced again to a proper temperature [about $80^{\circ} \mathrm{Fahr}$.], pour it into a vessel from which fresh ale or beer has just been emptied; let it work for three days, and then barrel it. When fit [after fermentation] to be stopped down, tie up a bag of beaten cloves and mace [half an ounce of each], and suspend it in the liquor from the bung-hole. When it has stood for half a year, it will be fit for use."

Mead remained in favour long after the introduction of malt liquors, and the northern inhabitants of Europe drank it habitually till comparatively modern times. Even so late as Dryden's day, it would appear to have been in much more common use than now : for he says of its employment for tempering strong wines :-

" $\mathrm{T}$ ' allay the strength and hardness of the wine,

Let with old Bacchus new metheglin join."

It was probably the liquor called by Ossian the joy and strength of skulls, and which so much delighted his heroes. It was the ideal nectar of the Scandinavian nations, which they expected to drink in heaven, using the skulls of their enemies for goblets, while they were to regale themselves also on boars' flesh. So we read in Penrose's Carousal of Odin :-

"Fill the honeyed beverage high,

Fill the skulls, 'tis Odin's cry!

Heard ye not the powerful call,

Thundering through the vaulted hall?

Fill the meath, and spread the board,

Vassals of the grisly lord ! -

The feast begins, the skull goes round,

Laughter shouts-the shouts resound." 
A quantity of mead sufficient for the very mundane tastes of these celestial heroes was supposed to be daily supplied by a goat, called Heidruna, of whom Cottle says :-

"Whose spacious horn would fill the bowl That raised to rapture Odin's soul ; And ever drinking -ever dryStill the copious stream supply." 


\title{
CHAPTER VIII.
}

\author{
WAX.
}

Origin-Production-Chemical Constitution-Comb Building-Detailed Description-Amount of Wax in Hives-Commercial Value -Properties.

IT was long thought that wax was a product derived, like honey, immediately from flowers. Not only did popular ignorance suppose that the pellets of pollen carried on the thighs of the worker-bees

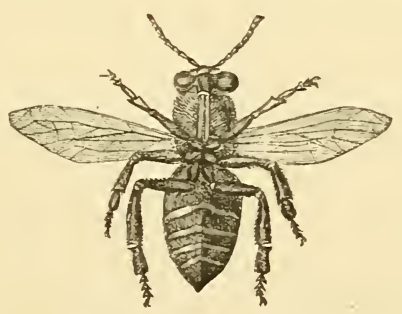

Fig. IO.-A Worker bee, showing the Scales of Wax.

consisted of this substance, but even some authors on apiculture fell into the same error. It is now ascertained with certainty that wax is a sort of animal fat, elaborated from honey by certain internal organs of the bee. It exudes in a liquid form from 
sacklets on the under side of each of the four intermediate ventral segments of the abdomen. There are two of these pockets to each segment, one on either side of the carina or elevated central part. They are trapeziform in shape, and impart the same form to the tiny plates which emerge from them. On reaching the air the liquid thickens, and dries in flakes like fish-scales. The secretion of wax is carried on by the workers only, queens and drones being destitute of the apparatus necessary for the purpose. No direct communication has been traced between the stomach and the wax-sacks, but it has been conjectured by Hunter that the secretion is effected by the network of vessels lining the receptacles as a membrane covered with hexagonal cells, somewhat like the second stomach of ruminating quadrupeds.

Chemically considered, wax consists entirely of carbon, oxygen, and hydrogen; and, as before mentioned, is elaborated wholly from honey. Some authors have maintained that pollen is necessary for its production, but this is the case probably only indirectly; that is to say, the nitrogenous constituent of pollen may be necessary for the nutriment and stimulation of the secreting organs. It certainly does not enter into the constitution of the wax itself.

The quantity of honey required for this process of wax-making is very large. It is generally believed, in fact, to be from fifteen to twenty times the weight of the material derived from it; in other words, for every ounce of -wax produced, at least a pound of honey is consumed by the bees. During the oxygenation of so large a quantity of saccharine matter, much 
heat is evolved-a fact frequently noticed when combbuilding is going on rapidly in a hive.

When wax is required for the abode of a fresh swarm, or for filling up vacant spaces with comb, the bees hang in festoons or chains, crossing the hive in different directions. Remaining almost motionless for about twenty-four hours, the wax-makers proceed with their business. Then, as soon as the

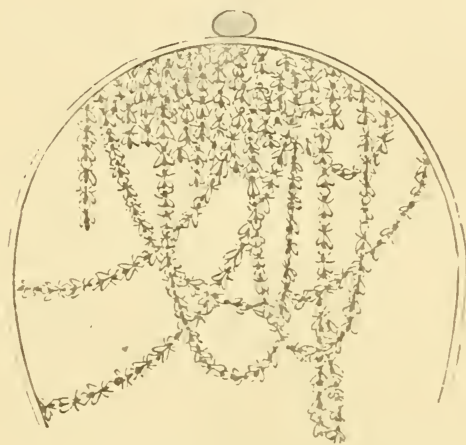

Fig. 11.-Festoons of Bees Suspended from the Roof of the Hive.

little scales are of the proper consistency, they are withdrawn by the hind-feet of the bee, and carried between the fore-legs to the mouth. There, worked up with a small quantity of saliva, the substance is softened ready for use, and being conveyed away by those who have prepared it, and deposited in small masses, it furnishes the materials from which the comb-builders do their share of the duties of the hive. Possibly some of the individuals of the lower parts of the festoons, or clusters, may pass up their portions of wax to those above them for transmission 
to the-top of the hive; but the fact is not thoroughly ascertained. Evans graphically says:-

" Lo, filtered through yon flutterer's folded mail, Clings the cooled wax, and hardens to a scale. Swift, at her well-known call, the ready train (For not a buzz boon Nature breathes in vain) Spring to each falling flake, and bear along Their glossy burdens to the builder-throng."

It often happens that the fine scales fall by accident, or perhaps, when superabundant in quantity, on to the floor-boards of hives, and it does not appear, from our observation, that those bees who happen to come upon these little portions of material carry them up for employment in cell-formation.

The wax is used in comb-building, and the subject is one of great interest on many accounts, but especially from the following considerations: the nature of the material; the organs by which it is produced; the implements with which it is fashioned into shape; the manner in which the work is done; the form of the cells, the mathematical characters of which are most surprising; their different sizes and shapes, according to the purposes for which they are destined; their perfect adaptation to the needs of the bee community.

With regard to the nature of the material, in addition to the facts already mentioned, we may note that it is a substance easily moulded, especially when exposed to a gentle heat, such as is generated in a hive. It is light, so as to add little to the weight of the contents which will be stored in the cells. It is also a very slow conductor of heat, a matter of great 
importance both in summer and in winter. For, if it readily both absorbed and radiated heat, the temperature would, in the former season, become too high; while, in the winter, too great effort, and a large additional amount of food, would be needed by the bees to keep up the temperature of the hive to a point of safety for its inhabitants. Again, wax is a material which, by means of propolis (of which we shall presently speak), admits of being fastened in position so securely as to be able to bear a great weight of brood, honey, and bee-bread, in the cells.

The organs by which wax is secreted, and the implements with which it is fashioned, will be described fully in the chapter devoted to the physiology and anatomy of the bee; but we may say here that they are exceedingly simple, and that it is wonderful such beautiful work can be accomplished by means of them.

But the manner in which comb-building is done is so marvellous, that it merits a detailed description. It is to Huber that we are indebted for the full exposition of this subject, and we cannot do better than quote his account of the process, as given by Kirby and Spence. We must premise, however, that the great naturalist thought there were two distinct classes of workers, the one of which he called the wax-makers; the other, the nurse-bees. Observations continued since his day have rendered it certain that this is a mistaken distinction. As a general rule the care of the young devolves, as we have already said, on the most recently hatched of the community, who are unfit, for some days after emerging from the 
cell, to take distant flight in search of stores from owers. The older and stronger workers, on the other hand, go abroad for supplies, and then, on their return, secrete whatever wax is needed in the economy of the hive.

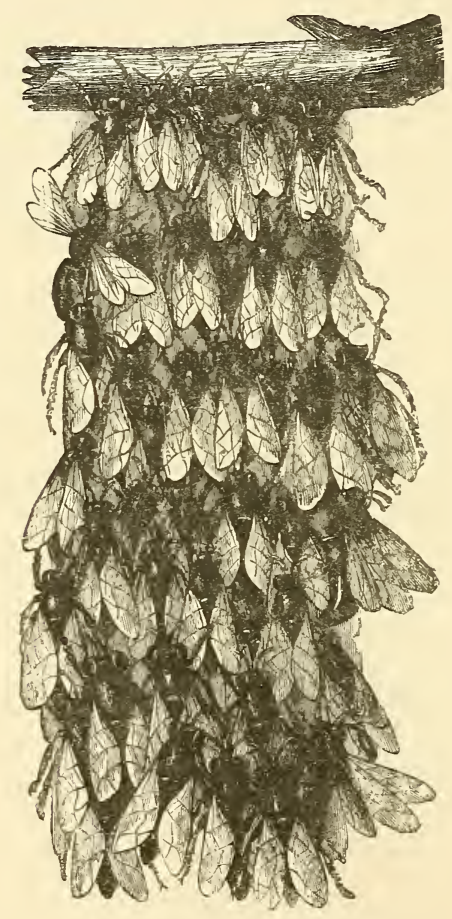

Fig. 12.-Cluster of Bees.

The process of comb-building is described by Huber as follows :- "The wax-makers having taken a due portion of honey or sugar, from either of which wax can be elaborated, suspend themselves to each 
other, the claws of the fore-legs of the lowermost being attached to those of the hind pair of trie uppermost, and form themselves into a cluster, the exterior layer of which looks like a kind of curtain. This cluster consists of a series of festoons or garlands, which cross each other in all directions, and in which most of the bees turn their back upon the observer. ... The wax-makers remain immovable for about twenty-four hours, during which period the formation of wax takes place, and thin laminæ of this material may be generally perceived under their abdomen. One of these bees is now seen to detach itself from one of the central garlands of the cluster, to make a way amongst its companions to the middle

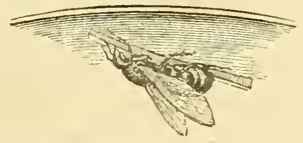

Fig. 13.-WAX-Worker commencing a Comb.

of the vault, or top of the hive, and by turning itself round to form a kind of void, in which it can move itself freely. It then suspends itself to the centre of the space which it has cleared, the diameter of which is about an inch. It next seizes one of the laminx of wax with a pincer formed by the posterior metatarsus (last joint of the leg), and tibia (last joint but two), and drawing it from beneath the abdominal segments, one of the anterior legs takes it with its claws and carries it to the mouth. This leg holds the lamina with its claws vertically, the tongue rolled up serving for a support, and by elevating it or depressing it at will, causes the whole of its 
circumference to be exposed to the action of its mandibles (or jaws), so that the margin is soon gnawed into pieces, which drop as they are detached into the double cavity, bordered with hairs, of the mandibles (jaws). These fragments, pressed by others newly separated, fall on one side of the mouth, and issue from it in the form of a narrow riband. They are then presented to the tongue, which impregnates them with a frothy liquor like a bouilli. During this operation the tongue assumes all sorts of forms; sometimes it is flattened like a spatula, then like a trowel, which applies itself to the riband of wax. At other times it resembles a pencil terminating in a point. After having moistened the whole of the riband, the tongue pushes it to make it re-enter the mandibles, but in an opposite direction, where it is worked up anew. The liquor mixed with the wax communicates to it a whiteness and opacity which it had not before; and the object of this mixture, which did not escape the observation of Réaumur, is, doubtless, to give it that ductility and tenacity which it possesses in its perfect state.

"The foundress-bee-the name which this first beginner of a comb deserves-next applies these prepared parcels of wax against the vault (or top of a frame) of the hive, disposing them with the point of her mandibles in the direction which she wishes them to take; and she continues these mancuvres until she has employed the whole lamina that she had separated from her body, when she takes a second, proceeding in the same manner. She gives herself no care to compress the molecules of wax which she has heaped together. She is satisfied if they adhere to each 
other. At length she leaves her work, and is lost in the crowd of her companions. Another succeeds and resumes the employment, then a third. All follow the same plan of placing their little masses, and if any one, by chance, gives them a contrary direction, another coming removes them to their proper place.

"The result of all these operations is a mass or little wall of wax, with uneven surfaces, five or six lines (twelfths of an inch) long, two lines high, and half a line thick, which descends perpendicularly. In this first work is no angle nor any trace of the figure of the cells. It is a simple partition in a right line without any inflection.

"The wax-makers having thus laid a foundation of a comb, are succeeded by the nurse-bees [here Huber is wrong $\left.{ }^{1}\right]$, which are alone competent to model and perfect the work. The former are the labourers, who convey the stone and mortar; the latter the masons, who work them up into the form which the intended structure requires. One of these bees now places itself horizontally on the vault (or bar-frame) of the hive, its head corresponding to the centre of the mass or wall which the wax-makers have left, and which is to form the partition of the comb into two opposite assemblages of cells; and with its mandibles (jaws), rapidly moving its head, it moulds in that side of the wall a cavity which is to form the base of one of the cells, to the diameter of which it is equal. When it has worked some minutes it departs, and another takes its place, deepening the cavity, heightening its lateral margins by heaping up the wax to right and left, by means of its teeth and

1 See remark immediately preceding the quotation. 
fore-feet, and giving to them a more upright form. More than twenty bees successively employ themselves in this work.

"When arrived at a certain point, other bees begin on the yet untouched and opposite side of the mass, and commencing the bottom of two cells, are in turn relieved by others. While still engaged in this labour the wax-makers return, and add to the mass, augmenting its extent in every way, the builders again continuing their operations. After having worked the bottom of the cells of the first row into their proper forms, they polish them, and give them their finish, while others begin the outline of a new series.

"The cells themselves, or prisms, which result from the reunion and meeting of the sides, are next constructed. 'These are engrafted on the borders of the cavities hollowed in the mass. The bees begin them by making the contour of the bottoms, which is at first unequal, of equal height. Thus all the margins of the cells offer an uniformly level surface from their first origin, and until they have acquired their proper length. The sides are heightened in an order analogous to that which the insects follow in finishing the bottom of the cells, and the length of these tubes is so perfectly proportioned that there is no observable inequality between them."

Thus writes the great Swiss observer of bees. Without quoting at greater length from his published observations, we may give some additional particulars relating to the geometrical characters of honey-comb. 
The cells of the first row laid down are pentagonal in shape. This gives them a stronger attachment to the hive than if they had had the hexagonal figure of the succeeding rows, But no form besides the sixsided prism would have answered all the conditions of the problem "how with the least expenditure of material to secure the greatest available space with the best arrangement for the purposes to be served."

Approached from the purely theoretical side, the question has been investigated by mathematicians.

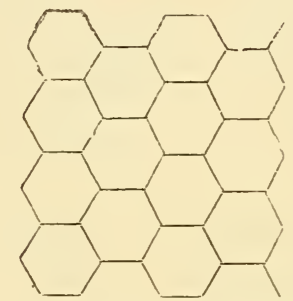

Fig. 14,-Diagram of Cells.

It requires no great acumen to determine that a hexagon of some sort is the geometrical figure which must be adopted. An equilateral triangle would make a very unsuitable abode for an insect with a

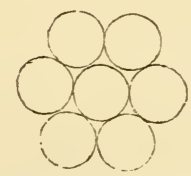

Fig. 15.-Supposed Circular Cells.

nearly round body. A square cell would hardly be more convenient. A series of circles would, of course, leave interstices between them, causing a useless expenditure of space, material, time and strength. 
A further difficulty would arise with regard to the storage of the honey, which finds points of attachment in the angles of a hexagon, and so is less liable to run out of the cells. The next matter then to settle is, the magnitude of the angles at which the sides of the hexagon should slope towards each other, so as to be the most advantageous. Réaumur put the problem in mathematical language before M. König,
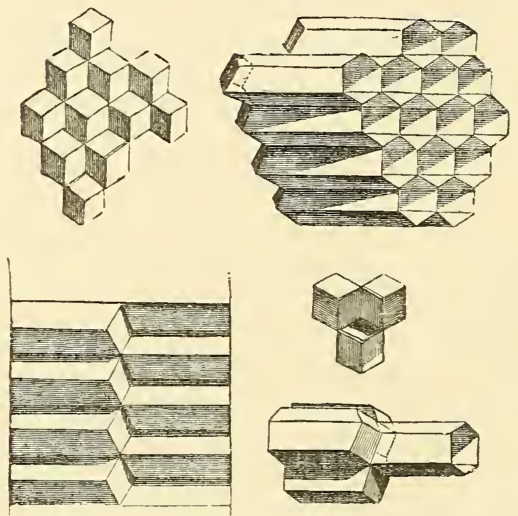

Fig. i6-Arrangement of Cells.

a skilful geometrician, thus :- "To determine by calculations what ought to be the angle of a hexagonal cell, with a pyramidal bottom, formed of three similar and equal rhomboid plates, so that the least matter possible might enter into its construction." The result of his investigations was that the angles of the rhombs must be $109^{\circ} 26^{\prime}$ and $70^{\circ} 34^{\prime}$. Cramer, professor of mathematics in the University of Geneva, also undertook the problem. His calculations, made on somewhat different principles from König's, gave for the angles $109^{\circ} 28^{\prime} 16^{\prime \prime}$, and $70^{\circ} 3 \mathrm{I}^{\prime} 44^{\prime \prime}$. Maraldi, a third 
mathematician, assuming the equality of the angles of the trapezia forming the sides of the hexagon adjacent to the rhombs and those of the rhombs themselves, and that the solid angle at the apex of the pyramid, composed of equal obtuse angles, is precisely equal to each of the three angles at the base, also composed of three equal obtuse angles, came to the conclusion that the angles must be $109^{\circ} 28^{\prime}$ and $70^{\circ} 32^{\prime}$.

These three sets of results, so remarkably accordant, when we consider the minuteness of the differences between them, in figures so small as the actual honey-comb cells, show the closest correspondence to the actual measurements of the work of the bees. Maraldi found the angles of the latter to be $110^{\circ}$ and $70^{\circ}$, as nearly as could be ascertained. We have dwelt at some length upon this point, because it illustrates, in a most marvellous manner, the power of that inborn faculty we call instinct, which arrives, without training, at results so precisely agreeing with those of the highest efforts of our intellectual reasonings. To the devout mind, the conclusion is inevitable that Divine Wisdom is the inspiring force which energizes the mental operations of the bees in their cell-building.

A further advantage of the actual shape of the honey-comb prisms is that, thereby, strength is combined with economy. No other form would so efficiently have carried the heavy weights constantly stored in the forms of honey, brood, and bee-bread.

The bottoms and sides of the cells are made of wax as thin as a sheet of writing-paper; but as walls of this thinness at the entrances would break down 
under the weight of the constantly passing insects, the margin at the opening of each cell is made four or five times thicker than the walls. Then, as the cells are lengthened, this thickness is reduced, always remaining the same, however, at the actual margins. Dr. Barclay also discovered that, though the tenuity of the divisions is so great, each, in point of fact, consists

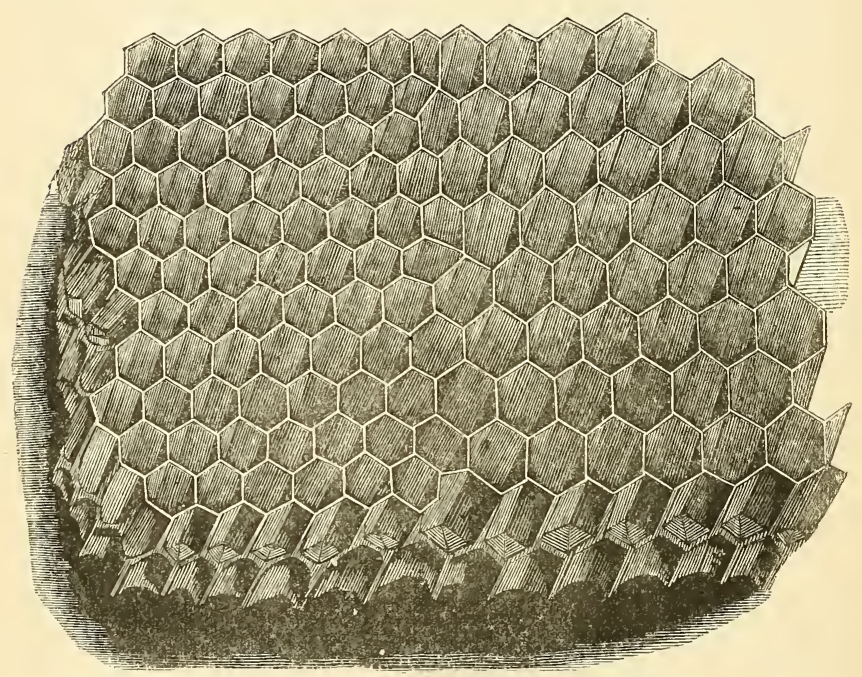

Fig. 17.-Diagram showing Slope of Cells.

of two distinct layers agglutinated together. This gives, again, an increase of strength, as any practical builder would know who, in his "bressummers," adopts the same method of attaining lightness and power of sustaining great weights.

The actual size of the cells in a hive varies considerably, as we might expect. Without regarding those for queen-progeny, we should anticipate that 
those in which young drones are to be developed would be considerably larger than those prepared for workers. This is, indeed, the case. But as an abrupt change from the one kind to the other would be impossible without waste, the bees prudently graduate the difference by interposing a suitable series of intermediate sizes, whose bottoms, of course, have to depart from the normal conditions, and sometimes consist of two rhomboids and two hexagons, varying in size and form, and corresponding with four, instead of three, opposite cells. In these, stores are often found, instead of brood. If eggs are laid in them, they are generally those which will develop into males, and the space for development being smaller than usual, the drones occupying such cells are not so large as the average size.

As a rule, the hexagonal ends of twenty-seven worker cells, or nineteen drone cells, occupy a surface of one square inch. All the cells lie not quite horizontally, but sloping slightly downwards from the mouth towards the bases. This arrangement is designed to prevent the honey from easily flowing out. As the cells are filled with the liquid, the lower edge of each is first raised, and, in due time, the whole of the once open end is sealed over with a coating of wax mixed with a little propolis. This covering not only keeps the contents from running out, but prevents fermentation or candying, from contact with the air.

Each comb consists of a double layer of cells, back to back, and forming a sort of flat cake. At first this is lenticular in shape, the middle part being advanced rather more rapidly than the ends. 
It is a curious fact that the bees do not, on being put into a hive, or when working in a bell-glass, begin several combs at once; but, having thoroughly laid the foundation of one, and having made some progress with this, they then start one on each side of the first, and, after a time, one on the outer side of each of the last begun. Usually, therefore, the combs hang in parallel series. If any obstruction occurs, a deviation from the normal direction takes place, but.

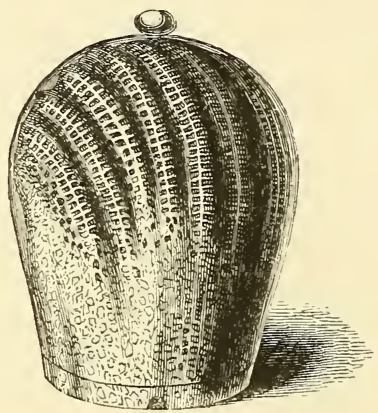

Fig. i8.-Arrangenent of Combs in a Bell-Glass.

manifest intelligence is shown in surmounting the difficulty, whatever it may be.

At first, the substance of the cells is of a dull, semitransparent, white colour, soft, and very brittle. After a time, a yellow tinge spreads over the comb, and, with age, this hue deepens to brown, and if some years old, becomes almost black. The colour, therefore, furnishes a tolerably safe guide as to the age of comb. The darkening seems due, partly to a chemical change from contact with the air, but still more to the constant traffic of the bees over it, and its getting smeared with dirt and propolis. 
It occasionally happens that, owing to a great in-flow of honey, the weight of the combs endangers their security, and the bees, seeing the danger of their breaking down, resort to a most clever method of rendering their treasures safe. Gnawing away a small part of the topmost row of the combs on one side, they lay a broader foundation, and then, with a strongly glutinous mixture of wax and propolis, they fasten afresh the upper cells to their points of attachment. Having completed one side, they then proceed in the same way with the other, till they are satisfied of the firmness of the whole structure.

Again, if the supply of food outruns the capacity of their store-houses as first made, they will often lengthen the cells, till, especially in the case of supers, they reach the length of even two inchesmore than twice the normal size.

The queen-cells are remarkably distinguished from those for workers or drones, in respect to size, direction, shape, and amount of material. They occupy

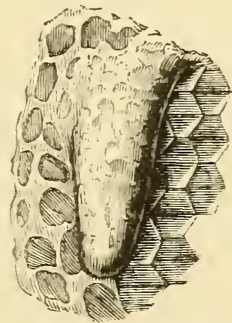

Fig. ig.-The Queen Cell.

at least as much space as half a dozen ordinary cells. They are directed downwards, instead of lying horizontally. They are irregularly oval or pyriform in 
shape, and are made up of a sort of mosaic of wax, which material, so sparingly used elsewhere, seems lavished on the royal nurseries. The reasons for this are, probably, to secure the young queens from danger while passing through the larval and pupal conditions, and to keep up the warmth necessary for

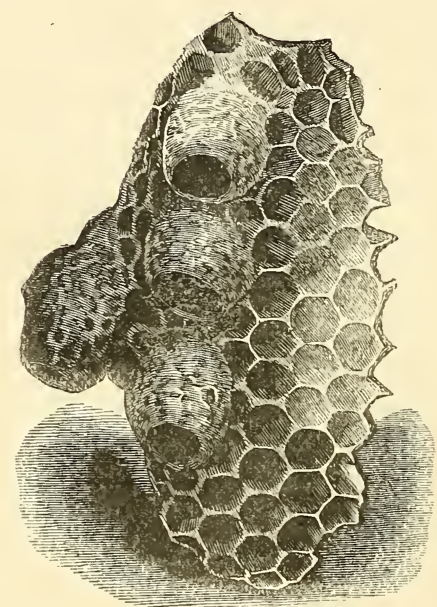

Fig. 20.-Queen Celles in situ.

their more rapid development. Wax being a very bad conductor of heat, the thick walls prevent the chilling of the brood, and, at the same time, allow of considerable clustering of nurse-bees, and consequent generation of warmth, without the danger of the cells being broken down by the pressure.

Bees-wax forms a not unimportant article of commerce. From Germany, Greece, Cyprus, and still more largely from North America, we derive what is needed to make up the deficiency in our 
home production of it. Its uses are numerous. For household purposes, especially for polishing furniture, for some varnishes and unguents, for candles and matches, for modelling, particularly in dentistry, it is consumed in great quantities. Since the introduction of paraffin and similar substances for lighting purposes, the amount used for candles has diminished, though the demand for it in other directions does not appear to have fallen off. Bee-keepers now use it greatly for "foundation-comb." 


\section{CHAPTER IX.}

POLLEN, OR BEE-BREAD.

Origin-Collection-Conveyance-Deposition-Quantity Stored-Uses -Artificial Substitutes.

HONEY consists, like most saccharine substances, of carbon, oxygen, and hydrogen. It is fitted, therefore, as a food to supply the waste in the body of the bee produced by respiration ; but for the nourishment of muscular tissue, and so for the growth of the larve and pupæ, some nitrogenous material is required. This is obtained by the insects from the pollen of flowers. This substance, we need hardly say, is the fertilising powder necessary for the production of seeds in plants, and growing on the anthers, or tops of the stamens, within the corolla of most flowers. The workers in search of honey rub off this farina with their hairy bodies and with the bristles of their leg.s. Then, on taking wing, they clear it off by rapid combings of their limbs; and rolling the powder into little pellets, they deposit it in pockets situated on the outside of the middle joint of the hindmost pair of legs. When filled, these receptacles with their loads appear like coloured balls on the laden workers. Sometimes the bees get 
so covered with pollen from plants containing large quantities of it, that they cannot clear themselves of the powder till they return to their homes; and, in some cases, they need the assistance of their fellows to brush off what adheres too tightly, or in places not easily reached by the individual herself.

When the pollen-laden bee has reached the combs, she searches for a cell already containing the same

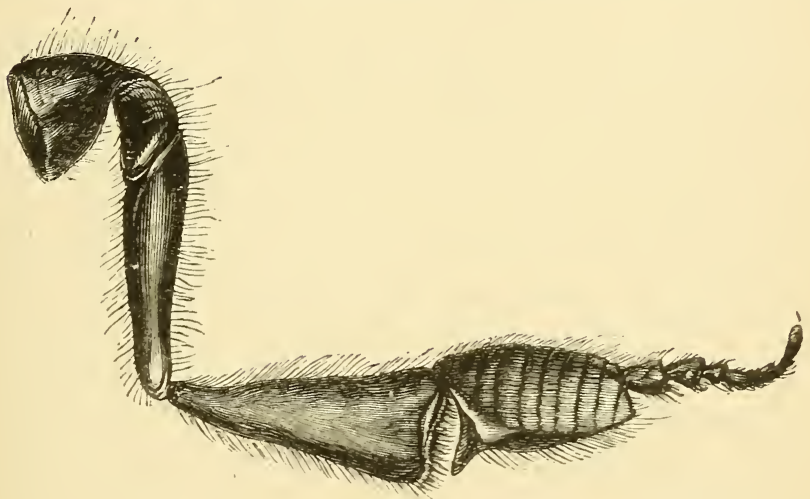

Fig 21,-HiNd-Leg of A BeE.

material as that she is carrying, or which is suitable for her purpose. Then, having found what she wants, she inserts her hindmost legs into the cell, and, by a dexterous movement, detaches the little balls, and, on retiring, gives herself some vigorous shakes, as if to clear herself of still adherent flower-dust. Then another worker, whose duty it is to see to the proper storing of the bee-bread, rams it down with her head into a compact mass, and the process goes on till the cell is filled.

No particular portion of the combs seems selected 
for the deposit of this substance, nor is it ascertained that what is procured from any particular kind of plant is placed apart; but a mixture of various pollens appears to be made, though during the prevalence of any special flower yielding the material, certain colours predominate, as might be expected, in the stores of bee-bread.

The quantities collected by a prosperous colony must be very great. Some writers put the amount at twenty pounds in the course of a season. The carrying in of this produce is usually a sure sign that there is brood in the hive. The absence of a supply going in generally raises the suspicion that no young are developing, owing to the loss of the queen. The amount seen to be carried in is, therefore, a rough indication of the prosperity of the community.

In early seasons its collection begins as soon as February. During April and May, i.e. in the height of the blossoming time, the largest quantities are stored; and this period corresponds with the most rapid and extensive increase of the population of the hive.

The nurse-bees take some portion of the pollen immediately it is brought in, and, working it up with honey and saliva, prepare the food for the larvæ. In some cases, they partially digest it before giving it to the young brood. It is believed that the queen, when laying her thousands of eggs, needs copious supplies of nitrogenous nutriment, and that her attendants diligently feed her with honey mixed with bee-bread, which has been partly prepared in their stomachs for quick assimilation in the body of their monarch. 
When plant-blossoms are scarce, the skilful apiarian supplies his stock with some substitute for pollen. Dr. Dzierzon was the first to propose fine rye-meal for this purpose ; and he was led to make the suggestion by having noticed, that, in the early spring, before flowers were blooming in sufficient quantity to satisfy the wants of his bees, they entered a neighbouring mill, and returned to their hives well powdered with rye-flour. Pea-meal has been tried with much success for this purpose. The method of using it recommended is to put the meal into a soup-plate, or shallow dish or trough, among shavings. The bees may be enticed to take to it by a little honey placed on the rim of the receptacle, or by showing a few individuals the way to it. When once the treasure has been discovered by the workers, they make abundant visits to it. They, indeed, prefer the peaflour to the old stores of bee-bread remaining in the hive; but, so soon as the natural supplies of the plant-blossoms are sufficient in amount for the wants of the brood, the substitute is quite neglected.

In extracting honey from combs by pressure, it is well to avoid any admixture of the bee-bread, as its taste is by no means a pleasant addition to the flavour of the sweet liquid. By using any of the "extractor" machines now in vogue, all danger of having the pollen mingled with the honey is avoided. 


\section{CHAPTER X.}

PROPOLIS.

Derivation of Word-Sources-Nature-Purposes-Quantity Collected -Adaptation of Materials to Wants of Bees.

ANother substance carried in, and largely used by the bees, is an exceedingly sticky material called propolis, from two Greek words signifying "before the city," as it was observed, in early times, that it was employed in strengthening the outworks of their fortress-home, or, at least, in firmly securing the rim of their hives to their floor-boards.

It was formerly a matter of considerable discussion whether this substance was a natural vegetable product, or whether it was elaborated, as wax is. There is now little doubt that it is chiefly a sort of resin derived from plants, and especially from the leaf-buds of certain kinds, like the horse-chestnut, the alder, birch, willow, and hollyhock. Huber, to whom we are indebted for so many interesting and careful observations on apiculture, tried the experiment of placing in pots branches of the poplar, before the buds had opened, and these he put near his apiary. The bees, settling on them, separated the folds of the largest buds, extracted the resinous matter in 
threads, loaded it on their thighs, as they do pollen, and carried it to their hives. In the spring one may often notice a loud humming round the foliage of deodars, firs, and other coniferæ; and some wonder may, at first, be felt as to what the busy insects can want from such absolutely honeyless trees. When we remember the turpentinous exudations which are so abundant in these cone-bearers, all difficulty disappears. It is for supplies of propolis the workers are searching. Evans says on this subject :-

"With merry hum the willow's copse they scale,

The fir's dark pyramid, or poplar pale ;

Scoop from the alder's leaf its oozy flood,

Or strip the chestnut's resin-coated bud,

Skim the light tear that tips Narcissus' ray,

Or round the hollyhock's hoar fragrance play."

It is most probable that, with the resinous substances collected from trees, they knead up a certain proportion of wax, to increase the tenacity. The resulting product is one of extraordinarily glutinous quality. With it the bees stop every chink and crack and cranny in their abodes. With it they stick down skeps to floor-boards, fasten, if they can, frames to the top of bar-hives, firmly fix the combs to their points of attachment, strengthen weak places in their dwellings, and, in some cases, where glass has been inserted in the walls of hives for observation purposes, the panes are found completely coated with propolis, so as to exclude the light.

In colour, this cement is greenish yellow, darkening with age to brown. Its odour is balsamic and somewhat powerful, resembling that of storax. It was formerly supposed to possess medicinal properties, 
and was kept in the shop of the apothecary. When smeared on the fingers, it is very difficult of removal. Soap has no effect upon it; water fails to wash it off; but spirits of wine readily dissolve it, and are the most easy and effectual means of getting it off the skin.

Bees usually choose the middle of the day for gathering this substance, as the warmth of the air, by softening the resinous material, facilitates the obtaining of it from the trees, and prevents its too speedy hardening before it reaches the hives. Sometimes, indeed, the resin becomes so firm in consistency by the time the collectors of it get home, that they require the assistance of their fellow-workers to detach it from their thighs.

One very remarkable use to which propolis is occasionally put by the bees, is for the covering up of mice, snails, frogs, or other intruders, whose expulsion is impossible, or who have died after entering the hives. Réaumur relates that, on one occasion, he observed a snail thus glued down to a piece of glass in one of his hives ; and, in another instance, where a slug had been stung to death, and was far too large for removal by the insects, these clever sanitarians completely enveloped the mollusc with a coating of propolis-varnish, to prevent the emanation of any noxious vapours when decomposition set in. It was, in fact, a distinct instance of embalming. Huish mentions that a mouse was similarly treated by one of his stocks of bees.

The quantity of propolis collected is sometimes very large, particularly where spaces are left at the top, sides, or bottoms of bee-dwellings. At present, 
this substance has not been turned to any serviceable human use.

In reviewing these various products gathered or elaborated by bees, we cannot fail to be struck with the marvellous adaptation of different materials to the wants of the community, the skill displayed in the application of them to the general purposes of the commonwealth; and, above all, the wondrous suitability of means to ends, shown by the workers of the hive. If we refuse to allow the possession of reason to these extraordinary insects, we must admit the existence in them of some faculty almost more to be admired; and, in any case, we can but bow in reverence before the all-comprehensive Divine wisdom and goodness, which have endowed creatures so small with powers so surprising-which have made them subservient to human needs or comfort, and which have enabled the bees to work even to better advantage under the tutelage of man, than when left to their natural habits and surroundings. 


\section{CHAPTER XI.}

\section{PHYSIOLOGY OF THE BEE.}

Nervous System-The Head-Eyes-Compound and Simple-Uses and Powers-Sir John Lubbock's Experiments-The AntennieStructure and Uses-Mouth-Detailed Description.

BEFORE proceeding to detail the most important facts connected with the internal economy of the hive, it will be desirable to describe with some minuteness the physiology and anatomy of the inhabitants, so that it may be more easy to understand the means by which various processes are accomplished, and the most important events of the community are brought about. Much that has been hitherto said will become more readily comprehended by attention to the structure of the various organs we are now about to describe.

It will hardly be necessary to enter into a more minute account, than we have already given, of the egg, the larva, and the pupa. We shall, therefore, confine ourselves to detailing the most interesting points in the physiology of the perfect insect.

It has been noted, in an earlier chapter, that the members of this division of the animal kingdom are characterised by having three very distinct segments 
in their bodies-the head, the thorax, and the abdomen. As the nature and arrangement of the nervous system forms one of the soundest bases of classification in the highest of the three kingdoms in nature,

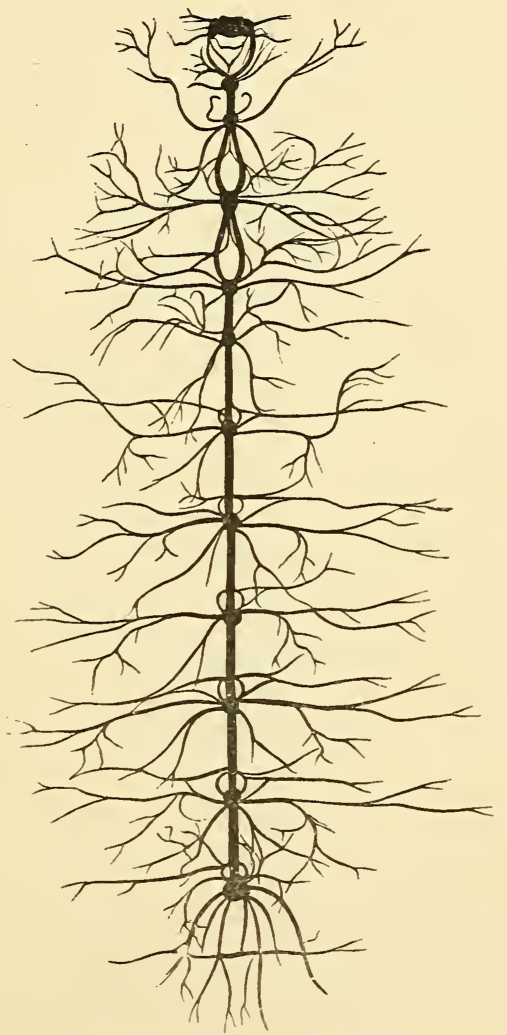

Fig. 22.-Nervous System of Privet Hawk-Moth.

we shall first direct attention, in each case, to this allimportant matter of detail. The general arrangement of the nerve-matter in the sub-kingdom 
Articulata, to which all true insects belong, is that of a double cord, with knot-like protuberances, called ganglia, at more or less regular intervals. The two filaments are in some cases close together: in others, quite distinct; while the larger nerve-masses-the previously mentioned ganglia-also vary in juxtaposition, according to the greater or less importance

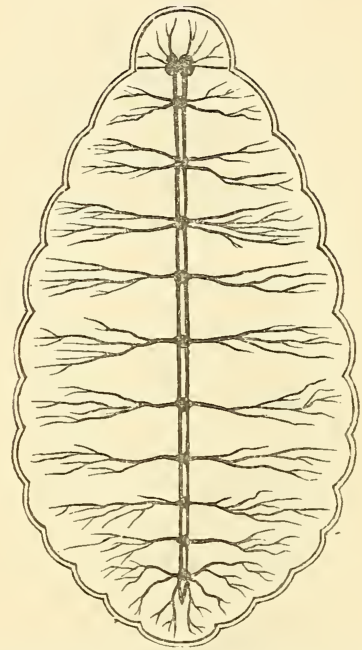

Fig. 23--Nervous System of Larva of Bee.

of the functions they regulate. In the illustration of the larva of Sphinx ligustri (the privet hawk-moth) (Fig. 22), the nervous cord is nearly uniform throughout its length, though at its upper portion a separation takes place into three loops. The ganglia also occur at almost equal distances. A very similar disposition of the nerve-structure is seen in the larval condition of the bee; but we may note the absence of loops, the larger development of the cephalic masses, without 
the separation of their filaments to inclose the gullet together with a more plainly-defined distance between the cords which run parallel through the rest of the body.

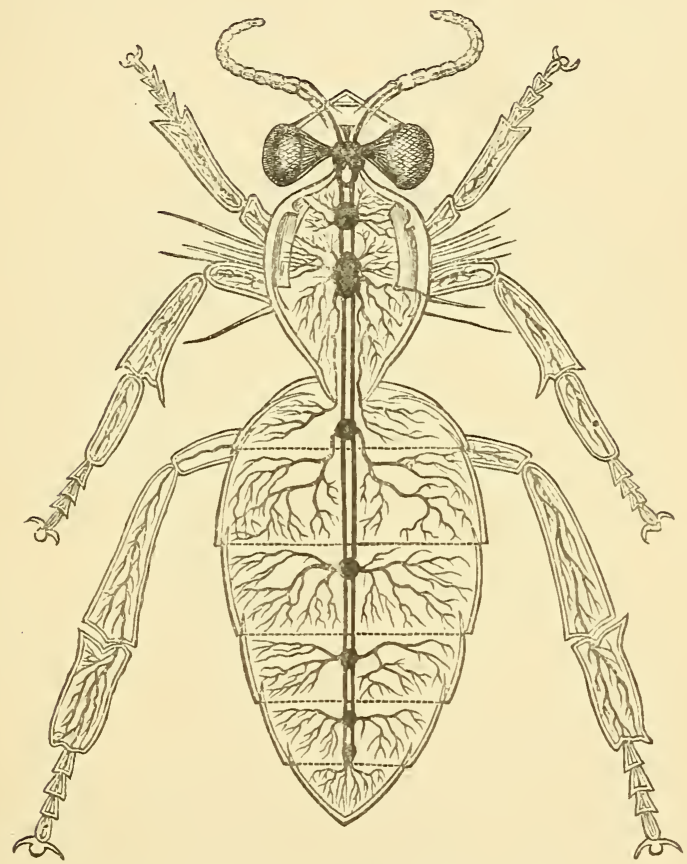

Fig. 24.-Nervous System of Perfect Insect.

In the perfect insect we observe some decided modifications to have taken place. The head portions have grown proportionally larger, and show a loop for the passage of the cesophagus, while two large ganglia in the thorax indicate the seat of impressions and impulses connected with the organs of motion-wings and legs-which had no existence in 
the larval condition. As the functions of the abdominal region, viz., those of digestion and circulation chiefly, remain much the same in the different states through which the individual passes after the hatching of the egg, we find, as we might expect, little change in the nervous system of the posterior segment of the body.

From each nerve-mass will be observed filaments branching on either side to the outer edges of the body. By means of these communication is kept up between all parts of the frame. Sensations are received and conveyed to the sensorial organs, and return-stimuli are sent to the organs whose movements depend for regulation on the different ganglia. This branching of the nerve-fibre is directly proportional to the variety and force of the several functions subserved by the various structures to which they proceed.

The Head.- We will now describe in some detail the structure and functions of the highly-important organs contained in the anterior segment, or head. And first in order let us take the

Eyes.-On either side of the head may be observed an oval lobe, convexly rounded and immovable, brown in colour, covered with a horny tunicle, and exhibiting to the unassisted eye a vast number of distinct points. These points, under a high-power magnifying-glass, are seen to be facets, hexagonal in shape, so as to occupy all available space, without interstices, and each connected with a minute tube and a thread of nerve-matter leading to the cephalic ganglia or brain. These compound eyes, as they are called, are common to most true insects. They may 
be easily seen in flies, bluebottles, moths, butterflies, \&c. The numbers of the facets vary greatly in different families of the Articulata. In the common house-fly there are, it is stated, about 4,000 ; in the white cabbage-butterfly, I7,000; in the dragon-fly, 24,000 . It has been computed that in each compound eye of the bee there are about 3,500 of them.

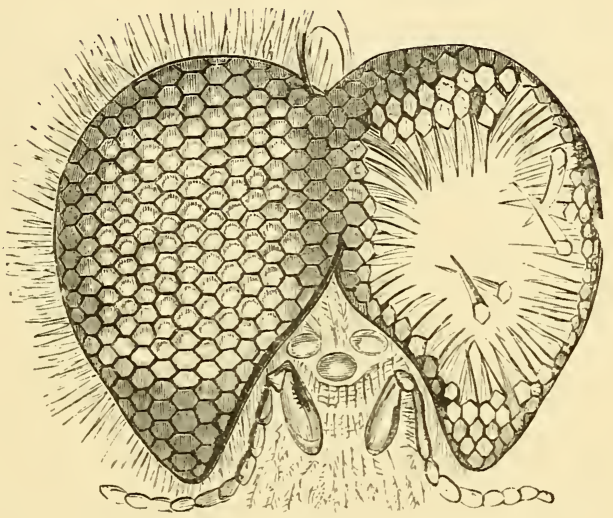

Fig. 25.-Eyes of a Bee, greatly Magnified.

Behind the horny covering, or cornea, which consists of two plano-convex lenses, is a layer of dark pigment, which gives the characteristic colour to these eyes. This is pointed like the neck of a vase, and serves the purpose of the iris in the higher animals. This is traversed by a minute aperture or pupil, through which the rays pass by a longer conical lens to the optic nerve. A vertical section shows that each ocellus (or little eye) is the frustum of a pyramid, the large end or base of which is bounded by the cornea, while the other and pointed end 
terminates against an expansion of the optic nerve. The eminent physiologist, Dr. W. B. Carpenter, says, in describing the minute structure of these organs: "The interior of this pyramid is occupied by a transparent substance, which represents the vitreous humour (of the eyes of vertebrates), and the pyramids are separated from each other by a layer of dark pigment, which completely incloses them, save at the pupillary apertures, and also at a corresponding set of apertures at their smaller ends, where the pigment is perforated by the fibres of the optic nerve, of which one proceeds to each separate eye. Each facet, or 'corneule' of the common cornea, is convex

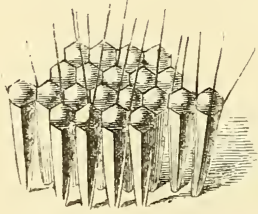

Fig. 26.-Facets of Eye of a Bee.

on both its surfaces, and thus acts as a lens, the focus of which has been ascertained, by experiment, to be equivalent to the length of the transparent pyramid behind it; so that the image produced by the lens will fall upon the extremity of the filament of the optic nerve, which passes to its truncated end. The rays which have passed through the several 'corneules' are prevented from mixing with each other by means of the layer of black pigment which surrounds each cone; and thus, no rays, except those which correspond with the axis of the cone, can reach the fibres of the optic nerve. Hence it is evident that each separate eye must have an extremely 
limited range of vision, being adapted to receive but a very small pencil of rays proceeding from a single point in any object; and as these eyes are immovable, they would afford but very imperfect information of the position of surrounding objects, were it not for their enormous multiplication, by which a separate eye, so to speak, is provided for each point to be viewed. No two of these, save those upon the opposite sides of the head, which are directed exactly forwards, can form an image of the same point at the same time; but the combined action of all of them may give to the insect, it may be imagined, as distinct a picture as that we obtain by a very different organisation." We venture to suggest that another reason for the vast multiplication of the numbers of "ocelli" is to enable the insects to see in what would be to us darkness. Nearly all the operations carried on in the interior of the hives are done, during the day-time, in very dim light; and in the night-time, when work is by no means intermitted, there would, to our eyes, be absolute darkness. To the bees, however, the scanty rays received by so many sensitive points may be sufficient to enable them to see with considerable clearness. If the simple enlargement of a single pupil, such as takes place in us on emerging from a strong into a dim light, makes so great a difference in our power of vision-a fact with which we are all familiar on going from a well-lighted room into what seems for the first few seconds complete darkness-we may well believe that the permanent means of entry into the sensorium of an immense number of separate rays may give greatly enlarged powers of seeing scantily illuminated objects. 
Still, an opposite view is held by many naturalists, for it seems very doubtful whether there is any power in the bee of focusing these eyes, so as to adapt their range to different distances. The probability is that no such faculty of adjustment exists in them. We should expect this from the structure of the visual apparatus. Yet it seems possible that the compound eyes act as telescopes, and serve for great range of vision, but not for near objects. For, while bees dart homewards from far-off fields with the directness of an arrow, they will frequently fly against persons or things in the direct line of their course, without apparently having seen them at a little distance off. Moreover, when they have alighted within an inch or two of the entrance to their hives, they often fail to perceive its position, and constantly wander to one side or the other, searching for their way in. We might conclude, therefore, that these compound eyes confer distinctness of vision afar, and possibly ability to use up scanty light, rather than any great discernment of objects near at hand.

In addition to these "facetted" eyes, bees have, on the top of the head, three simple ones, called by some writers "coronets," by others "stemmata." Their position and arrangement are shown at $g$ in Fig. 27, p. 98. The focal length of their lens is said to be short, and they are supplied with numerous filaments from the optic ganglia. The special purpose of these simple organs is not well ascertained. If their focal length is short, this would seem to imply that their range of vision is also very limited. But it is very possible they may possess a focusing power, which would adapt them for seeing 
at all distances. Réaumur thinks they may, with their hemispherical lens, act as microscopes. This point needs further investigation, as the subject of the uses of these two kinds of visual apparatus is, at present, very far from satisfactorily elucidated. One remarkable fact relating to the "stemmata" must be mentioned. It is that, if they be covered with a little opaque paint, the bee, on being let go, will fly continually upwards. Dr. W. B. Carpenter considers this curious fact due to a utomatic movements initiated by the ganglia connected with flight, uncontrolled by the visual impressions which the simple eyes convey in their natural condition. Neither kind of eye has a lid, but both are protected from dust by numerous small hairs growing round them, and in the points of junction of the facets.

How far the eyes of bees enable them to distinguish colours is still a moot point. On a priori grounds we should expect that one very definite object in the hues of flowers is to attract the notice of insects, just as we have strong reason to believe that odours exhaled in the vegetable world serve this purpose. Sir John Lubbock has detailed a series of experiments on this point, the following summary of which is abstracted from his work on Ants, Bees, and Wasps. He says, p. 304: "In recording the results I marked down successively the order in which the bee went to the different-coloured glasses (on which honey was placed). For instance, in the first journey from the nest, as recorded below, the bee lit first on the blue, which accordingly I marked I; when the blue was removed, she flew about a little, and then lit on the white; when the white was removed she settled 
on the green ; and so on successively on the orange, yellow, plain, and red. I repeated the experiment a hundred times, using two different hives-one in Kent, and one in Middlesex - and spreading the observations over some time, so as to experiment with different bees, and under varied circumstances. Adding the numbers together, it, of course, follows that the greater the preference shown for each colour, the lower will be the number standing against it.

"The following table gives the first day's observations in extenso:-

\begin{tabular}{|c|c|c|c|c|c|c|c|}
\hline Journeys. & Blue. & Green. & $\begin{array}{l}\text { Plain } \\
\text { Glass. }\end{array}$ & Orange. & Red. & White. & Yellow. \\
\hline I & I & 3 & 6 & 4 & 7 & 2 & 5 \\
\hline 2 & 5 & 4 & 7 & 6 & I & 2 & 3 \\
\hline 3 & I & 4 & 7 & 6 & 5 & 3 & 2 \\
\hline 4 & 2 & 4 & 6 & 7 & 5 & I & 3 \\
\hline 5 & I & 4 & 7 & 2 & 6 & 5 & 3 \\
\hline 6 & I & 2 & 3 & 6 & 5 & 4 & 7 \\
\hline 7 & 2 & I & 4 & 7 & 3 & 5 & 6 \\
\hline 8 & 3 & 4 & 6 & 2 & 7 & 5 & I \\
\hline 9 & 5 & I & 7 & 4 & 6 & 3 & 2 \\
\hline IU & I & 6 & 7 & 5 & 3 & 2 & 4 \\
\hline \multirow[t]{2}{*}{ I I } & 4 & 6 & 5 & 2 & 7 & 3 & I \\
\hline & 26 & 39 & 65 & $5 I$ & 55 & 35 & 37 \\
\hline
\end{tabular}

"In the next series of experiments the bees had been trained for three weeks to come to a particular spot on a large lawn, by placing from time to time honey on a piece of plain glass. This naturally gave the plain glass an advantage; nevertheless, as will be seen, the blue still retained its pre-eminence. It scems hardly necessary to give the observations 
in detail. The following table shows the general result :-

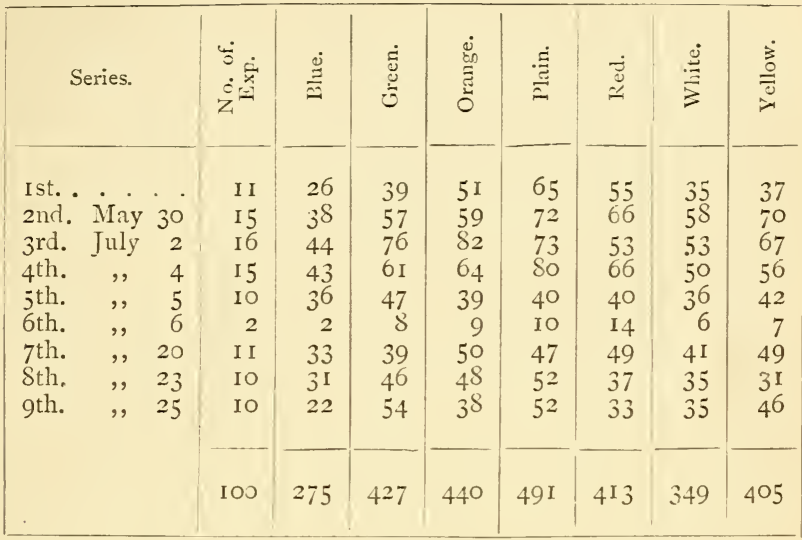

"The precautions taken seem to me to have placed the colours on an equal footing; while the number of experiments appears sufficient to give a fair average." As this table differs in form from the other, it may be as well to explain the first line of figures in illustration of the whole. The first series consisted of eleven experiments. The preferences were noted as before, and when the numbers indicating these were added up, the results were that twenty-six represented the total for the blue glass, thirty-nine for the green, fifty-one for the orange, sixty-five for the plain glass, fifty-five for the red, thirty-five for the white, and thirty-seven for the yellow-the blue being again manifestly the most attractive colour to the bees. Some practical beekeepers consider the question by no means settled. The field is doubtless open for further exploration. 
The Antenne.-In the front part of the head are two organs, which appear to supplement, in some remarkable way, probably by touch-sensations, the power of vision, and also to possess other capabilities constituting a sense to which we have nothing strictly analogous. These organs are called antenne. They spring from origins near together, at equal distances from the medial and anterior point of the head, and are connected, by distinct and somewhat large filaments, with the nerve matter forming the cephalic ganglia. Externally they consist, first, of one segment nearest the head, much longer than the rest. This part is called the scape. Then, forming a sort of elbow with it, is the flagellum, consisting of eleven joints in queens and workers, and of twelve in the drones. These segments are tubular, and so attached to each other as to give the greatest possible freedom of motion. Their extremities are wonderfully sensitive, and it is probable that there is a very delicate power of feeling in each of the joints. For the cleansing of these organs, special provision is made in the construction of the fourth and fifth joints of the most forward pair of legs. At the anterior part of the tibia, or fourth joint, is a spur, within, and at the base of, which is a small angular projection, called the velum or sail. At the base of the next joint, and opposite the play of this velum, is found a deep notch. From the fact of its being fringed with hairs, this is called the curry-comb. Upon this notch the velum can act at the will of the insect, and, when shut over one another, they form a circular orifice, just large enough to take the antennæ. When the latter organ needs cleansing, it is laid within the notch : the velum 
is pressed over it, and being drawn through the round space, dust and other soilures are removed from its surface. So particular are the bees about keeping their antennæ thoroughly clean, that they may often be observed continuing this operation of drawing them through the curry-comb till perfectly satisfied with their condition. Doubtless, the delicate nature of the impressions to which these organs are susceptible, supplies the reason for the care taken in freeing them from all extraneous substances.

The uses served by the antennæ are various and very remarkable. Their first function seems to be to supplement vision. Endowed with exceeding flexibility, they are kept by the insects in constant motion; and when their eyes fail to guide them to particular spots, such as the entrance to the hive, or as to the nature of objects with which they come into contact, the antennæ appear to supply the necessary information. There is little doubt that these "horns" or "feelers," as they are commonly called, are sensitive, also, to impressions from objects at some distance. Vibrations of the air too feeble to affect our organs affect them. It may even be that other qualities of the atmosphere are apprehended by them. The shape of the cells; the suitability of these for brood of various kinds, for honey or for bee-bread, is ascertained by the antennæ. Every want and every duty is recognised by them; the presence or absence of the queen is discovered by their use, and intelligence is conveyed from one individual to another by means of them.

Of these facts, Huber has given the following striking evidence. He divided a stock hive into two 
parts by metal network, sufficiently fine to prevent the passage of the bees, but with meshes wide enough to allow the antennæ to be passed through. At first, by a pair of such gratings at a little distance apart, he separated the two portions, so that no communication whatever could take place between them. Very soon that half from which the queen was excluded showed signs of commotion and distress, and even began to prepare queen-cells, to supply themselves with a new sovereign; but when, by the removal of one grating, Huber allowed the feelers to be used to convey intelligence between the bees on opposite sides of the remaining division, he saw the insects by hundreds making inquiries as to what had happened. Then the queen was observed on the grating, and the bees being assured, by crossing antennæ with her, that their mother was still in the hive, though shut off from free access to one set of her subjects, they all quieted down, left off making the royal cells, and resumed their various avocations.

Huber tried the further experiment of depriving two queens of their antennæ, and introducing both into the same hive. The population did not seem able to recognise their own sovereign from the stranger, and both were let alone; but, directly he put in a third queen, unmutilated in these organs, the workers fell upon her, and slaughtered her.

The antennæless queens lost all purpose, laid eggs at random, and wandered about the hives as if they had "lost their heads."

Another very curious fact is, that if a worker is deprived of her feelers, and then allowed to fly, she becomes incapable of recognising her hive, even 
when near to it, and is hopelessly lost as to her whereabouts. From this circumstance we are inclined to conclude that the antennæ are possessed of sensibilities to which we have nothing strictly analogous - that, in fact, there resides in them a sense, or senses, with which mankind is not endowed, one of which we are disposed to call the "homing-sense."

Numerous observations show that by the antennæ, also, distinct information can be given. We have ourselves tried the following experiment in confirmation of this point. Having placed near the entrance of a hive a dead humble-bee, we first noticed one of the sentinels rush to the body, and with her feelers investigate its nature. Finding it was a lifeless creature, and one, therefore, simply to be got rid of, she began to tug at it, to move it towards the edge of the floor-board. At once discovering that the weight was too great for her strength, she went to the entrance, and meeting a friend, by crossing their feelers, the one was made aware of the difficulty of the other. The second then went to the aid of the first; but, as the body was too great a burden for their united efforts, the new-comer gave up her attempts to move it, as if the duty did not concern her much. The first bee, however, would not be baffled till she had fetched several other individuals, one at a time, to the work in hand. But, at length, as she could get no combined action, and as no two were sufficiently strong to haul away the large carcase of their distant relative, she gave up the task in despair, and retired to the hive in apparent disgust.

On a moonlight night the sentries may be observed 
marching eagerly about the entrances of their abodes, and vigorously moving their antennæ, to ascertain whether moths, or other unwelcome intruders, are trying to get inside the hives. The presence of an enemy being detected, he is soon chased away.

By some naturalists the feelers have been thought to afford the capacity of smell. It is, however, more probable that this sense resides in the mouth itself, or in its immediate neighbourhood.

Whether or not bees appreciate sound, is another moot point. It is, indeed, doubted by many observers whether hearing is possessed at all by insects. Sir John Lubbock records a series of experiments which he conducted on this point, to which we shall make reference a little later on. Those writers, who credit bees with the ability to distinguish sound waves, incline to the belief that the power resides in the antennæ. As modern science has shown that all our physical impressions are modifications of vibration, variously interpreted, according to the means by which they are conveyed to the sensorium, we may readily imagine that more than one faculty may reside in these jointed organs of which we have been speaking, and that each separate part may possibly have its own specific function; while, by combined action, such differences may be made as are analogous to chords, and harmonies, or discords in music, as compared with the striking of single notes.

We have dwelt at considerable length on the subject of the antennæ, not simply because what is known of them is so remarkable, but because we wish to draw attention to the fact that there is here a most interesting field for further investigation. 
Much remains to be done to clear up the mysteries still unsolved, and to harmonise the various observations already made respecting the nature and properties of these organs, which, not only in bees, but in many other families of insects, play such an important part in their life-history.

The Mouth.-Passing next to the mouth, we find a somewhat complex structure; for it consists of many parts, each of which has its ascertained function. We find first, the labrum, or upper lip; the epipharynx, or valve closing the aperture of the gullet; the pharynx, or gullet, forming the true mouth, as well as the entrance to the cesophagus, or food-pipe; the hypopharynx, lying just below the gullet; the labium, or lower lip; and the proboscis, or true tongue. These are all single parts; but there are also pairs of mandibles, or upper jaws, and maxilla, or lower jaws, besides palpi-certain jointed, sensiferous organs, whose functions are not well understood, but which are possibly connected with the sensation of taste.

The labrum, or upper lip, has a vertical motion, and when not in use falls over the organs beneath it; while it is covered, in its turn, by the mandibles, which are jointed on to the cheeks, and act laterally.

The pharynx is a cavity lying beneath the epipharynx, and can be closed by the latter, over which the two previously described parts lap, so that the entrance to the œesophagus is trebly protected.

The labium, or lower lip, is capable of being pushed forward and retracted, and lies, when not in use, within the under cavity of the head.

On either side are the maxilla, or so-called jaws, 
which form the under sheath of the rest of the lingual structures when in repose.

The true tongue is attached to the middle point of the lower lip, having the labial palpi at its sides. It is much elongated when thrust out in use. While

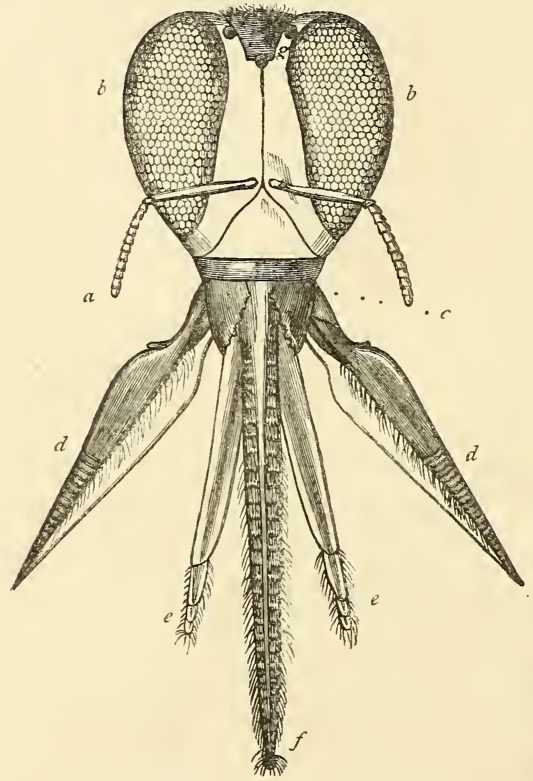

Fig. 27.-Head of Bee, with Antenne.
a. Antennæ.
b. Compound eyes.
c. Jaws.
'd. Maxillæ.

e. Labial palpi. $f$. Ligula, or tongue. $g$. Stemmata.

at rest, the anterior part folds back upon the posterior portion, when it is covered by the maxillæ, which seem then like a part of the tongue itself. The back is much larger than the front. The whole is flattened, when not sipping liquid. It is then much broader than its thickness, but its edges are rounded. It 
narrows from its base to its extremity, at which there is a slight inflation, which seems to have a perforation in its centre, and is surrounded by hairs. The tongue has also a large number of cartilaginous rings, each bordered with minute hairs, which appear to be the means used for sweeping up the last remains of any fluid which has been almost exhausted. The act of imbibition is performed, not so much by suction, as by lapping. Its motions being free in all directions, it can easily draw liquid into the mouth on all sides. We notice, however, that when the supply of food being taken is very considerable, the segments of the abdomen have a vibratory motion, or, rather, are alternately lengthened and shortened, as if fluid were being pumped into the body. It is, therefore, possible that, under some circumstances, suction as well as lapping may go on. Still, it is remarkable that a bee does not insert the tip of its proboscis into a drop of honey or other saccharine material, as it would do if it intended to draw liquid through a tube. It much rather uses the middle of the upper surface of the tongue, curving round the point as if not to employ it. If, however, the honey or syrup be very thick, the fore-part of the tongue is thrust into it, possibly to dilute the liquid with saliva, and thus to render it fit for lapping. In all cases the insect tries to load the upper surface, whence the fluid passes backward under the sheaths to the gullet; and we see no reason to believe that the proboscis constitutes a tube for imbibition. A further confirmation of this conclusion is given by Shuckard, who says, "By pressing towards its origin, I have detected the liquid which gave it its extension; but 
all my pressing would never make the liquid pass through the extremity, although the pressure has sometimes made it almost rend the membranes to give it an opening to escape by."

A further use of the tongue is for shaping the pliant wax in comb-building; and it appears to be employed much as a trowel is by a bricklayer, or, perhaps, we should rather say, like a finger by a moulder of plaster of Paris.

As we have mentioned, the jaws open vertically; but the mandibles and maxillæ work horizontally. They are thus enabled to seize and tightly hold any object they can grasp. The mandibles of the drone and the queen have two notches or teeth. Those of workers are not thus furnished, probably because, for shaping and smoothing the cells, an unbroken edge is much more convenient than a notched one. These organs are, however, very strong, and enable their possessor to grasp enemies, drones or queens; to nibble hard kinds of food; to break away pieces of damaged comb; and to mould wax for building purposes. In the last of these operations they are, doubtless, aided by the shear-like maxillæ. 


\section{CHAPTER XII. \\ HEARING, TASTE, AND SMELLING.}

Hearing-Sir John Lubbock's Experiments-Sounds uttered by Queen -Effects produced by them--Smell-Organs-Purposes-Liking for, and Antipathy to, certain Effluvia-Discovery by Bees of Nectar and Honey.

WiTH regard to the sense of hearing, Sir John Lubbock says: "The result of my experiments on the hearing of bees has surprised me very much. It is generally considered that, to a certain extent, the emotions of bees are expressed by the sounds they make, which seems to imply that they possess the power of hearing. I do not by any means intend to deny that this is the case. Nevertheless, I never found them take any notice of any noise which I made, even when it was close to them. I tried one of my bees with a violin. I made all the noise I could, but, to my surprise, she took no notice. I could not even see a twitch of the antennæ. The next day I tried the same with another bee, but could not see the slightest sign that she was conscious of the noise. On August 3 Ist I repeated the experiment with another bee, with the same result. On September I 2 th and I 3 th I tried several bees with a dog-whistle and a shrill pipe, but they took no notice 
whatever; nor did a set of tuning-forks, which I tried on a subsequent day, have any more effect. These tuning-forks extended over three octaves, beginning with A below the ledger-line. I also tried with my voice, shouting, \&c., close to the head of a bee; but, in spite of my utmost efforts, the bees took no notice. I repeated these experiments at night, when the bees were quiet; but no noise that I could make seemed to disturb them in the least. In this respect the results of my observations on bees entirely agreed with those on ants."

These experiments do not appear by any means conclusive. It may well be that sounds which are merely loud or shrill would pass unnoticed by the insects, as conveying no meaning to them. In like manner, a clap of thunder, the firing of a cannon or gun, the playing of a brass band, will produce no manifest effect upon them; but, if the queen utters, as she sometimes does, a peculiar sound, an instantaneous and very remarkable recognition of it takes place. The sound referred to is usually heard at the time when the young princesses are ready to emerge from the cells in which they have been developed. When thus emitted by the young queens, no attention appears to be paid to it by the workers, who, however, restrain the mother-queen from destroying her royal daughters. But, when these are released from their natal captivity, and the queen, standing with her thorax against a comb, makes, with her wings crossed over her back and in rapid vibration, a certain sound, it receives immediate attention. Huber tells us that bees which had been plucking at, biting, and chasing the queen, hung down their heads when this 
peculiar noise was uttered, and remained altogether motionless; and whenever she had recourse to this assertion of authority, the same effects followed.

Again, unless observers are fanciful in their interpretation of the sounds to be heard at various times in a hive, we must conclude that certain feelings, such as those of anger, grief, consternation, satisfaction, joy, \&c., are expressed in distinct tones. If this is the case, we can only conclude that, difficult as it may be to localise the organ of hearing, such an organ must exist. Nor, in all probability, shall we be mistaken in assigning its position to the antennæ; for recent investigations into the anatomy of these organs in ants, ${ }^{1}$ lend much support to the theory that an auditory apparatus is situated in them.

Taste. - Next as to taste. We have already spoken of the close connection between this sense and the preceding ; but, whatever doubt may be entertained as to the possession of the former, there can be none as to the latter. Huber, indeed, from the fact that bees are often seen lapping stable-liquid and sewage, thought the sense of taste could exist in them to only a very small degree. It must be remembered, however, that, like many other creatures, they are fond of certain salts, and to this, no doubt, may be ascribed their visits to the above-mentioned liquids. On a priori grounds we should conclude that the possession of this faculty was most important, for the detection of nectar suitable and unsuitable for the purposes of the hive. Moreover, we find a marked preference shown for flowers which produce the best honey; and the eagerness with which they will lap up

1 Vide p. 227 of Ants, Bees, and Wasps, by Sir John Lubbock. 
any thoroughly sweet liquid confirms the idea that they taste very readily.

Smell.-Probably of all the senses of bees none is so acute as that of the perception of odours. Not only do they distinguish the citizens of their own hive from those of other communities; not only do they discriminate between the fragrance of various flowers; not only can they detect the aroma of honey concealed from their sight, though not from their olfactory nerves, but they show a marked antipathy to certain human individuals, which can only be accounted for by supposing that from these persons proceeds an effluvium disagreeable to the bees, though not perceptible by, or unpleasant to, man.

A remarkable anecdote in confirmation of this wellknown fact is given by Bevan, on the authority of M. de Hofer, Councillor of State to the Grand Duke of Baden. This gentleman's father had for years kept bees, and had devoted much personal attention to them. He had, indeed, attained such familiarity with them, and such skill in their manipulation, that he could, without fear of being stung, search for and find the queen, and take her in his fingers. Unfortunately, he fell ill with a severe fever, which kept him for a long time a prisoner to his house. After his convalescence he visited his bees, returning to them with his old confidence and pleasure. Greatly to his surprise and dismay, he found their feelings towards him entirely changed. They would no longer allow him to approach the hives, much less to perform any of his former manipulations; and that this was not the effect of a change of the population, through the natural perishing of the workers, 
but was due to some alteration in him, was shown by the fact that he was never again able to resume his old familiarity with his favourites. Some change in his blood, brought about by the fever, made the emanations from his skin permanently offensive to the bees, though no such difference was perceptible to any of his human friends.

M. Feburier and other observers assert that a certain antipathy is manifested towards persons with red or black hair. We have reason to doubt the correctness of their opinion as to the latter class, and we more strongly incline to think that fair-complexioned people are less agreeable to bees than those who are darker. As a corroboration of this, we may mention the case of two brothers, one of whom could always approach the hives with impunity, while the other could not come near them without danger of being stung. Though both of them were dark, the obnoxious one was decidedly the fairer.

A further evidence of their scnse of smell is the anger they manifest on the crushing of one of their number. Like the terror inspired into an ox by the smell of freshly-drawn blood in the slaughter-house, is the odour of a bruised comrade to bees. Again, the smell of the liquid from one of their poison bags excites them strongly. A wound just made by a sting rouses others to inflict more wounds; and, if the fluid be presented to them at the entrance of their homes, it at once stirs their fury. If, however, it be allowed to crystallise, and thus to become incapable of emitting any odour, it will be quite disregarded by the bees. Sir John Lubbock tried various experiments with eau-de-Cologne and rose-water, and found 
that, till the insects had become habituated by frequent use to these liquids, they always came out to the entrance, to ascertain the meaning of the odours which had penetrated into the hives. It is well known, also, that they dislike the smell of paint so much, that it is not advisable to place a swarm in a freshly painted box, lest they should forsake it, from its unpleasant odour.

We may well conclude that it is owing to the keenness of this sense that they perceive the presence of flowers containing nectar; and, guided by it, they wing their flight to distant fields where the white clover attracts them, or to more barren districts where the heath promises them abundant pasturage. It is very certain that the fragrant aroma of honey is at once perceived by them at many feet from their dwellings; and in taking their sweets from them it is, for this reason, necessary to avoid all exposure of broken combs, or the dripping of their contents. Great trouble is, in fact, often occasioned by the readiness with which they thus detect the presence of their own produce. Within our personal knowledge, at a provincial show of bees, hives, and honey, the fragrance of the liquid attracted bees from the neighbourhood in such immense numbers that they carried off, during one afternoon, some seventy pounds of honey from the tent in which it was being exhibited.

The position of the organ of smell is not clearly ascertained. By some, as we have said, the antennæ have been credited with the power; but, though many observations may seem to favour this opinion, we must remember that we have on record some striking facts, which would seem, at least, to 
show that powerful odours are able to be recognised by other portions of the body. Lehmann and Cuvier came to the conclusion that the spiracles, connected with the respiration of bees, are the means by which the sense of smell is exercised. The idea was based on the notion that odours can only be perceived by the inhalation of air. This, of course, is not a sufficient ground for the inference arrived at. Kirby and Spence, again, inclined, as we have already mentioned, to the belief that the organ of smell lay in or near the mouth. This supposition was partly founded on the close relation between taste and smell. Huber's experiments lent some confirmation. to this theory. He presented a camel's-hair brush with a little oil of turpentine on its tip to every part successively of the abdomen, trunk, and head, without producing any discomfort to the bee. He then tried the eyes and antennæ, without any apparent effect; but, as soon as he directed it a little above the insertion of the proboscis and close to the mouth, immediate signs of annoyance showed themselves. This experiment, repeated with other stronglysmelling liquids, gave similar results; but, when the mouths of the insects experimented upon were stopped with paste, the perception of odours appeared no longer to exist.

For the present, then, the matter remains in doubt ; but we may suggest to our readers that observations on this point, carefully and patiently conducted, may lead to much useful information being obtained.

It is impossible to pass from an examination and description of the head-apparatus of the bee, without being struck with the marvellous beauty, and equally 
wonderful adaptation, of each of its parts to the varied functions required of them. Whether observed by the unassisted eye, or by a lens of low or high power, we cannot fail to see how exquisitely each minutest portion is fashioned; how remarkably the various organs are protected according to their delicacy; how supplied with nerve-fibre in proportion to the sensitiveness required in them; how supplementary one to another in their diverse duties; how harmonious in their working; and how fitted as a whole to the wants and the instincts of the insects to which they belong. Nor, as it seems to us, is it possible to believe that any force of evolution, unguided by a distinctly controlling and Divine creative power, could ever have elaborated organs so precisely what might have been expected to result from the exercise of infinite wisdom and manifest purpose. 


\section{CHAPTER XIII.}

THE THORAX.

Detailed Description-Legs-Wings-How used in Flight-Hooking together-Employed for Ventilating.

THE thorax of the bee is divided into three sections, or imperfect rings. Of these, that nearest the head is called the pro-thorax, the middle one the meso-thorax, and the hindmost the meta-thorax. To the first of these are attached the most forward pair of legs; to the second, another pair of legs and one pair of wings ; to the third, the last pair of legs and the other pair of wings. These organs of locomotion constitute, in fact, all that is worthy of special interest in this segment of the body, and we will, therefore, give a short account of them.

The legs of all insects consist of five parts, or joints, and in the case of the bee they are not only the means of walking or crawling, but, like some of the head organs of which we have spoken, serve several purposes. The first of the leg-segments is called the coxa, or hip, and is short and round, appearing, indeed, to be little more than the joint by which the limb is articulated to the body. The second is named the trochanter, and is very similar 
to the coxa. One purpose effected by these two portions is to give great freedom of motion to the whole member. Next comes the femur, or thigh, a longer and flatter division. This is followed by the tibia, or shank, a stouter and thicker division, which, especially in the hind-legs, becomes gradually wider

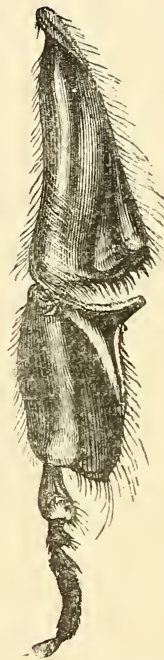

Fig. 28.-Lower Segnents of Hind-

LEg of BeE, considerably ENLARGED.

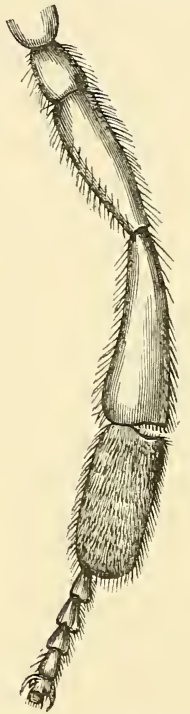

Fig. 29.-CoMplete Hind-LeG OF BEE.

downwards, and in the workers is adapted to a very special use, as we shall directly see. Then in succession we have the tarsus, or foot, consisting of five joints, the first very much stouter than the rest, and as long as the remaining four. It is terminated by a pair of hooked claws, with a cushion or pulvillus.

We have already spoken of the remarkable apparatus found in the four anterior tarsi, adapted to 
the purpose of cleansing the antennæ. At the junction of the fourth and fifth segments (the tibia and the tarsus) of the leg of a worker a cavity is formed by the uppermost edge of the latter and the lower of the former. The cavity can be opened or closed at the will of the insect. This pocket, or pollenbasket, is lined along its upper edge with a row of lancet-shaped hairs, which aid in detaining the tiny balls of pollen, as they are successively deposited on the leg. Like a series of prong-tines, they can be pressed into the yielding bee-bread, and keep it from falling off; while, as they point downwards, they present no obstacle to the brushing off of the whole mass by the bee, on its return to the hive. The slight hollowing of the tibia and the tarsus at the approximating ends, affords more space for the gathered pollen, and also assists in its safe carriage to the cells.

The last joint of the tarsus is armed with a pair of double claws, and between them lies a hollow cupshaped cushion, somewhat like that which enables the house-fly to walk on glass or other very smooth surfaces, only that the pulvillus of the fly is double. The edge of the cup is fringed with cilice, or very minute hairs, of such delicacy that a powerful lens is required to see them. Under the microscope, the object is one of great interest.

The claws serve for hanging from the roof or sides of hives, and for clinging to each other at swarming or wax-making times, the cushion for walking on smooth surfaces. It is worthy of remark that all the joints of the legs are covered with hairs more or less stiff, and all pointing downwards. Their uses are to 
collect pollen, and to act as brushes and combs to all the external parts of the body, which need constant cleansing from flower-dust, and other matters less useful to the bee.

Passing now to the wings, new marvels and beauties await our observation. These organs are four in number, the forward pair being considerably larger than the hinder. Each wing consists of a double membrane, dotted all over with fine hairs, whose purposes are to protect the delicate structure from

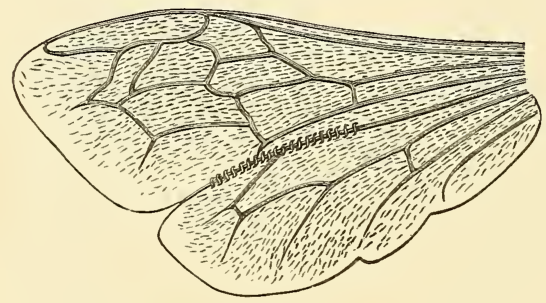

FIG. 30.-WING OF BEE.

wet, and from particles of various kinds which would adhere to it, and injure its surface. As a support for this expanded tissue, there is a ramification of stronger material, constituting nervures, and acting like the ribs of an umbrella. With these are associated air-vessels, or trachea, for the circulation of air, and, possibly, to assist in giving buoyancy to the organ. By another set of tubes a portion of the nutritive fluid is conveyed to certain parts of the wing, though no general circulation seems to take place in it. The substance of which the expanded portion, as well as the nervures, is composed, is very tough, and, as our readers may remember, the 
natural order to which the bees are assigned is named Hymenoptera, from the strongly membranous wings they possess.

We can readily understand the importance to these insects of having their organs of flight powerful, and yet not weighty, tough without being clumsy. Considering the length of their daily journeys, and the constant and rapid movements they require to make, we easily discern how well suited to their needs is the structure of their wings. But we must call attention to a remarkable provision for the further
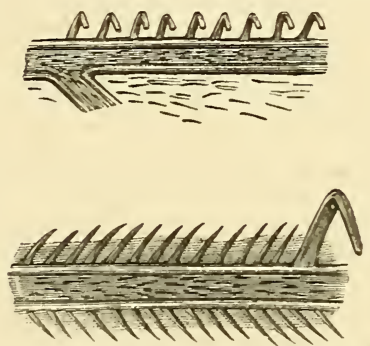

Frg. 31.-Hooklets of A BeE's Wing.

utility of these organs. Under a lens of medium power may be seen, along the anterior edges of the hind wings, a series of hooklets of hair, while on the posterior edge of the front wings is a rib, or bar, which the hooklets can grasp. By this means the two wings, when used for flight, become practically one, thus presenting unbroken resistance to the air, and, in consequence, greatly increasing the power of propelling the body. When at rest, the unhooking of the edges enables the wings to be folded out of the way-no mean advantage in the crowded hive. 
But there is a further benefit thus conferred on the insect. During hot weather, and when the population is very dense, ventilation is constantly and vigorously carried on by the workers, who, fixing themselves firmly by their claws to the floor-board at the entrance, some outside and some just within their homes, direct numerous currents of air into the hive. Of course there must issue a quantity corresponding to what is driven in, and thus a perpetual and free circulation is kept up. Now, if the wings worked independently, not only would a smaller quantity of air be affected by each stroke, but the two sets of motions would, to some extent, counteract each other. As it is, the hooked wings act like well-constructed and well-used fans. By the simple experiment of slitting such an implement down the middle, the comparative advantages of a broken and an unbroken surface, for fanning purposes, can easily be put to the proof.

Thus, again, we are struck with the fact that the more closely we examine the organs of any segment of the body of the insect, the more reason do we find to admire the skill, and the care for His creatures, manifested by the infinitely wise and the infinitely good Maker of them all. Beauty, adaptation, perfection, are the words which are continually suggested to our minds by the contemplation of the structure of the bee. 


\section{CHAPTER XIV.}

\section{THE A B D O M N.}

Respiratory Organs-Circulation of Nutritive Fluid-Digestion and Nutrition-Secretion of Wax-Reproductive Organs-Detailed description of Sting-Effects of Poison-Queen's Sting.

THE abdomen constitutes the largest and hindmost segment of the body, and is important as containing several structures which have most essential functions in the economy of the insect. Among these are the chief parts of the respiratory apparatus, the digestive, the wax-making, the reproductive, and stinging organs.

First, it must be noted that the bee has nothing strictly analogous to our lungs, heart, liver, and other structures making up a true circulating-system. At the same time there is a real oxygenation of the fluids of the body, with a consequent evolution of heat, water, and carbonic acid gas.

The breathing apparatus has not its aperture for inspiration and expiration situated in the head, as is the case in the higher animals; but air is admitted and expelled through apertures along both sides of the body. In the thorax are two pairs of such openings, and there is a pair on each ring of the 
abdomen. These air-holes are called spiracles, or stigmata, and lead into two minute chambers, one behind the other, the outer being provided with a number of short hairs, to prevent the entry of foreign particles likely to obstruct the important passages.

From these vestibules the air is conducted by tubes, or trachea, into sacs or bladders communi-

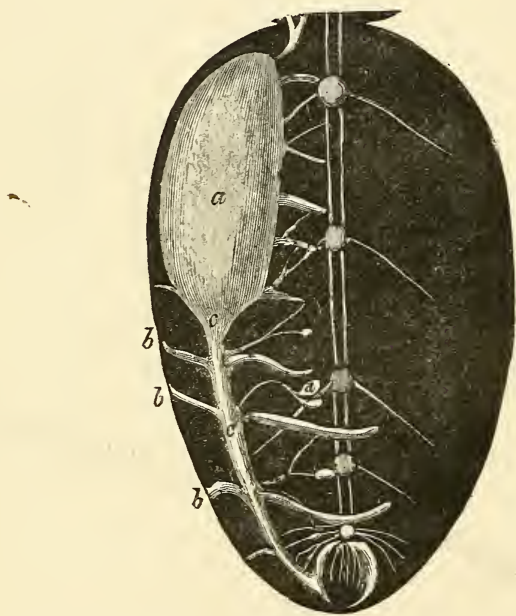

Fig. 32,-AbDomen of Bee, showing Respiratory Organs. a, Air-sac. $b b b$, Spiracles.

cating with each other. The largest pair of these cavities is found in the abdomen, and from these two main trunks lead, one into the thorax, and the other to the termination of the abdomen. From the latter there branch out subsidiary tubes, leading into the minuter chambers, called sacculi, or little sacs. Those going upwards do not subdivide till they 
reach the head, in which are found two air-chambers of considerable size. Reasons for this distribution of the secreting vessels may be found, on the one hand, in the need of the oxygenation of the tissues, especially those connected with the nutrition of the ganglia of highest functions; and, on the other, in the requirements of buoyancy in the segments relatively the heaviest, and destitute of organs of support in the atmosphere, such as the wings furnish.

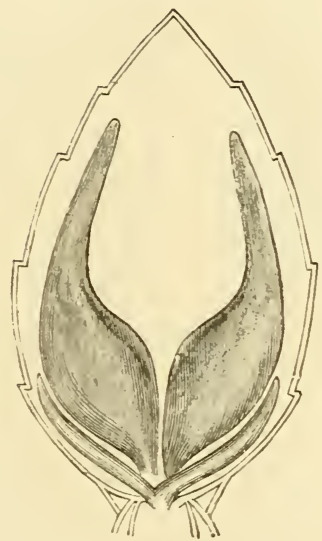

FIg. 33.-AIR-SACS OF WORKER.

A confirmation of the second of these purposes is derived from the remarkable fact, that in the queen bee, who does not fly more than once or twice in her life, the great air-sacs of the abdomen are almost obliterated, their space being needed for the large ovaries.

The structure of the trachece is very remarkable. Under a powerful microscope they are seen to consist of a double membrane, between the two coats of 
which are coils of an elastic thread, which act like the spiral wire frequently used for keeping open and strengthening india-rubber tubing. By means of this structure the air-pipes are maintained in a condition for the free passage of the atmosphere, and if closed by pressure, the elastic fibre reopens them directly the pressure is removed.

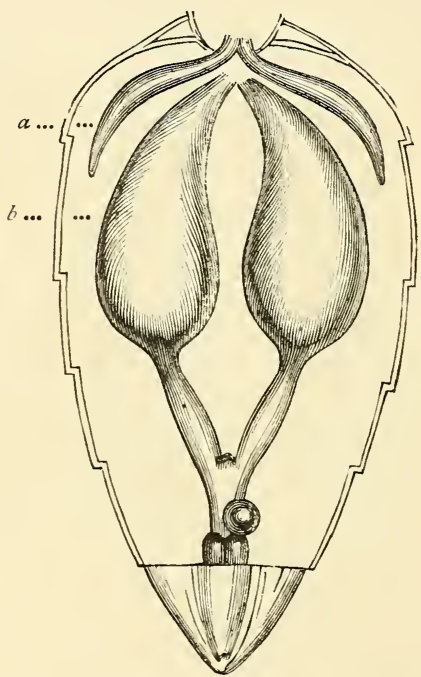

Fig. 34.- $a$, Air-Sacs, $b$, Ovaries, OF the Queen.

With regard to the circulation of the nutritive fluid in the system, considerable obscurity prevails. What is known is, that along the back of the insect runs a vessel called, from its position, the dorsal vessel, attached to the outer covering of the body by bands of ligamentous tissue. The portion of this tube contained in the abdomen is enlarged at intervals into chambers communicating with each 
other by valves, which allow the fluid to go forward to the head, but not back towards the other extremity. Passing by a simple elastic tube through the thorax, the blood, if we may so call it, is propelled to the anterior segment of the body. Its subsequent course is not very clear; for, while some anatomists speak of a small vessel leading back to the hinder part of the body, others consider that the sanguineous, or

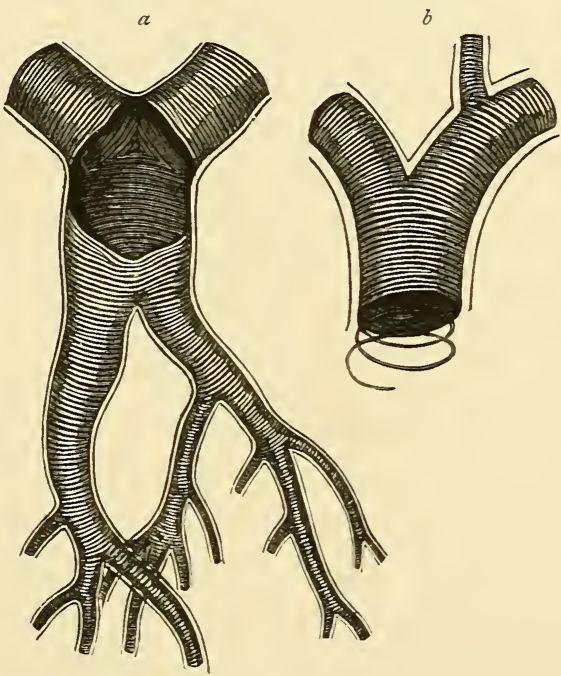

Fig. 35.- $a$, IracheE; $b$, Elastic SPIRAL of TracheE.

nutritive, liquid finds its way from the cephalic parts to other vital organs, and after bathing them, returns to the dorsal vessel by a second set of valves permitting its ingress only.

Turning next to the nutritive organs, we have already spoken at sufficient length of the mouth and its appendages, and have mentioned that the nectar 
of flowers is conveyed first to an enlargement of the gullet, analogous to the crop of birds. From this, some is regurgitated by the workers into the cells, for storage, while another portion passes on to the true stomach. $^{1}$ A certain amount of nitrogenous food, chiefly pollen, also finds its way to this cavity, and there undergoes a second mastication by the socalled gastric teeth. These consist of silica, and are therefore very hard.

After undergoing considerable digestion in the stomach, the chyle, as we may now consider it, passes into a short intestine, where it receives fluid from the so-called "biliary ducts." Further on is an expansion, called the colon, after traversing which the portions of food not absorbed into the system, together with the waste products brought to the intestines, are expelled from the body. It is probable that the nutritive parts of the aliment find their way through the walls of the intestine, and mingling with the sanguineous liquid returned from the cephalic extremity, pass with it into the dorsal vessel.

Closely connected with the digestive apparatus is that which is concerned in the making of wax. By pressing the abdomen of the bee, so as to cause its extension, there can be seen, on the under side of the four medial ventral segments, two trapeziform whitish pockets, one on either side of the carina, or elevated central part. These are of a membranous texture, and are covered with a reticulation of hexagonal

1 Pastor Schönfeld has recently made some most interesting researches into the anatomy and communication of the two stomachs. A translation of his articles may be found in The British Bee Fournal for July, I883. 
meshes, reminding one of the inner coat of the second stomach of the sheep, and other ruminating

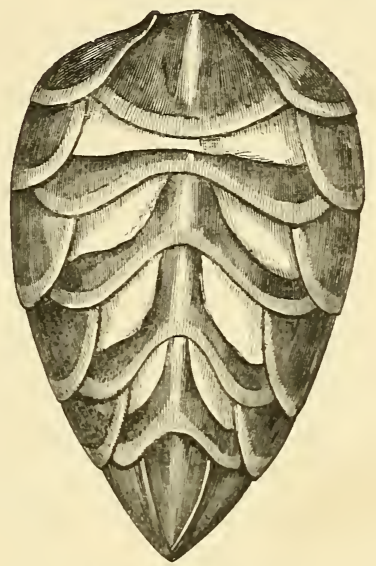

Fig. 36.-UNder Side of Abdonien, showing Wax Scaties.

animals. There is no direct communication between the stomach and these pockets; but Hunter suggested
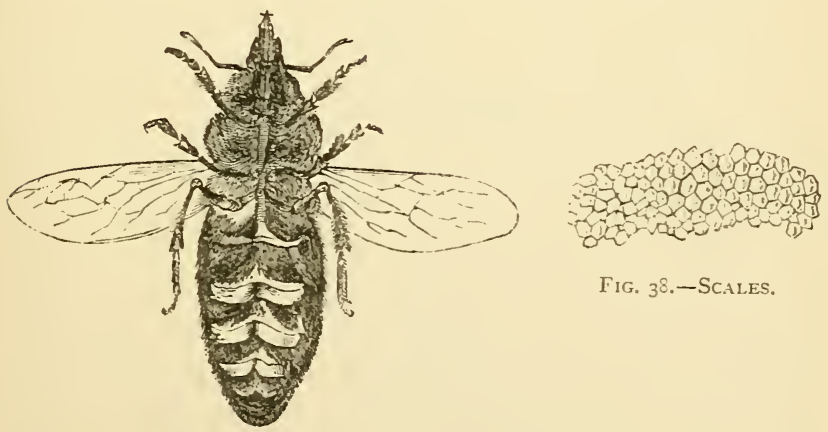

Fig. 37.-EeE, SHowing the WAx Scales.

that the secreting surface is in the membrane just alluded to. We cannot follow the process by which 
the change from honey to wax is effected, any more than we can account for the elaboration of bile, saliva, and the pancreatic liquid, from our blood by the different organs connected with their production. All we can say is, that the membrane of the waxreceptacles is endowed with the peculiar power of transforming the nectar of flowers into an oil. The actual chemical change may be stated in general terms thus: Honey and sugar contain, roughly speaking, equal chemical equivalents of oxygen, carbon, and hydrogen. In wax, the quantities of the first of these elements is diminished to about an eighth part, while the carbon and hydrogen are more than quadrupled. In other words, the saccharine material suffers very great de-oxidation in passing into the condition of wax.

The wax-oil, when it has filled the pocket in which it is secreted, passes out of the body of the insect in lamine or scales, which take the shape of the bags in which they have been produced. In contact with the air, the wax absorbs a small quantity of oxygen, and loses an equal amount of carbon. When about to be used by the bee, it is picked off the under segments of the body by the hind-legs, passed on to the forefeet, and by them is conveyed to the mouth, where, by being mixed with saliva and well kneaded, it is rendered pliant, ductile, and more tenacious.

The reproductive organs of the queen consist, first, of two large bags, one on each side of the abdomen, and called ovaries, in which the eggs are generated. When mature, these eggs pass by a tube from each ovary to a common duct, on one side of which is found a small yellow vesicle, called the spermatheca. 
On examination under the microscope, this is found to be filled with a viscous fluid, in which, with a lens of high power, may be seen moving thousands of spermatozoa derived from the drone. By voluntary effort on the part of the queen, each egg, as it passes this vesicle, may be touched with a most minute drop

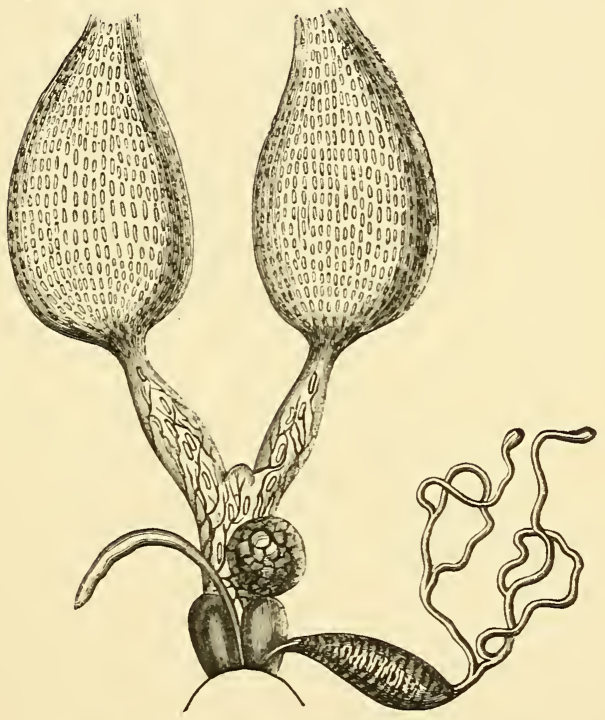

Fig. 39.- Jvaries and Spermatheca of QueEn.

of the fluid just mentioned. Then this very marvellous fact results. An egg thus fertilised develops into a queen or a worker, according to the conditions under which it is hatched; while those eggs which are not brought in their passage into contact with the fluid, and receive no spermatozoa, become drones. Herein lies the explanation of fertile workers giving birth to drones only, and of queens, 
hatched after the drones of a season are dead, also laying eggs which will develop only into male bees. We are absolutely unable to account for these most extraordinary circumstances, which open up interesting fields for future investigation. Not the least wonderful point is the exercise of will, on the part of the queen, in the production of the particular kind of egg which, without making mistakes, she lays in the cells specially provided for the three classes of her offspring.

The last of the abdominal organs we have now to describe, is one which is not essential to the life of the individual, but has been conferred by the Creator as a means of offence and defence, viz., the sting. Those who have frequently felt its effects have no need to be told how formidable a weapon it is; but few probably are fully acquainted with the structures which give it such potent force. If a bee be irritated, and made to thrust out its sting, we observe a dark brown and sharply-pointed dart. This, when magnified, is seen to be the sheath, in which the true sting lies and is moved. The sheath is divided down the centre, and between the two parts the real piercers work, though the sheath itself is thrust into the wound. It consists of two horny scales, smooth and closely adherent to the true darts. These last are stiff filaments, barbed along their outer edge. They are not quite equal in length, so that the teeth of the one do not lie exactly opposite those of the other. They work side by side, and, possibly with alternate motion, pierce deeper and deeper into the punctured material. The teeth give a firm hold to the imbedded weapon, and prevent its easy withdrawal. In fact, 
when plunged into human flesh, or into thick leather gloves, these barbs hold so tightly that the insect is unable to free itself, and if forcibly detached, or if by a vigorous effort it escapes, the sting is left behind, and frequently attached to it are portions of the viscera. The bee thus loses its life, and the injury it inflicts is the more severe. The mere puncture of the weapon, however, would be a quite unimportant

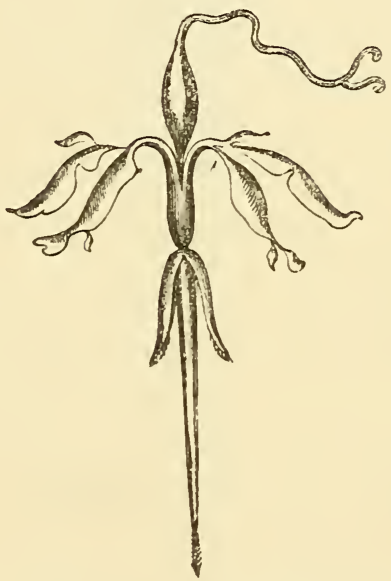

Fig. 40.-Sting of A beE, greatly Magnified.

matter, were it not that, connected with the groove in which the dart works, is a short tube leading from a bag containing a liquid of the most acrid and poisonous nature. By powerful muscles, attached to the upper part of the sting, the barbs are thrust out; the sheath follows them into the pierced substance, and then, by the pressure of other muscles, a drop of the poison-liquid runs down into the wound, and immediately sets up a violent pain and inflammation 
of the surrounding parts. So powerful is the action of the irritant, that numerous cases are on record of death ensuing through its influence. We are, however, bound to say that, by many authorities, such fatal consequences are considered to result from syncope produced by fright, rather than from the direct effect of the poison on the nervous system.

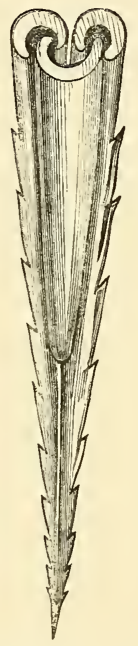

Fig. 4t.-Barbs of a BeE's Sting, very highly Magnified.

Still, there is no doubt of the very formidable nature of the liquid, as may be generally seen in the amount of swelling and discomfort caused by the exceedingly minute portion injected by the sting of a bee.

The poison is secreted by tiny glands, from which it is conveyed, by tubes or ducts, into the reservoir, where it is stored ready for use. Chemically, the 
liquid is said to have an acid reaction. Hence the application of ammonia, and other alkaline solutions, will most effectually counteract its effects.

The sting of the queen differs from that of the worker, in having its barbs curved, instead of straight. This modification makes it a much less formidable implement. Moreover, it is very seldom employed. It is, indeed, almost impossible to make a queen sting the hand, even by great provocation. Almost the only circumstances in which her majesty employs the weapon are, first, for mortal combat with a rival, and second, for murdering, if permitted by the workers, the princesses before they emerge from the cells in which they have developed.

The drone is without a sting, and, indeed, seems never to show fight at all. Its jaws might furnish no despicable weapons, but the insect seems to lack spirit to use them, even in self-defence, and when attacked by the mandibles only of the workers, manifests no inclination to employ its own against its tormentors. Struggles to escape, and haste to flee, seem to betray its absence of courage ; though, possibly, an instinctive knowledge that its assailants have in reserve a more deadly piece of armour than strong jaws may make "discretion the better part of valour."

With regard to the sting of the bee, Paley aptly remarks that it "affords a beautiful example of the union of chemistry and mechanism: of chemistry in respect to the venom, which, in so small a quantity, can produce such powerful effects ; of mechanism, as the sting is not a simple but a compound instrument. 
The machinery would have been useless, had it not been for the chemical process, by which, in the insect's body, honey is converted into poison; and, on the other hand, the poison would have been ineffectual without an instrument to wound, and a syringe to inject the fluid." 


\section{CHAPTER XV.}

THE DISEASES OF BEES.

Dysentery: How Produced-Indications-Treatment. Foul-Brood : two kinds-Nature-Propagation. Mr. Cheshire's Discoveries and Treatment-Fatal Effects of Disease-Detection-VertigoAnalogy of Human and Bee Diseases.

How far the diseases of domesticated animals are due to the conditions to which they are subjected by man, and which are always, to some extent, contrary to the natural mode of life of the creatures, we are at present unable to say. We can, however, point with some certainty to cases in which birds and quadrupeds, which are made subservient to our needs or our convenience, suffer in consequence of our treatment. In some degree, this is true with regard to bees. In a wild state their habitations may, indeed, expose them to risks they do not run in hives, but these artificial dwellings, on the other hand, tend to the development, or the extension of, at least two maladies to which their occupants are subject. These are the deadly evils of dysentery and so-called "foul-brood."

Dysentery has been known in apiaries from the time of Columella, in the first century of our era, 
who attributed it to the effect of food derived by the bees from the elm and the spurge. Other more recent writers have ascribed it to over-indulgence in spring-honey, wheresoever derived : others, again, to the consumption of stores which had candied in the cells during the winter. More recent investigations show that there are several means by which this trouble may be generated. In the first place, ineffective ventilation, by permitting the condensation of moisture on the combs, and its admixture with the food stores, is a prolific source of the mischief. During the winter, the low temperature is constantly reducing to a watery condition the aqueous vapour given off by respiration. This vapour, like our own perspiration, contains matter derived from impurities in the circulating fluid, and is the natural vehicle for their removal. If, then, such moisture again enters the body of the bee, it is simply a poison, whose effects become manifest by producing diarrhœa, distension of the abdomen, and more or less speedy death.

Again, if the stocks be supplied in the late autumn with syrup too watery for the bees to seal over in the cells, contact with air sets up a chemical change, and a certain amount of acid is generated, which makes the honey most prejudicial to the health of the stock, by deranging their digestive functions.

Thirdly, if during the winter time, when the insects are closely confined to their dwellings by the weather, and when they are, under ordinary conditions, very quiescent, they be disturbed and excited, they are apt to gorge themselves with food ; and having no natural means of working off the extra quantity they have 
taken, the system is overloaded, and the stomach and intestines suffer from the too great burden thrown on them.

The occurrence of this malady is indicated by the altered appearance and odour of the excrement, which, instead of being reddish yellow, becomes of a muddy black colour, and has an intolerably foul smell. It is, moreover, deposited by the weakened insects, contrary to their cleanly habits, on the combs, the inner walls of the hives, on the floor-board, and at the entrance of their dwellings.

The avoidance of the causes of the generation of the disease is a comparatively easy matter. The means of cure are, first, the removal of the reasons for its occurrence, and, secondly, the immediate and thorough cleansing of all parts of a hive soiled by the sick bees. It is still better, if possible, to remove the stock into a perfectly fresh dwelling; and it is advisable to take away all combs with unsealed honey, and substitute sealed stores, or to feed the bees with barley-sugar.

"Foul-brood" is a much more formidable malady, and is often encountered. It is, indeed, a terror to apiarians, for not only is it very fatal to any stock in which it appears, but, from its ready contagiousness, it may depopulate any number of previously healthy communities, and may extend from one apiary to several others in the neighbourhood.

As the name implies, it has been thought to be a disease of the larvæ, and there are said to be two kinds, called respectively the $d r y$ and the wet. The former of these is much less serious, and is not contagious. The young merely die in their cells; 
their bodies desiccate, and there is an end of the matter. In the other variety, the brood remains dark and shiny in the hatching-places, and emits a most offensive odour, perceptible at some distance from the hive. When the mischief is very great, combs are sometimes removed which are masses of corruption and fœtor.

Microscopical investigations led to the belief that the source of this dire pest was a microbe, allied to micrococcus. If the germs of this lowly organism find a lodgment on the tender skin of a larva, they propagate with immense rapidity, and cause the death of the young insect. Then, wafted about the hive by the currents produced in ventilation, they pass from one part to another; or, attaching themselves to the bodies of adult bees, they are carried from cell to cell, and each of these thus infected, in its turn, becomes a new centre of deadly plague.

Dr. Schönfeld in Germany made a series of interesting experiments, which he considered conclusive on the question of the origin and spread of this disease. From a small piece of foul-brood he propagated, by suitable means, large quantities of the fatal so-called micrococcus, and with it he was able to infect a healthy stock. He, moreover, established the fact that the dried germs float readily in the air. Placing some of the foul-brood in a bell-glass, : in which he inserted lightly a plug of cotton-wool, he caused a gentle atmospheric current to pass into the glass, and out by the tube. Then, moistening the cotton-wool with water, and putting some of the liquid under a microscope, he detected what he concluded to be numerous spores. 
This circumstance throws a light on the contamination of the different hives in an apiary, through one that has become infected; as, no doubt, during the process of ventilation, many germs of the disease find their way out of the entrances. It is probable that robber-bees are also very frequently the carriers of contagion. Taking advantage of the dwindling down of a stock suffering from the disease, these plunderers pilfer the honey, and, in so doing, receive on their bodies the fatal seeds of the malady, which they then carry to their own stocks. In this way the existence of the pest in one community may become the cause of its extension throughout a neighbourhood. It is, therefore, of the utmost importance that the signs of the appearance of the evil should be constantly watched, and very stringent measures applied whenever its existence is ascertained.

Until quite lately it was thought that no means of cure, strictly so called, existed. The germs are so minute, and are capable of such diffusion and adherence in a hive, that half-measures proved, as usual, of no avail. The removal of the combs and bees to a fresh hive, and thoroughlysprinkling them with salicilic acid and water, has been recommended as a remedial course; but bee-keepers found that nothing short of the complete destruction of the infected community was likely to be really effective, and the first loss, in such a case, might save the entire destruction of all the stocks in the apiary. The very honey stored in the combs had to be sacrificed also; for in it the dangerous germs settle, and being used by the nursebees for feeding the larvæ, become the continued, and possibly unsuspected, source of mischief to any hive 
to which it is imparted. If the disease appeared in a straw skep, it was considered desirable to destroy it with fire. If it found its way into a bar-frame hive, every frame, every portion, even every crevice, must be treated. Thorough boiling in a copper has been found helpful in eradicating the mischief, but could not alone be relied upon. A strong mixture of chloride of lime and water, or of salicilic acid and water, applied carefully to every part, has been found more effective. The important facts to be remembered are that, owing to the extreme minuteness of the germs, their multitudes, and their great vitality, it is very easy for some to escape destruction, and to become the sources of future mischief, unless the most radical methods of destruction are applied to them.

A new light has, however, just been thrown on this important subject by Mr. Frank Cheshire, of Acton, who has done so much good work in the anatomy of bees, and in their practical management. He has now satisfied himself, by long-continued and careful microscopic investigation, that the origin of foulbrood is a bacillus, not a micrococcus, ${ }^{1}$ and that the disease extends to all the inmates of the hive. But what is of far greater moment to apiarians is, that Mr. Cheshire claims to have discovered a means of completely curing the dire plague. This consists in the administration of phenol, which is one of the components of carbolic acid. Syrup is made with $3 \mathrm{lbs}$. of loaf-sugar to a quart of water, and to this is

1 Those who wish for details on this and other points should read Mr. Cheshire's admirable papers in the British Bee-Journal for August, I884. 
added $\frac{1}{500}$ part of pure phenol. By removing the stored honey, and pouring the syrup into cells around the infected parts of combs containing foul-brood, the bees are induced to consume the medicated food. The "nurses" supply it also to the larvæ, and the result is, that not only is the progress of the disease stopped, but renewed courage and hope are infused into the community, who remove the dead larvæ, clear out the polluted cells, and bring about an entire renewal of healthy conditions. Should further facts prove all that Mr. Cheshire expects, he will be regarded by apiarians in future with as much admiration as Jenner, the introducer of vaccination, is looked upon by the medical world. His generous publication of his discoveries, so that all interested may have the benefit of them, lays all bee-keepers under great obligations to him.

As an example of the terrible results of this pest to the bee-keeper, the case of the well-known German bee-master, Dzierzon, may be mentioned. In the year 1848 the disease broke out in his apiary, and more than 500 stocks were destroyed by it; in fact, only ten hives escaped the pestilence. John Hunter - the author of a good Manual of Bee-Keepingrecords that from a friend, who had complained of not finding his bees profitable, he purchased all his stocks, some twenty in number, and removed them to his garden. They proved to have foul-brood in them, and not only did the whole of them perish, but all Mr. Hunter's own stocks, and, in addition, two or three years of trouble were required to eradicate the mischief from the apiary. 
The late Mr. Woodbury, whose name is "a household word" among bee-keepers, was unfortunate enough to have this disease among his hives in the spring and summer of I863. He published a graphic account of his trouble in the Joumal of Horticulture of July 2 Ist, I863, entitled, "A Dwindling Apiary." By very vigorous measures he was able to get rid of the pest ; but the conclusions to which he came were the following: "First let me endorse the opinions of both Dzierzon and Rothe, that, except under very especial circumstances, it is unadvisable to attempt the cure of a foul-breeding stock: better, far better, to consign its inhabitants to the brimstone-pit: the hive itself, if a straw one, to the flames : the comb to the melting-pot: and appropriate the honey to any purpose except that of feeding bees."

The detection of signs of the disease is not very difficult, especially in hives with moveable frames. If, during the working season, a stock seems not only not to increase, but to diminish in numbers; if fewer and fewer bees appear active about the entrance; and if, above all, a peculiarly disagreeable odour is perceptible, at even one or two feet from the entrance, it is time to look to the condition of the interior. An infected comb, on examination, is seen to be dark and unwholesome-looking. If the caps covering the brood be distinctly sunk, so as to show a concave surface, the existence of the disease is almost a certainty; and if the covering of one or more of these cells be removed, there will be found dark coffee-coloured, slimy liquid, the remains of the larvæ destroyed by the bacillus. 
From what we have said of this disease it will be seen that it is most important for any one about to commence bee-keeping to be sure the stocks he may purchase are not only themselves free from disease, but come from an apiary absolutely uninfected by it. Many a beginner in apiculture has been so disheartened, and has suffered such severe loss from foul-brood in his hives, that he has given up beekeeping in disgust. We need hardly say that any man who knowingly sold hives with foul-brood in them, would deserve to be visited with penalties for damages, which we have no doubt his victim could obtain by legal process.

Some writers enumerate vertigo, or giddiness and staggering, among the diseases of bees. We incline to the belief that cases of the kind observed were due to the individuals having been stung in fighting, though it is possible that mistakes in pasturage may occasionally be made, and that the nectar of certain flowers may induce disorder in the bee-constitution. We, however, doubt the likelihood of the quick senses of the insect being at fault with regard to food which will prove hurtful.

One other malady has been occasionally noticed, viz., the swelling of the terminal segments of the antennæ. The occurrence of this mischief is too rare to need further remark, beyond the suggestion that it may be the result of microbe germs having made a lodgment in the tender organs affected.

There is a striking analogy in the results of insanitary conditions, and the propagation of zymotic disease among the human family and among bees. 
Unwholesome food, defective ventilation, the diffusion of poisonous germs, produce, among both orders of beings, similar disastrous effects; and this sketch of the diseases of one class of domesticated insects may serve to point a moral for the guidance of mankind in social economy. The same inexorable laws of health and sickness prevail in the highest and the inferior orders of animal existences, and with unvarying steadfastness is proclaimed the solemn warning"Be not deceived: God is not mocked. Whatsoever a man soweth that shall he also reap." 


\section{CHAPTER XVI.}

THE ENEMIES OF BEES.

Birds-Mice-Moths-Brasla Caca-Hornets and Wasps-SpidersToads-"Robber Bees"-Prevention of robbing.

IT might well be imagined that creatures armed with such deadly weapons as bees, would have few enemies who would dare to contend with them. The fact is, however, that they are exposed to dangers from numerous sources. Various kinds of wild birds, domestic fowls, mice, certain species of moths, hornets, wasps, ants, spiders and toads, are more or less destructive to them.

Among the common birds fond of these insects as food, may be mentioned the titmouse tribe. Mr. Hunter says he has found hundreds of stings of bees adhering to a fence, evidently extracted by these active and clever little birds previous to swallowing their prey. Their depredations, however, are usually not great, and they are often satisfied to regale themselves on the dead insects which are carried out of the hive. In America, the King-bird (Tyrannus muscicapa) is mentioned by Langstroth as devouring scores of our winged friends, which he does not hesitate to seize on flower-blossoms, showing, indeed, 
a sensible preference for those who are distending their honey-bags with nectar. The swallow was credited by the Greeks with being a robber of apiaries, as the address of the old poet indicates :-

" Attic maiden, honey-fed,

Chirping warbler, bear'st away

Thou the busy buzzing bee,

To thy callow brood a prey?

Warbler, thou a warbler seize?

Winged, one with lovely wings?

Guest thyself, by sunmer brought,

Yellow guests whom summer brings?

Wilt not quickly let it drop?

'Tis not fair; indeed, 'tis wrong,

That the ceaseless warbler should

Die by mouth of ceaseless song." 1

We have no reason to charge our swallows with the crime of bee-eating. Domestic fowls will sometimes regale themselves with a meal of live bees, it they can reach the entrances to the hives, so that it is advisable to forbid their access to them. Mice occasionally effect an entrance, especially into skeps, and annoy the inhabitants by their disagreeable odour, and by gnawing the combs; and eating brood and honey. The winter is the time when there is most danger from these plunderers, as the bees are then too torpid with the cold to notice and to attack the intruders. It is easy to prohibit their inroads, by sufficiently contracting the entrances, and preventing their gnawing the rims of the hives, or getting under the top coverings.

Moths, being active at night, require constant watchfulness on the part of the bee-sentinels to exclude them from their abodes. Attracted partly

1 Translation given in Langstroth on the Honey-Bee. 
by the favourable conditions for egg-hatching, through the steady warmth kept up in the hives, they lay their eggs in crevices, and along the borders of bee-homes. The larvæ, when able to crawl, make their way over the combs, which, with their contents, they greedily devour, and if attacking in large numbers they sometimes prove fatal to a stock.

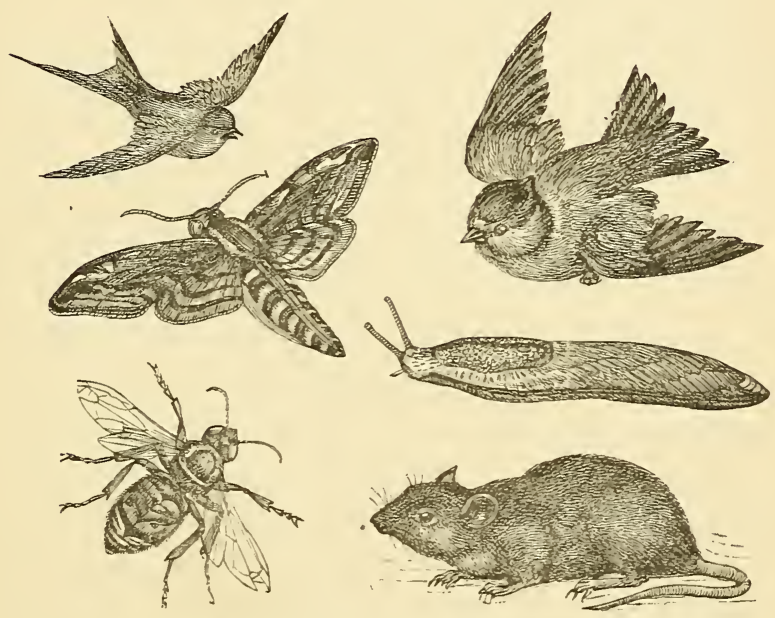

Fig. 42.-The Enemies of Bees.

The two kinds most destructive are the British wax-moth, Achroia grisella, and the Galleria mellonella. The latter is more troublesome in Italy than in our own country. If the population of a hive be strong and in thoroughly sound condition, there is not much danger to be apprehended from either of these foes. Should, however, a colony be weak, and still more if queenless, such a hold may be gained by 
these their lepidopterous enemies, as will be wholly ruinous. Combs in store are yet more liable to their attacks, but the moths may be dislodged, and their eggs or larvæ destroyed, by exposing such combs to the fumes of burning brimstone. An examination of hive-coverings and floor-boards in the spring and autumn, and the destruction of all grubs found about them, will often save much trouble from the moths. The presence of these intruders among the combs may be detected by the occurrence of their excrement, resembling grains of very fine gunpowder, on the floor-boards.

The death's-head moth, Acherontia Atropos, is also said, by some writers, to be troublesome to apiarians ; but it is too rare an insect to be seriously destructive. A parasitic louse, called Braula caca, is occasionally found in considerable numbers in hives on the Continent. Happily, the English climate does not appear to suit its constitution well, so that its occurrence is not very frequent, and is generally the result of the introduction of Ligurians and other foreign varieties into an apiary.

Pre-eminent among the enemies of bees stand hornets and wasps, particularly the latter in the autumn of the year. They are active, courageous, and persistent robbers; and, unless the hive-entrance be well guarded, they will slip in, and, escaping notice, will pilfer the honey without stint. So determined are their attacks, that they will utterly ruin weak colonies, and will sometimes so dishearten even tolerably vigorous ones, as to make them desert their hives. When once they have learnt there are stores to be plundered, they do not fail to come in numbers 
if they know that only a feeble resistance will be offered to them. Various means of stopping their depredations may be adopted. The most radical measure is to destroy queen-wasps in the spring. They are the only ones in existence then, and are considerably larger than their worker-daughters. Again, every wasp's nest in the neighbourhood of an apiary should be got rid of, by pouring gas-tar into the entrances, and ramming earth over it. Thirdly, by hanging a narrow-necked bottle of sweetened beer near the bee-hives, many wasps will be attracted to the liquid ; and, becoming surfeited and silly, will be unable to escape, and will be drowned. A fourth precaution is to narrow the entrances of the hives, so that one or two bees can defend them. The sentinels are able to master these their enemies in fair fight; indeed, the wasps rarely show any inclination for a battle. They trust to their activity and boldness, rather than to any real courage. The best preventive measure is to keep the stocks of bees strong. It is usually only the weak who suffer serious attacks from their insect enemies.

Spiders prove a nuisance and destructive, chiefly by spinning webs into which the weary workers fall when returning home, or into which they unwarily rush on emerging from their abodes. Care in sweeping away the cobwebs will remove danger from this source.

Toads are credited, or charged, with a love of honey-filled bees, and may sometimes be seen watching their opportunity of making a meal near the entrances, where they are said to pick up many a dainty morsel with honey-sauce ready made. These 
slowly-moving creatures may easily be caught and taken away, so as to do no more mischief.

We must not pass from this part of our subject without speaking of the aptness of bees to rob one another. If an unfortunate individual makes the mistake of going to a hive not its own, it will immediately be seized as an intruder. In the hope of propitiating the assailants, it will extend its proboscis, and offer some of its internal honey-store. Nor will the custodians refuse to accept what is evidently intended as a peace-offering; but they will not cease their attempt to drag off or to kill the interloper, who is happy if able to escape from the onslaught. This kind of robbery is, in a manner, to be regarded as justifiable.

Such is not the case, however, with the organised or desultory pillage which frequently goes on when the inability of a stock to defend itself has been discovered by its neighbours. We have known the contents of a hive completely cleared out by "robberbees" in a few hours, crowds of them rushing in and filling themselves. Then, having carried the spoil to their own homes, they will return again and again, till there is nothing left for them to plunder. Of course the community attacked wholly perishes in the battle or from starvation. Nor is this the worst of such an occurrence; for, when once these unhallowed sweets have been tasted, when these insects-it must be confessed, of very low morality-have discovered that robbery is much more easy and more productive of results than honest work, they appear seized with a perfect mania for living as freebooters, and will attempt hive after hive, when their first onslaught 
has been effective. Terrible mischief is often the result ; for, not only is the habit of ordinary nectarseeking broken off, but fierce battles are fought with strong stocks, and many hundreds of the combatants perish. Moreover, the ordinary avocations of an assailed colony are completely interrupted, and general disturbance, if not complete disorganisation, prevails.

Such a disastrous state of things is sometimes begun by carelessness on the part of the bee-keeper, in allowing pieces of honeycomb to lie about within reach of any of his stocks. The taste of the sweet liquid, for which they have a perfect passion, seems to act like a glass of gin on an abstainer who has formerly been a drunkard. Their thirst for more is fired, and, once enkindled, will not easily subside. It is particularly necessary, therefore, especially in the late summer and the autumn, when supplies from flowers begin to fall short, to take care not to provoke the lust of having honey at all hazards, by allowing any to be exposed to the smelling or other perceptive powers of the bees. It is equally important in feeding stocks to prevent any exposure of the syrup, and not to permit stranger-bees to get at the feeding-bottles.

If the mischief of robbing is detected in its early stage, much may be done to stop it by narrowing the hive entrances, so that only one bee at a time can get in. This will enable the sentinels to examine each one who tries to enter, and to turn back strangers. If, however, the evil has taken a serious hold, it is better to close the attacked hive altogether for a time, and to hang near the entrance a sponge or cloth soaked in diluted carbolic acid, or some liquid potent and disagreeable in its odour. If these 
methods are of no avail, it will be better to remove the colony to a distance, or to a dark cellar; and by taking care to secure ventilation, and to give a supply of syrup, the community, which would otherwise surely perish, may be rescued. If returned in three or four days to its former stand, it is well to take the precaution of placing a sloping board before the entrance, so that its exact position may escape the notice of would-be robbers. These can often be detected early in their operations by their hovering restlessly in front of a hive, without the courage to settle, or, perhaps, because they do not know precisely where the opening is. A shower from a watering-pot will sometimes send them about their own proper business.

Another method for stopping robber-bees from their plundering is to put at night into the hive attacked a small quantity of some strongly-smelling substance -a little musk, for example. The unwonted odour seems to rouse the inhabitants, and if they have a healthy queen, they will, in the morning, resolutely meet the robbers. Moreover, if any of these get in, the musk will so scent them that when they return to their own hives they will not be recognised by their own people, but will be put to death; and thus a double check is put on their depredations.

It is a remarkable fact that, if a robbed colony be queenless, or if the queen is killed in the mélée, survivors from the fight will often fall to on the remnants of the stores, and, joining the forces of the conquerors, will convey the honey to the hive whose inhabitants are the plunderers, and will be peacefully accepted as citizens among its population. Of course 
the absence or the slaughter of a queen much more readily exposes her disheartened subjects to attacks from other bees; and this is another reason for seeing that no such calamity as queenlessness has befallen any stock when food is scarce.

In the facts recorded in this chapter we have striking evidence of "the struggle for existence" which seems to have been ordained as "a law of nature" in this world. We can readily discern some useful purposes connected with it, both as regards conquerors and vanquished. For, on the one hand, it is for the benefit of the race that the strongest individuals should, as a rule, survive to propagate it; and, on the other, it is better for a sharp and speedy end to occur to a weak community, rather than that it should perish by the slow pangs of hunger, or from inability to continue the rearing of a progeny. But, even in this respect, as in several others, bees furnish a serious difficulty to the theory of evolution. For it is not the strong and victorious community which propagates the race, but the individual queen; and she, of course, may be weaker than the one whose stock has been destroyed by the more numerous robbers. The case evidently is not a genuine one of "survival of the fittest," so far as the succeeding generations are concerned; nor do we find any special adaptation for future advantages secured. The battle is lost and won, but there can be no impress made, even by successive victories, on the general physical condition of the stronger party ; for the fight is never undertaken by a single drone or queen, who alone can transmit any qualities to posterity. 


\section{CHAPTER XVII.}

HIVES.

Natural Abodes of Wild Bees-Taking Honey from Roof of HouseStraw Skeps-Cottager's Hive-Supering-Nutt's Collateral Hive -Village Hive - Woodbury Hive - Abbott's Hives - Sectional Supering-Stewarton Hive-Carr-Stewarton Hive-Observatory Hives-Bee-houses.

IN a state of nature bees avail themselves of hollow trees, crevices in rocks, or other cavities of various kinds. Swarms escaped from apiaries will frequently find an entrance to the space between the roof and upper ceilings of houses, and extraordinary quantities of comb, brood, and bees have been taken from such places. Two gentlemen, well known to the writer, have given the following account in The Bee Journal for July I, I882, of their successful taking of bees, brood, comb, and honey, from the roof of a house at Lockinge, near Wantage, Berks.

"The house is very old, and built of lath and plaster in the old style, with gables. There was a bricklayer at our service to open walls where suggested. We commenced at the back gable, and the bees were situated, one lot in the roof, and two others in the walls. 
No. I in the wall was the first opened. There was a space eight or nine inches wide, and five feet long, and there was disclosed to us a wonderful sight. In front of us were continuous honey and brood-combs, four feet six inches long, and as wide as the opening. The combs were four in number. Then we took No. 2 (next above), and in a similar opening found a quantity of brood, honey, and bees, the combs being smaller.

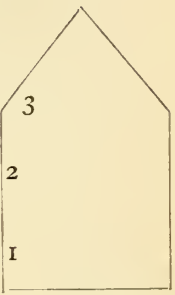
Then we ascended to No. 3, where the bees entered by the eaves. After taking some splendid honey, some gathered by a swarm a month old, the bees took a turn further in the roof, and we left them. In the front gable we commenced cutting away the lath and plaster of the top lot, and opened a space six feet long and eight or nine feet wide; and here we were surprised in the extreme : a comb five feet six inches long (exactly one foot more than the other) was in front, and the combs were three feet deep, nearly as wide as the opening. We captured two queens and a large quantity of bees, and brought away a lot of brood as well. The whole of this work was done from a ladder; and had not our time been precious, we should have liked another day at it, as there were a quantity of bees, \&c., still left behind. The combs were measured in the presence of the host and a friend, as well as ourselves, and I vouch for the correctness of my statement."

From the time that man learnt the value of the bee as a domesticated insect, habitations more or less suitable for securing honey have been furnished to the industrious workers. It is unnecessary to 
detail the various kinds of abodes which have been, or still are, in use for the purpose in different countries. It will be more interesting to our readers to know what are the principal forms of hives at present in use among us. Of these the most antiquated, and, we fear we must say, still the commonest, is the old-fashioned dome-shaped straw skep. We shall not enlarge upon its merits, though we are prepared to admit some; but, as it is almost universally condemned in its primitive form by skilled

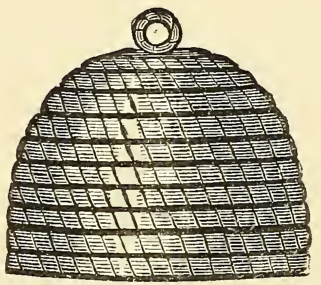

Fig. 43.-Straw Skep.

apiarians, we prefer to speak of some easy modifications of it which render it less objectionable.

In the first place, it must be borne in mind that every system which requires the slaughter of the bees for securing honey from them, is radically bad, and therefore wholly to be discountenanced. At the same time, every bee-keeper expects, and rightly, that he should get honey; and this can be managed even with straw hives, if they have a flat top and a perforation in it sufficient to allow the population to go up into supers, wherein to store their produce. Fig. 44 shows such an adaptation. The lower and larger receptacle is for brood and the maintenance of 
the stock. The top one, much smaller, and not so high, is for the surplus honey, which the bees will carry up when the population is becoming crowded below. The middle and smallest is merely a covering for the

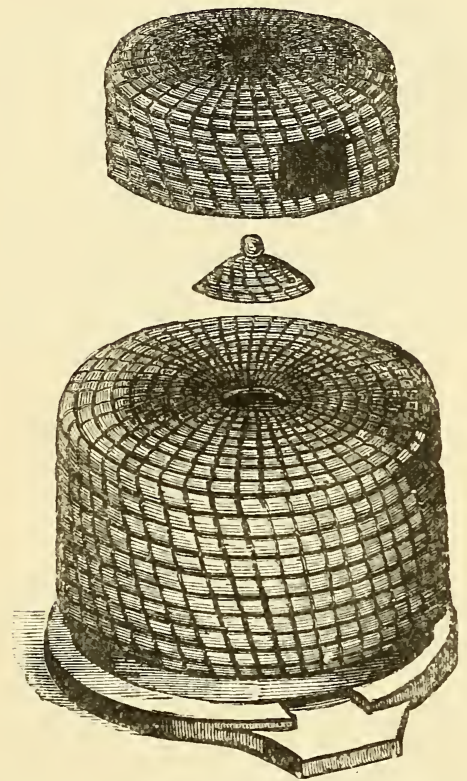

Fig. 44.-Flat-topped Hive and Straw Super.

other two, and for the sake of keeping all warm, dry, and snug.

An improved Cottager's Hive (Fig. 45) differs from the preceding chiefly in the substitution of a glass for a straw super, and the addition of a window at the back, ${ }^{1}$ closed by a door, for observing the internal conditions of the stock portion.

1 In the illustration the hive is turned round on the floor-board, to show the window. 
A still better modification is shown on the opposite page (Fig. 46), and is called, from the inventor and maker, "Neighbour's improved Cottager's Hive." In this the lower part has a stout wooden top with three perforations, which may be closed, at the will of the owner, by a metal slide. Over each opening is placed a bell-glass, and admission to these is given

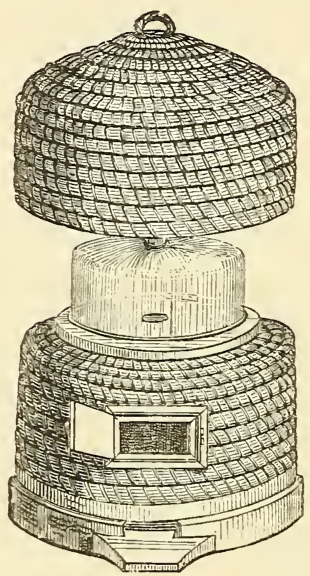

Fig. 45. -Neighbour's Improved Cottager's Hive.

to the bees either singly, or by two or all three apertures. In use, the bell-glasses are encased with flannel, felt, or some other good non-conducting substance, and then the upper hive is let down over the glasses on to the board. There are three windows in the lower hive, each closed by a hinged shutter, so that inspection may be afforded at more points than one. Each bell-glass is furnished with a ventilating tube of perforated zinc, and a ventilating cap is fitted to the top cover. There is also in the middle of 

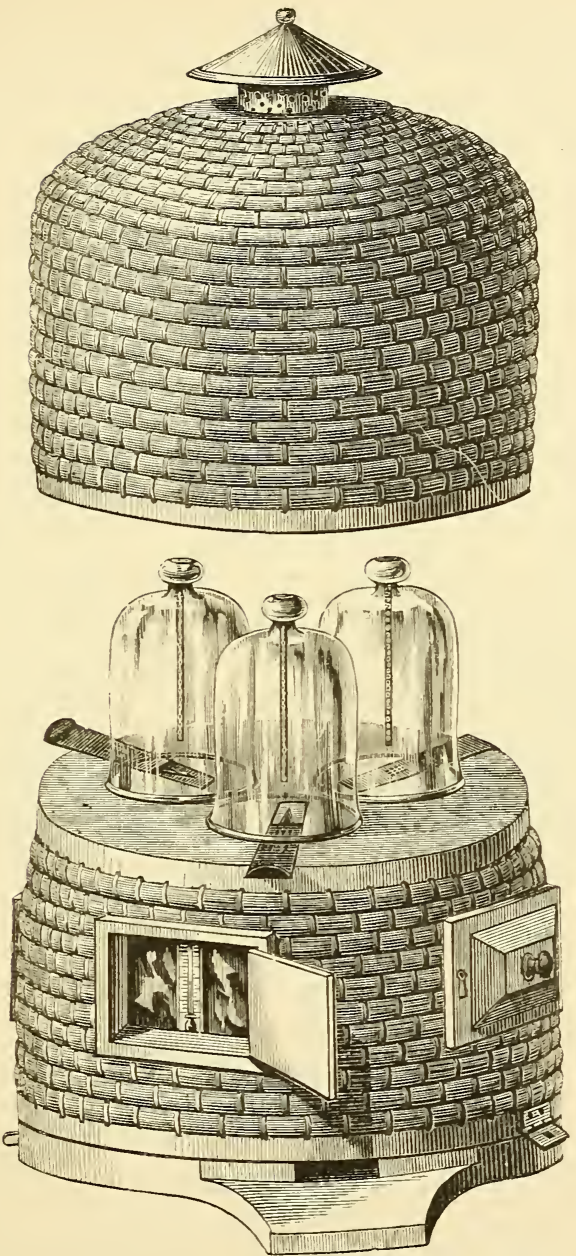

Fig. 46.-Neighbour's Improved Cottager's Hive. 
the back window a thermometer fixed, for ascertaining the temperature of the stock-hive. By these arrangements the affairs of the community may, to a certain extent, be regulated by the master, and pure honey, free from bee-bread or brood, may be secured without the destruction of any of the workers.

The three hives now described are, perhaps, the best for those who have not the requisite time and skill for the more approved methods of apiculture. But they should, in other cases, be looked upon as merely the stepping-stones to systems of bee-management of a really scientific character.

Passing now to the notice of some of these, we will draw attention first to "Nutt's Collateral Hive"named from its first maker, who may be considered a pioneer in the improved modern methods.

It consists of three boxes side by side, and having thin wooden partitions, with six or seven perforations, to admit of the passage of the bees from one compartment to another. These may be stopped by zinc slides. In the centre of the top is a wooden cover, to contain a bell-glass for supering. A ventilator over each of the side-boxes secures the proper temperature of these. "The grand object," as explained by Mr. Nutt, "is to keep the end boxes and the bell-glass cooler than the pavilion or middle box, so as to induce the queen to propagate her species there only, and not in the depriving (i.e. honey-storing) part of the hive. By this means the side and upper combs are in no way discoloured by brood. The queen requires a considerable degree of warmth. The bees enjoy coolness in the side-boxes, and thereby the whiteness and purity of the luscious 
store are increased." When the centre box is filled, access to the super and one side-box may be given by opening the slides. The glass is likely to be filled first, if kept warm by suitable coverings, and can be removed when the honey is sealed in the combs. If the season be very productive, one or both of the side-boxes may also be taken before the end of the summer, if sufficient stores are left in the

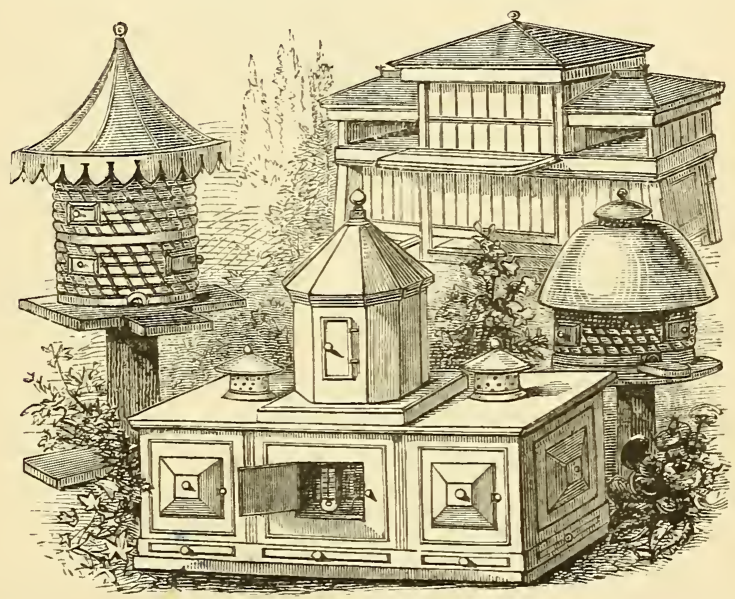

Fig. 47.-Modern Hives. Nutt's Collateral Hive in the foreground.

central stock-portion, or if any deficiency be made up by judicious feeding.

The next and most important modification to which we come is the introduction of movable frames into hives, admitting of separate removal, either for examination as to conditions, or for the taking of honey. Bevan-whose admirable work on The Honey Bee, published nearly half a century ago, is the foundation of modern systems of apiculture in this country- 
speaks of a straw hive with bars, instead of a solid top, invented by Mr. Golding, and named by him "The Village Hive." Even now we consider this variety might well be the cottager's introduction to the more enlightened methods of procedure: and it would, at the same time, satisfy, in large measure, old-fashioned prejudices in favour of straw for the material of the stock-hive. If the bars are properly furnished with "guides," straight and symmetrical combs may be secured, and the depriving of surplus honey-stores may be easily effected without murdering the workers.

Previous to this invention, Réaumur, Bonnet, and Huber had suggested, and tried, the use of boxes with movable bar-frames. The last named apiarian is said to have borrowed his idea from the inhabitants of Candia, and he called it the "leaf-hive." In its original form it had eight frames, secured to each other by hooks and eyes, the external ones being glazed, and covered with a shutter.

The idea of frames removable separately having once been established, various improvements were speedily effected. In I84I Major Munn, an Englishman, obtained a patent in France for his Bar-andframe Hive, an account of which was published in this country in I844. In America, the distinguished apiarian Langstroth made known his modifications of Huber's hive, and Dzierzon, in Germany, a little while before, and quite independently, had adopted the same principle of bars with certain special features, while Von Berlepsch, in I853, added frames to his countryman's bars. In England the bar-frame system was not really known till its re-introduction 
by Tegetmeier, in I860. Mr. Woodbury, to whom reference has been already made more than once, afterwards brought out the frame-hive which met

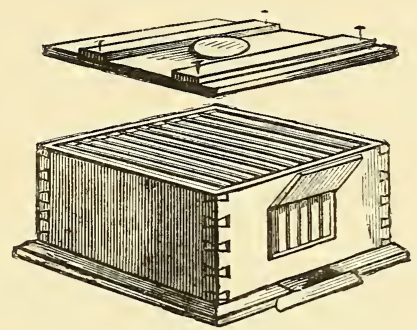

Fig. 48.-The Woodburi Hive.

with the first general acceptance by apiarians in this country.

As originally made, it consisted of a wooden box, I $4 \frac{1}{2}$ inches square on the inside, and 9 inches deep.

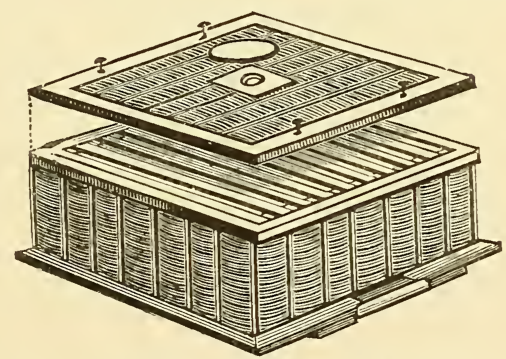

Fig. 49,-Woodbury Straiv Bar-Frame Hive.

The frames were ten in number, each $\mathrm{I} 3$ inches long by $7 \frac{1}{4}$ inches high. The ends projected, and fitted into notches at the back and front; but this arrangement was found to be objectionable, from the secure manner in which the bees were able to glue them down with propolis. As facility of lifting without 
jarring the frames is of great importance, better means of keeping them in place had to be, and have been, devised.

Subsequently to his first introduction of the abovedescribed hive, Mr. Woodbury suggested that the sides, back, and front should be made of straw, as being a better non-conductor of heat, affording a little ventilation, and absorbing the moisture of respiration more readily than wood. We give a figure on page 157 of this modification.

Various improvements on the original of Mr. Woodbury's pattern have been made. Of these we will mention first Mr. Cheshire's bar-frame hive, and we had better, perhaps, describe it in his own words :"It consists of two main portions-the super-cover, the upper half of what may be denominated the body, and the hive proper, in the lower portion of which breeding is carried on, and where the bees pass the winter. In front of the lower part may be seen the porch, with its roof consisting of a stout piece of pine, about three inches wide, and running completely along the hive-face. This is chamfered off towards the end, the more effectually to carry away drip, and has a channel near its front edge, which acts as a gutter, by which the rain is conveyed to its ends. This gutter is shown in the cross-section at $\mathrm{E}$. The bottom board of the hive projects $2 \frac{1}{2}$ inches along the front, so as to form a very convenient alighting board. Ten inches of the central part of this is grooved, so that, should it be reached by driving rain, the convex parts remain free of water, affording the bees a dry passage to the interior. The flight-hole is ten inches in length, and is formed by cutting from the 
hive-wall a piece a full quarter of an inch deep. There are two sliding shutters (shown in Fig. 50), by which the entrance-way may be regulated as occasion may require. The super-cover is hinged, and so contrived by the aid of a chain, that it can only open until its lines, horizontal when in situ, become perpendicular,

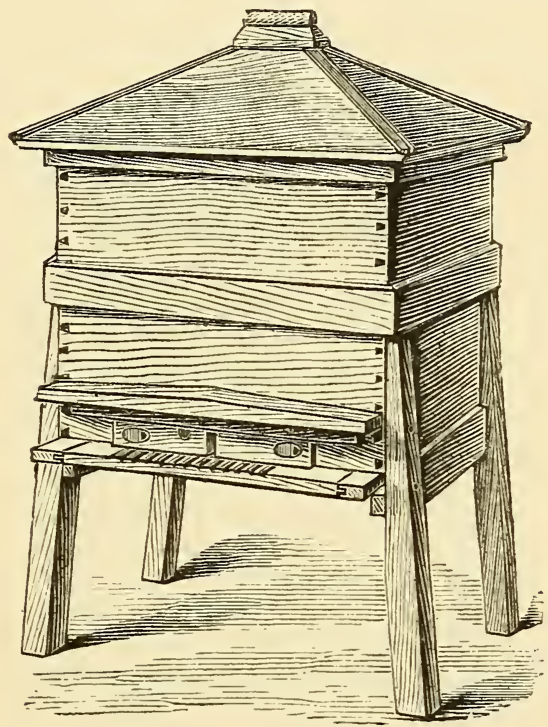

Fig. 50.-Cheshire's Bar-Frrame Hive.

and vice versâ. The walls of the hive are double, and have between them a space containing dead air. As heat is conducted by air with extreme slowness, these means prevent the escape of that generated by the bees during rigorous weather, while they also exclude the ardour of the sun's rays during summer. In order to give room for the ears of the frames, the inner skin, front and back, is made an inch shallower 
than the outer one. Standing three-eighths of an inch above the former are two strips of zinc (I and 2 Fig. 5 I) each about an inch wide, and which serve to carry the frames so that they cannot be propolised, while they can be slid backwards and forwards with the greatest ease during manipulation. The depth of

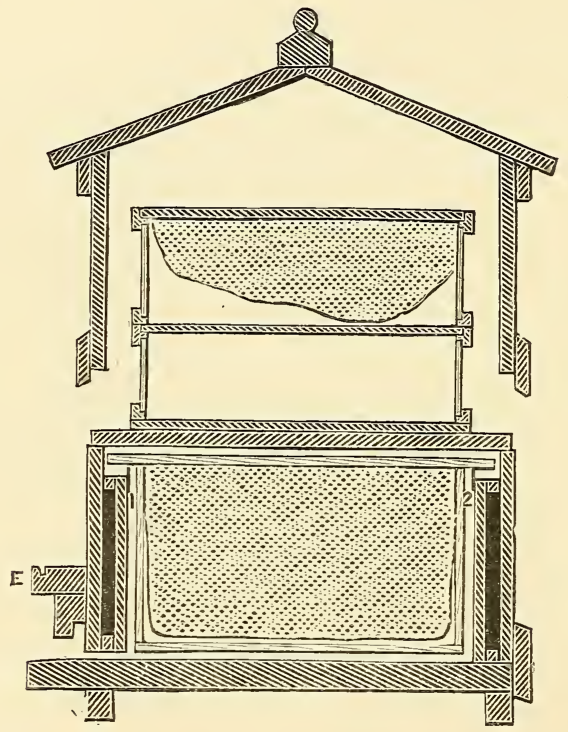

Fig. 51.-Cheshire's Par-Frame Hive (Sectional view).

the hive is $8 \frac{3}{4}$ inches, the width $14 \frac{1}{2}$ inches inside. The length will vary with the number of frames used." Fuller details are to be found in IMr. Cheshire's excellent book called Practical Bee-keeping.

Mr. Abbott, the well-known maker of apparatus of all kinds for apiculture, who was the editor and proprietor of The Bee Journal for many years, has 
also made various arrangements and improvements to secure advantages beyond those of the original Woodbury hive. We cannot detail all these modifications; but among them may be mentioned that the ends of his frames are so notched as to

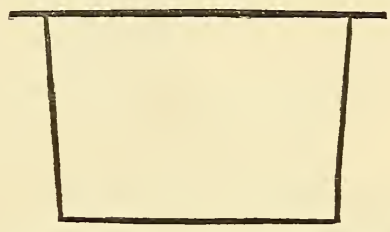

Fig. 52.-Abbott's Standard Frame.

render them easily held by the fingers when it is required to lift them, and to replace them. Mr. Abbott also makes hives of various degrees of cheapness, according to the conveniences required and the neatness of workmanship demanded. We may safely

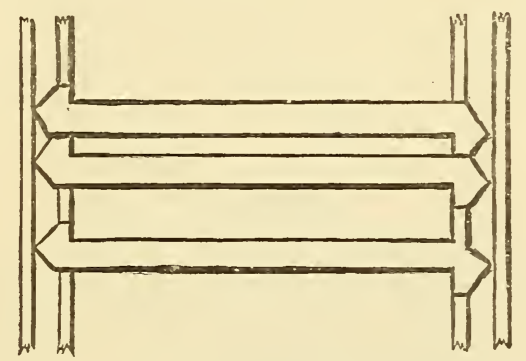

Fig. 53.-Abbott's Standard Frame (top view).

attribute to him a vast influence on scientific beekeeping, and a visit to his works and apiary at Southall, not far from London, on the Great Western Railway, will well repay any one interested in apiculture. 
All the hives we have just been describing are adapted for supering, i.e. for getting honey stored in receptacles above the stock portion. The usual and most convenient form of such receptacles is that of

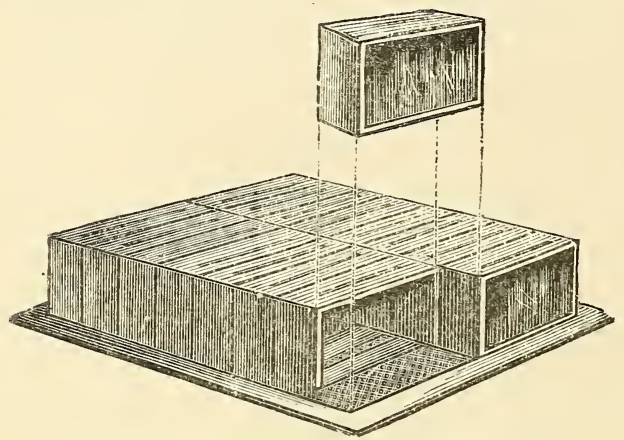

Fig. 54.-Neighbour's Sectional Super (open).

small oblong cases, without front or back, cut in one flat piece of wood, and easily folded into shape, their slotted ends fitting, by pressure, tightly into one another. At the top of each, when folded, a small

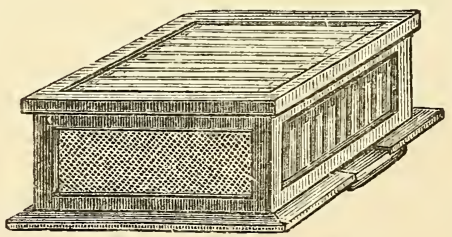

Fig. 55.-Frame SUPER.

piece of guide comb is attached, as a help and an attraction to the bees in beginning their work in them.

It is usual now to pack a certain number of these 
into a frame or "crate," so that they may conveniently be placed upon, or renoved from, the top

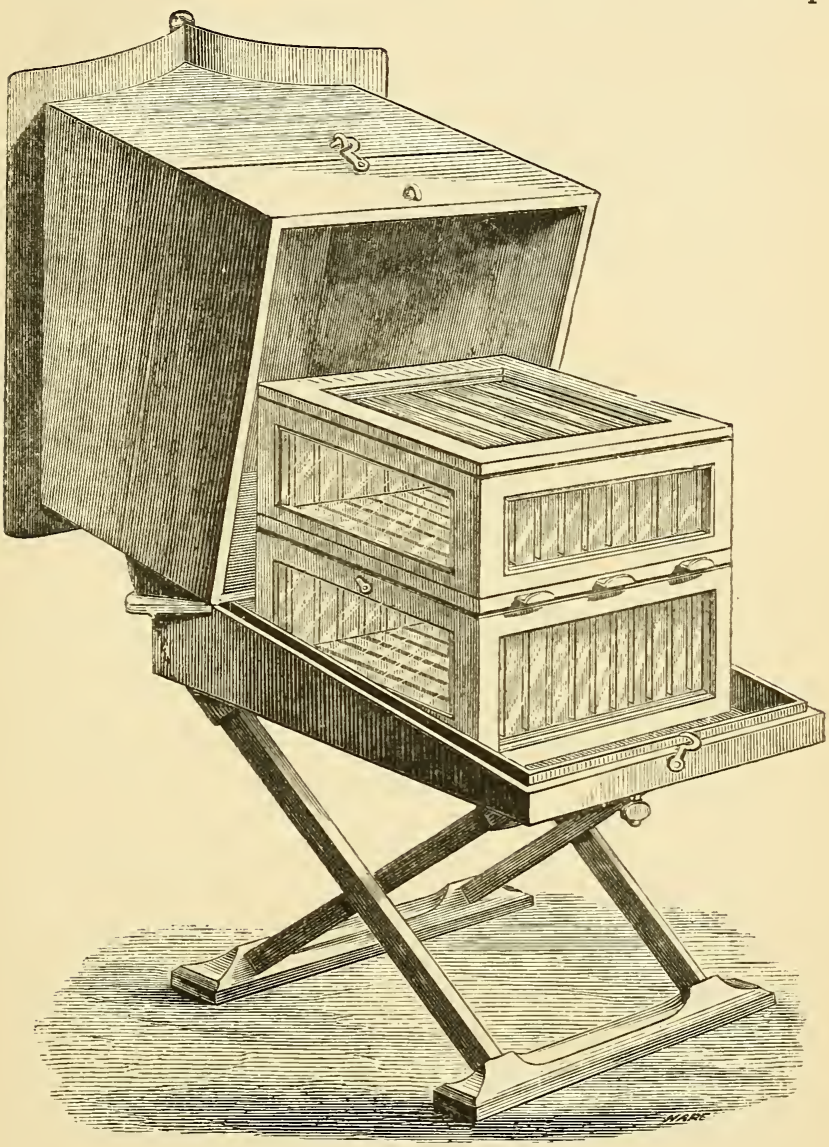

Fig. 56.-Glass Frame Hive, with Super.

of a hive. If kept properly warm, and well protected by their cover, not only do the bees, when needing room for storage, readily take to them, but 
they afford means of collecting, in a very neat, attractive, and convenient form, large quantities of purest and sealed honey. Thousands of hundredweights are now annually secured in this manner in our own country, and tons of such filled sections are every year imported from America, from which country, we believe, was derived this ingenious little invention, which has done so much towards the promotion of the pleasure and profit of bee-keeping among us.

Some people, however, still prefer to secure their super-honey in bar-frames similar, except in point of depth, to those of the stock hive. Such an arrangement may be seen on the preceding page, which represents one made by Messrs. Neighbour and Son.

A form of hive first brought out at Stewarton, in Scotland, and named after the place of its original manufacture, is a great favourite with many beekeepers, and certainly often yields admirable results in the way of super-honey. We are warranted, therefore, in giving some account of it.

It consists (see Fig. 57) ordinarily of four octagonal boxes. Three of these, $A, B$, and $C$, are called "bodyboxes," and serve as abodes for the bees, for nurseries and supplies of food, for rearing the young and for winter use. Each is fourteen inches in diameter in the widest parts, and five and a-half inches deep inside. Nine bars range along the top of each. These are not movable, but serve as guides to the bees for building straight combs. Between them, and beyond the outer ones, are ten narrow strips made to slide in grooves in the bars, so that the top is completely 
and securely covered. The figure represents the way in which the slides shift. The top box $D$ is that in which the honey to be taken by the bee-master is stored. It is four inches in depth, its other dimensions being similar to those of the boxes below it. It is furnished with only seven or eight, instead of nine bars, the object being to induce the bees to build longer cells for depositing honey in. This not only secures

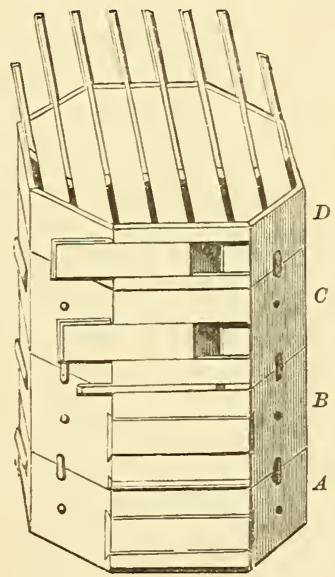

Fig. 57.-Stewarton Hive.

a greater quantity for less expenditure of wax, but prevents the queen laying eggs in them, if she should go up into the top box. For her majesty, finding it impossible to reach the bottom of the cells to place her eggs as she has been accustomed to do, will retire to the lower boxes, where she finds places perfectly adapted to her instincts or her needs. The honey is thus kept free from brood, and it presents a massive and rich appearance. Bees seem greatly 
to appreciate this form of hive, and a strong swarm will often fill the two lower boxes with comb in ten days. To get the full advantage, however, of this system, it is best to put a swarm into each of the lower compartments, or in the first and third, if two colonies of bees cannot be procured on the same day. If they be kept asunder a few days by slides with perforations, to let their odours commingle, they may be allowed to join their forces, and the queens will settle the sovereignty by a battle, ending in the death of the weaker. When the stock-boxes have become well filled with bees, admission may be given to the honey-box, and, in a good season, splendid combs of honey may be secured in this way. We have seen supers of great weight and beauty taken from the Stewarton hive. Its merits have been well described from time to time in The Journal of Horticulture and The Bee Journal, by a "A Renfrewshire Bee-keeper."

Mr. C. W. Smith designed a modification of the above hives which he named the Carr-Stewarton. In it the square form is substituted for the octagonal, so as to secure the interchangeability of all combs -an important matter in the practical affairs of an apiary.

The chief points of recommendation in the Stewarton hive seem to be, its excellence as winter quarters for its inhabitants, and the readiness with which large quantities of super-honey are stored in it.

In order that some of the wonders of bee-work may be seen in the process of performance, various arrangements have been made, constituting what are 
called "Observatory Hives." In these glass is substituted for wood in the sides, shutters being fixed over them to exclude the light. In some cases Venetian blinds are used instead of shutters. The frames with the combs are sometimes arranged vertically in one or two series, and sometimes laterally-a dozen or more standing one behind another. In the latter instance both the top and the sides are of glass. The whole hive may be made

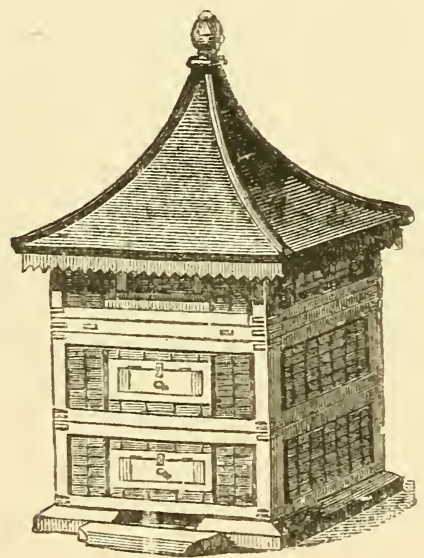

Fig. 58.-The Carr-Stewarton Hive.

to revolve by means of two iron wheels, the one fixed to its bottom, the other to a stout board running its whole length. In the centre of the floor-board there is an opening into a passage below, which leads to the open air. This arrangement enables the hive to be turned in any direction without interfering with the egress and ingress of the bees. If the queen with her attendants cannot be found on one side of the combs, the other side may be brought into view 
by rotating the hive, and the different classes of the population can be studied, and their work surveyed in security and continuously.

The unicomb hive may be stocked in various ways. The simplest plan is to take from a bar-frame hive the comb on which the queen is, and put it into the unicomb hive with as many more empty frames as will fill all the space intended for their reception.

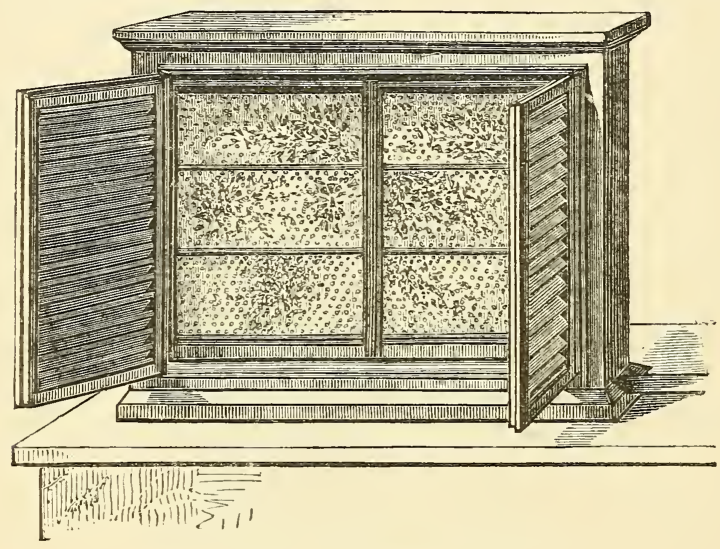

Fig. 53.-Unicomb Observatory Hive.

In this way new clean comb will be made, giving a much better appearance to the colony. Another plan is to take brood-comb in frames sufficient in number to fill the hive at once. The bees will then make a queen for themselves, and the interesting process may be watched in all its stages, provided, of course, that there are some freshly-laid worker-eggs in the cells.

It is not advisable to try to keep the bees alive in an observatory hive during the winter, because so 
much heat is lost by absorption through the glass sides and top. It is best, therefore, to replace the frames and their tenants, early in the autumn, in the ordinary wooden hives.

Much discussion has taken place among apiarians as to the merits of bee-houses. Those who advocate their use do so on the following grounds: Firstly, the protection afforded by a permanent building to contain the stocks, secures them from dangers of severe storms of wind, hail, rain, and snow. The first kind of tempest is apt to overthrow hives; the second to terrify the bees by the violence of the impact of the ice-drops; the third to saturate the floor-boards, and even to penetrate the top coverings; and the last will sometimes choke up the entranceholes, and cause the suffocation of the bees. Secondly, for manipulating purposes in all weathers the shelter of a bee-house is very convenient, beside diminishing the danger of chilling the brood under examination. Thirdly, hives under cover of a roof are less affected by sun and moisture, and last longer without requiring paint, than if exposed to all weathers.

Those who advocate the placing of each hive on a separate stand in the open air, allege the following objections to bee-houses: Firstly, that of expense. Secondly, that they form a shelter for mice, moths, spiders, \&c. Thirdly, that they promote dampness. Fourthly, that they encourage robbing by the bees. Fifthly, that they are inconvenient for manipulating, by causing disturbance in neighbouring hives while operations are going on. Sixthly, that they tend to the loss of young queens returning from their 
marriage flight, by the sameness of appearance in the entrances, and the nearness of the hives to each other.

We cannot discuss the replies given to most, if not all of these objections; but must content ourselves with saying that we advise all who have a shed which can be converted into a bee-house, or who do not mind the expense of putting up a building, to secure the advantages of such a shelter, and to take the easy precautions against possible inconveniences. ${ }^{1}$

${ }^{3}$ An able paper, on this subject, by the Rev. G. Raynor, may be found in The Bee Journal for February Ist, I882. 


\section{CHAPTER XVIII.}

\section{NATURAL SWARMING.}

General Facts connected with Swarming-Reconnoitring-SettlingHiving-Curious Incidents-Transferring Swarms to Bar-frame Hives-Division of Swarms-Placing Swarm in Permanent Po:ition-Number of Bees in Swarming- "Casts" and Later Swarms -Prevention of Swarming-Feeding of Swarms.

THE facts detailed up to this point will enable the subject of swarming-both natural and artificial-to be understood very clearly, and we will now speak of this most important matter in its various bearings.

Firstly, it must be mentioned that swarming is the result of so great an increase in the population of a hive that work cannot efficiently be carried on, in consequence of the crowd of bees. In ordinarily good seasons the queen has produced so large a progeny by the second or third week in May, that a colony will be ready to start. The workers, being previously impelled by the growing numbers of the hive, will have prepared some royal cells. As the time for the emerging of the princesses approaches, the old queen, in her rage at the thought of coming rivals, attempts to destroy her future compeers. In this, however, she is thwarted by her otherwise obsequious attendants. In her wrath, she utters a 
succession of shrill, angry notes, having the sound of "peep, peep." To this one or more of the unhatched queens will reply in similar tones; and these constitute what is known to bee-keepers as "piping." It is especially noticeable previous to the issue of swarms after the first, and may be heard, particularly in the morning and evening, on placing the ear to the side or back of a hive about to send off another colony, and especially about the eighth day after the first issue.

Another indication of the approach of swarming is the clustering of bees in idleness near and outside the entrance of the hive. This is specially observable if, through unfavourable weather, an enforced delay occurs in the departure of the colony.

When the old queen has become sensible that she must depart with a portion of her subjects, she usually chooses a fine morning for her exodus; and, under ordinary circumstances, takes her flight between the hours of ten and one in the day. Occasionally, however, from some cause, she will delay her start, and the writer has had one instance in his own experience in which the swarm came out at the unusually late hour of a few minutes after five in the afternoon.

All the bees who are about to accompany their sovereign, take the precaution of securing a supply of food sufficient to last them several days; for they instinctively know they will be so occupied in waxmaking and the internal preparations of their new home, that there will be no opportunity for them to get supplies out of doors, while, of course, they expect to tenant an empty dwelling. When all is ready, and their honey-bags are distended to the full, 
they rush to the entrance, from which they excitedly pour by hundreds and thousands. Among them is their proper sovereign; for, as we have already hinted, it is always, except in the rarest cases, that the old queen heads, or rather accompanies, the swarm. Dzierzon records one case in which the old queen refused to quit the hive, and three strong swarms were led forth, within a few days of each other, by her royal daughters.

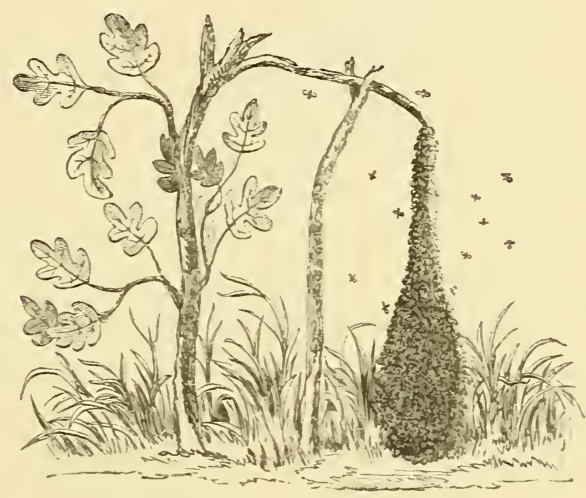

Fig. 60.-A SWARM.

And now, when the main body of the emigrants has issued from their quarters, the whole air seems alive with the excited, flitting, buzzing insects. The noise of their humming can be heard for many yards away, and a novice may well wonder what is to be the end of the commotion. Ordinarily, however, within a few minutes, after their exodus, it will be observed that a gathering of a thicker crowd is taking place at some particular spot-most frequently on some low tree or bush. There her majesty has settled, and at once 
her loyal subjects assemble around her, and form a living cluster. Quickly, from all sides, they continue to gather, and in a quarter of an hour or twenty minutes a dense mass will be hanging one to the other, till it seems wonderful the queen and those in the interior of the living ball are not suffocated.

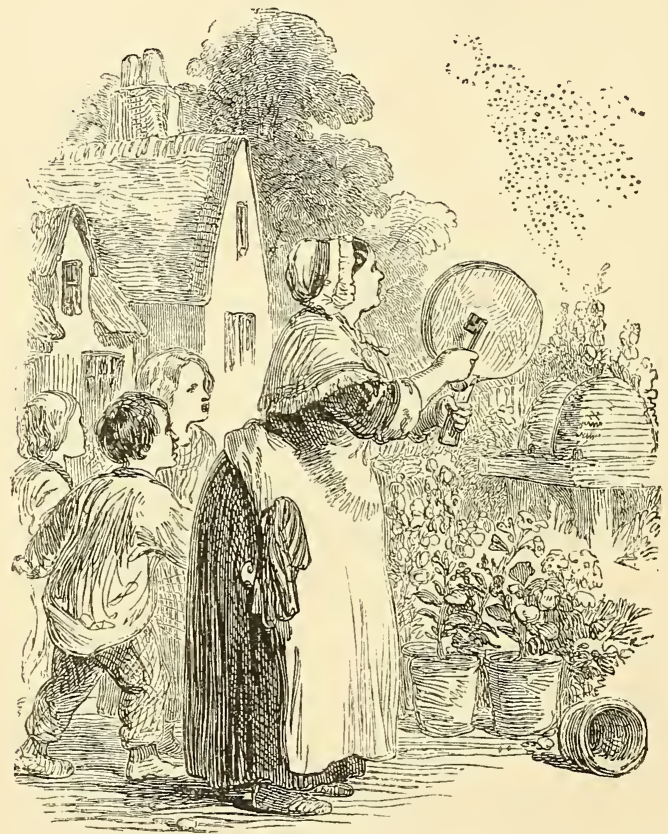

Fig. 6r.-"TANGING."

In country places it is still the custom to beat warming-pans, tin kettles, frying-pans, or other unmusical vessels, with keys or sticks or hammers, while the bees are swarming, under the idea that the noise makes them settle the more quickly. That any 
effect is produced on the insects is not any longer believed by apiarians; and there is good reason for thinking that the origin of the practice was altogether different from its supposed use. The probability is, that it indicated at first nothing more than that some one wished to proclaim to the neighbours the fact of his bees having swarmed, so that he might lay claim to them wherever they might settle.

It sometimes happens that the inclination to cease flying is delayed beyond the usual time. It is said by Langstroth that the throwing of a few handfuls of dust into the air, or the flashing of sunlight by a mirror among the bees, will have the effect of bringing them down. Vergil, nineteen centuries ago, pointed out that, in what he called their battles, but which were probably only the confusions of swarming, the flinging of dust or earth among them would have a quieting effect.

Sometimes, unfortunately, a strong and wayward queen will lead off her colony far beyond the precincts of the apiary in which she has been living. The writer has, during the past season (I 883 ), had to regret the vagaries of such a queen, who, the previous year, came into his possession through her abandoning her former master, without giving any clue as to her ownership; and this year, after twice settling, and being once hived, within some two hundred yards of the apiary, took wing again, and was entirely lost, though followed more than half a mile. Few things are more vexing to the bee-keeper than such mishaps; and it becomes necessary to take all precautions which are possible against them. When, therefore, a swarm has once decidedly gathered into 
a cluster, it should be shaded from the direct rays of the sun ; for the excitement, the close massing, combined with the natural warmth of the surrounding air, will raise greatly the temperature of the mass; and, to escape suffocation, a second flight is sometimes undertaken. A wet sheet, an umbrella, a sack supported on stout sticks, and many another simple expedient will answer the purpose of promoting a requisite coolness.

Next, immediate preparations should be made for hiving. As a rule, bees, when swarming, are very good-tempered, because they are gorged; and, like Englishmen, improve in disposition under the influence of good food. Some curious stories, indeed, have been told of the perfect inoffensiveness of these insects when thus forming a colony. We will give two of these, narrated by Bevan.

A gentleman wishing to hive a swarm that had settled on the branch of an apple-tree, gave the hive in which he was going to place them into the hands of a maid-servant. She, being a novice, and somewhat timid, covered her head and shoulders with a cloth, to protect her face. On shaking the tree, most of the bees fell upon the cloth, and quickly crept under it, covering the girl's chest and neck up to her very chin. Her master instantly impressed her with the necessity of being perfectly quiet, and refraining from all buffeting, while he began to search for the queen. Having found her majesty, he gently removed her; but, to his disappointment, the swarm showed no signs of following her. Suspecting at once that there was a second queen in the cluster, he made another search, and found his supposition was correct. 
On securing her, and placing her with a small cluster of bees in the hive, the rest followed in crowds, till, in two or three minutes, not a single one was left on the girl, who was thus relieved from her anxious, and what might have proved most dangerous position, had she excited and alarmed the insects.

The other incident is no less striking. A skilled bee-master had a little friend who was very much afraid of being stung. One day, a swarm having come off, the queen was observed to settle by herself at a short distance from the cluster. The gentleman at once called the child to him, that he might show her the queen. Becoming interested in the somewhat uncommon sight, the girl desired to observe the royal insect more closely; so the bee-master, having made her put on gloves, placed the queen in her hand. Immediately the whole of the bees in the swarm thronged around. With an admonition to the child to remain motionless and speechless, and without fear to retain her self-possession, the gentleman quietly covered her head and shoulders with a very thin handkerchief, and made her stretch out her right hand, in which the queen was. The swarm at once began to settle, and hung from the girl's hand and arm as if from the branch of a tree. Delighted at the novelty of the affair, and finding herself unstung, the child then requested to have her head uncovered. After a while, when the bees were all quiet, a hive was brought. By a vigorous shake the swarm was made to fall into their abode, and every one of the insects was got rid of without the infliction of a single wound.

Probably it would not often happen that such 
completely harmless results would follow such occurrences : for, it is not unfrequently the case that a few bees, perhaps having joined the swarm without having had the opportunity to fill themselves with honey, prove somewhat spiteful ; and, notwithstanding the general quietness of a just-emerged colony, even experienced apiarians by no means always escape punishment when dislodging a swarm. It is, however, quite easy to secure complete protection by means of a properly made veil to guard the face and neck, and gloves to cover the hands. We strongly advise all novices, therefore, to make use of these preservatives from stings, when proceeding to get the bees into the hive intended to receive them.

Some persons advise that the skep into which the swarm is to be brushed or shaken, should be dressed with a mixture of beer and sugar, applied with a wisp of elder-branch and leaves. It is just possible that the sweetened liquid may be drunk by some of those not quite satiated with honey, and that thus an increased quieting influence is exerted upon the whole mass; but the most skilled apiarians have given up the practice, in the belief that it is useless, if not positively mischievous, by wetting the bees, rendering many of them helpless, and probably destroying numbers of them.

The facility of hiving depends altogether upon the place chosen by the cluster for settling. From the end of a bough, or from a low shrub or bush, there is no difficulty in securing the swarm. Taking a clean skep in one hand, and holding it just under the mass of insects, a sharp shake is given with the other hand to the branch, and nearly the whole of the 
bees will fall into the hive. Comparatively few will fly, the vastly larger proportion having clung too tightly to one another readily to disengage themselves. As soon as possible, a floor-board should be quietly and gently placed over the open end of the skep, which must now be inverted, so as to rest on the board. One side may be slightly propped, to

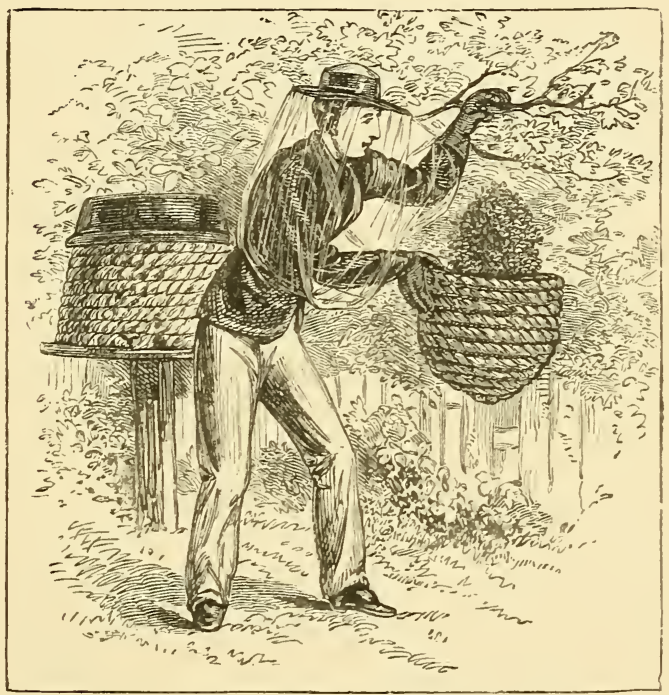

Fig. 62.-Hiving a Swarm.

afford the flying bees opportunity of more speedy admission to the interior than the ordinary entrance hole would give them. Another quarter of an hour or twenty minutes will suffice for all but a small number of stragglers to join their companions inside. Meantime, a shade should be again provided, till all have entered. 
If it is intended to locate the colony in a barframe hive, this should have been also previously made ready, the frames being furnished with sheets of guide-comb. The coverings being then removed from the top, and the skep containing the bees held above the frames, by a sharp jerk downwards, and a rap or two on the top and sides of the straw hive, all the bees may be made to fall on the bars of the frames. They will speedily crawl down on to the sheets of guide-comb, especially if a light cloth be gently laid above them.

Another method of transferring them from the skep is to spread a sheet, or nerspaper, in front of the bar-frame hive, which should be slightly raised in front from the floor-board. Then, by a smart jerk, as before, the bees are thrown on to the sheet or newspaper, close to the entrance, and they will immediately run in and up on to the combfoundation.

Sometimes a swarm will divide into two parts, each of which will settle separately. In such a case, it is tolerably certain that two queens have emerged together, as very often happens with second or later swarms. When such a division of forces occurs, unless each portion is sufficiently large to form a stock by itself, it will be advisable to hive them separately, and then speedily to unite them, leaving the rival sovereigns to fight for the supremacy.

Occasionally a colony settles around the stem of a tree, or some place equally inconvenient for being detached. The difficulty may sometimes be met by brushing as many bees as can be got at into a hive, or by holding a hive above the place of settling, and 
by smoke driving the insects upwards, till they learn the whereabouts of comfortable quarters. At other times there is no resource but making the swarm take to flight, in the hope that a more suitable place will be chosen by them for their next assemblage. There is a danger, however, that if thus compelled to move, a too distant excursion may be made, and the whole colony thus be lost.

As soon as all, or very nearly all, the bees have gone up into the skep, or into the quarters they are to occupy, it is advisable to move them to the stand intended for their permanent position. Some apiarians, however, recommend waiting till evening for taking this step. We must dissent from their opinion for two reasons: firstly, because it often happens that, in a place away from the apiary, something may occur to disturb the bees, and they will forsake the hive. In fact, last season ( $188_{3}$ ) we have ourselves lost a valuable colony, which, through not being brought home at once from the place where they had settled, were meddled with by a passing dog, and took another flight far away, and, though followed long and diligently inquired after, they were not again discovered. Then, too, the sooner the bees are placed in their proper position, the sooner will those going in quest of supplies learn their new hume. If left so little as six or eight hours in the spot at which they first settle, many will continue to hover about it all the succeeding day, and even longer. For these reasons, therefore, we advocate a speedy carrying of a swarm to the site selected for it.

It is an established fact that, previously to swarm- 
ing, bees often send forth scouts to select a place for settling. Neighbour records a curious instance of this kind. He says: "A lady, who lived about a quarter of a mile from our apiary, sent to us to say that a swarm had gone in at a hole over her stable, and to ask us to come and hive them. On our going to do so, her gardener told us that he had seen, three days previous, two or three bees as if reconnoitring; next day several came, and about eleven o'clock on the third day the whole swarm went in, and took up their position between the rafters [? joists] under the flooring. The difficulty was now to get at them. A carpenter was sent for, the boards were taken up, a hive was set over, with a brood-comb placed in it attract them, and by dint of smoke and brushing to with a feather, the queen and her retinue were coaxed to ascend into the hive. Some of the bees had already gone out to forage, and there were many flying about that had not settled; so, to secure these, and to make it easy for them, we brought the hive out, and erected a sort of platform on a pair of steps close to the hole, which we stopped. By night-time all the out-flying bees had joined the swarm, and were easily removed."

The number of bees in a swarm varies considerably, but the usual amount is from 10,000 to 15,000 . In rarer cases, there will be from 20,000 to 25,000 . Von Berlepsch, by careful experiments, estimated that about 4,000 gorged bees weighed I lb. : so that a good swarm will weigh from 3 lbs. to 5 lbs. As may be easily understood, the more numerous the bees, the better for the future of the colony, provided there is space in the hive for them to work in. 
The hive which has sent forth a colony usually contains large quantities of brood and eggs, and some cells in which princesses are more or less developed, so that queens would be provided in proportional succession. If the stock has been so weakened that it is not intended, by the workers remaining, that another colony should issue during the season, the first queen who emerges is allowed to destroy all her royal sisters remaining in the cells, and she, at once, avails herself of the opportunity of so doing. If, on the other hand, the amount of the on-coming brood is very large, and it is manifest that again the hive will become too crowded, the queen is restrained from her murderous propensities. She resents this interference by uttering the sharp cries of "peep-peep," previously mentioned, and is answered in similar tones by her still imprisoned rival sisters. This is a sure sign of the approaching emergence of a second colony. Within two or three days of the piping being heard, the expected event takes place, though occasionally it may be delayed, by cloudy or wet or cold weather, till the fifth day. Such a second exodus is called a "cast." Sometimes in the excitement of "casting" several young queens, who have been under guard, will escape; and as many as five have been known thus to issue with a second swarm: indeed, Langstroth mentions one instance of eight queens having thus left the parent stock at one time. Of course, when such an event occurs, if all are hived with the general cluster, they will fight till one only is left to enjoy supremacy in the community. If the settling of the swarm takes place in two or three places, it is pretty sure that more than 
one queen has come forth. It is best then to search for one or more, and to remove them, to be used, if necessary, in other hives, and then to unite the separate clusters.

To third and later swarms from the same hive, the fanciful names of "colts" and "fillies" have been given, but they are going out of general use.

Swarms subsequent to the first are usually less than it in amount of bees. For this reason it is advisable not to make them into separate stocks, unless very strong, but either, after removing the queen, to return them to the parent hive, or to unite two or more casts, so as to form one strong colony. It may be remarked that there is this advantage about a cast, that all the bees, queen included, are young, and so are likely to work with vigour; and if sent off early in the season, and naturally or artificially strong in numbers, they may become a powerful community: but everything will depend upon the two conditions just mentioned.

Where it is not really wished to increase the number of stocks, it is much better to prevent "casting," by cutting out all queen-cells five or six days after the first swarm. The reason of the delay in the operation is, that, by that time, all eggs and larvæ left by the old queen will have advanced to a stage at which the workers cannot convert them into queens, even if they desire to do so.

Another reason, besides the weakness of after swarms, why efforts should be made to prevent casting is, that the old stock often becomes, by the swarming mania, too greatly diminished in population to prosper, and a double loss is incurred-loss 
of honey, which would be stored largely by a stock restrained from self-diminution, and loss of general strength, through there not being bees enough to collect food for store, and to look after the constantly hatching brood.

A curious illustration of sagacity in the workers is, that casts and after-swarms, if allowed to build in a box as they please, select a corner, instead of the middle, for beginning, knowing that, through the smallness of their numbers, they are unlikely to fill their abode with comb, and so taking the precaution to secure the snuggest and warmest position for such combs as they will be able to construct. They feel that their only chance of surviving as a colony is their being able to keep up sufficient heat to hatch the eggs, and to bring forward the brood in the early autumn and the next spring. First swarms, confident in their strength, commence their work in the middle of a hive.

We have already mentioned that the bees, in swarming, start with their honey-bags full. This supply will last them about three days. If, at the end of that time, the weather should be dull and unfavourable for flying abroad, great benefit will be conferred on the young colony by giving a supply of syrup. We shall speak later on of the method in which it is to be administered. As bees waste nothing, and never remain idle because they have a store of food, whatever is given them will be economically used. Moreover, they prefer their natural sources of supply, and will not take advantage of their owner's generosity in giving them syrup, if they can gather honey. At the same time, the needs of a 
new stock are great during the first two or three weeks, since much wax has to be made, and homes and provender for the coming young have to be in readiness. It is, therefore, a wise and benevolent and paying plan to feed all swarms whom the weather prevents from gathering abundant supplies in the fields. By this means no time is lost in comb-building: all the workers remain vigorous for flight and indoor duties: the queen, encouraged by finding no lack of food for her future offspring, will get on with laying as fast as the cells are ready to receive her eggs; and thus all the elements of a prosperous community will be secured. 


\section{CHAPTER XIX.}

\section{ARTIFICIAL SWARMING.}

Advantages-Driving: Close and Open-Transfer to Bar-frame HiveConditions of Successful Driving-Various Methods of Artificial Swarming with Bar-frame Hives.

THERE are some mortifying incidents connected with natural swarming, which the skilled apiarian will endeavour to avoid, by taking the matter of the making of colonies into his own hands. WV have spoken already of the annoyance and trouble often caused by the flying away of a swarm. This accident at the beginning of the honey-season means, at least, a loss of what would be worth from a sovereign to thirty shillings, either in stock or honey. Another, but minor, disappointment comes from seeing the bees hanging outside a hive in handfuls, idle and useless, waiting for the queen to come forth with a swarm. In this way the work of some thousands of bees for several days is lost, and that often at a time when honey is most plentiful in the fields. Now, both these difficulties may be met with complete success by what is called artificial swarming-an operation which is conducted in different ways, according to the kind of hive to be operated upon. 
We will speak of the process called driving. This is the method adopted with the ordinary skep, and is practised as close or open driving. In the first case, the plan pursued is as follows: Into the entrancehole of the hive to be operated upon a few good puffs of tobacco, or other smoke, are blown. This frightens the bees, and they immediately rush to the cells, and gorge themselves with honey. After giving them a couple of minutes for this purpose, they become much more quiet and tractable. If this precaution be not taken, many of the workers will fly in anger at the operator, and, though be may be protected by veil and gloves, will greatly disturb the comfort of his manipulations. The hive is then lifted from its floor-board, and inverted, i.e. turned upside down, on a tub, pail, or pan, partly filled with water, to keep it firm. Upon it is placed an empty hive of the same diameter, and round the junction of their rims is tied carefully a round-towel, or a bandage of some kind, so as to prevent the escape of any of the bees. At the same time, or as soon as possible, another empty hive, with a little syrup sprinkled on the interior, is put on the stand from which the stock has been brought, so that the bees, who were abroad when their home was removed, may be amused, or, at least, diverted from going to other hives, where they would be attacked and slain as robbers. Returning then to the hive from which the swarm is to be driven, it must be beaten smartly, but not sharply enough to shake down the combs. A tolerably stout stick in each hand, or the hands themselves, may be used for the purpose. It is best to begin gently, and to increase the force of the 
blows, letting the drumming be continuous, but not violent. The bees, already terrified by the smoke blown amongst them, will in the course of a few minutes begin to run into the upper hive, and a large enough proportion, together with the queen, will have gone up within ten minutes or a quarter of an hour. Their passage up may be ascertained by the buzzing sound of the multitude of vibrating wings; and when this has subsided the cloth may be taken away, and a large cluster of the driven insects will be found in the top hive. This should then be placed on the stand from which the stock was taken, so as to be reinforced by many of the population who were abroad for supplies. If it is intended to transfer the new colony to a bar-frame hive, they can be introduced either by being shaken on to the tops of the frames, to run down between, or thrown on a sheet in front of the bar-frame hive, which should be slightly propped up, as already described in speaking of natural swarms thus put into wooden hives. The old stock, containing much brood and a fair residue of bees, may be placed at a short distance from its former stand. It will be sure to have an attraction for many of the adults of its population so unceremoniously ejected, and some of the most recently hatched will have refused to quit it. These combined forces will suffice to tend the brood; and in a few weeks, with a young queen, the tenants will be almost as numerous as before the driving took place.

Open driving is performed in a similar way, except that the hive, into which the bees are to be made to ascend, is placed over the other at an angle, and 
only resting upon it for three or four inches. It is supported in this sloping position by skewers or iron wires thrust through both hives where they touch, and with others to prop them well open in front. This arrangement frees the hands of the operator: enables him, in many cases, to watch the going up of the queen-an all-important matter for the success of the artificial swarm: and gives him the opportunity of judging when a sufficient number of the stock have been frightened out of their abode to form a satisfactory colony. The terrified insects make no attempt to escape by the wide opening free to them, but rush in a continuous stream up the connected portions of the hives, and form a cluster in the roof of the upper one. They have filled themselves with honey, and, between repletion and fright, are as inoffensive as so many flies. We have ourselves had the opportunity of displaying to two members of the Royal Family the harmlessness of driven bees, by taking some hundreds with an ungloved hand, and holding them to the view of Prince Christian and Princess Beatrice. To the Prince's inquiry, "Why do they not sting?" the reply was, that they became like Englishmen after a hearty meal - very good-tempered, an answer which not only amused His Royal Highness, but was correct as an explanation.

The best time for the operation of driving is near the middle of the day, when many of the workers are abroad in the fields. Should the weather be cold, it is advisable to warm the skep into which the driving is to take place. A further detail of great use in quieting and reconciling the ejected 
colony is, to sprinkle between the combs, a quarter of an hour before driving, some weak syrup, made of one pound of sugar to one pint of water. A wineglassful will be enough to use for one hive, as too large a quantity might seriously wet the bees, and perhaps glue their wings and limbs harmfully. After settling down in their new home, they will be occupied with clearing themselves and each other of the syrup, which will serve also the purpose of still further replenishing their honey-bags.

It is difficult to get the bees to leave by drumming a hive only partly filled with comb. They will cluster about the unoccupied portions, and resolutely refuse to go. In this case they may be ejected on to a sheet, spread to receive them, by three or four sharp jerks in a downward direction.

It is advisable not to drive a colony after very hot weather, and when there is a great in-take of honey: otherwise some of the liquid will begin to flow out of the cells when the-skep is inverted, and will cause much trouble and waste, and possibly the destruction of many bees by drowning them in their trickling stores. It will be better to wait till the next morning, when evaporation and the coolness of the night will have thickened the liquid sufficiently for it to remain in the cells during the manipulation. The combs, also, will have become firmer, and less liable to fall, with the diminished temperature.

The operation of driving from skeps is abundantly practised by apiarians, in the autumn, among the hives of those cottagers who would otherwise follow the old and most barbarous plan of killing their bees to take the honey. Several stocks of bees thus 
drummed out of house and home may be united to form a strong colony. If supplied with frames of comb, or "foundation," and fed with syrup (made with $2 \frac{1}{2} \mathrm{lbs}$. of sugar to each pint of water, with a dessert-spoonful of vinegar boiled up with it, to prevent crystallisation), they may be brought safely through the winter, and become, by the spring-time, well worth the expense and trouble they have cost.

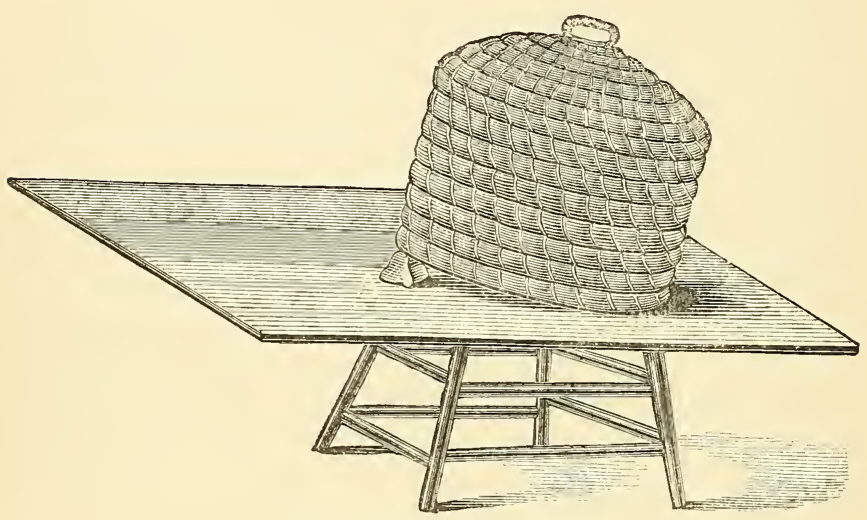

Fig. 63.-Sivarming Board.

With bar-frame hives the making of artificial swarms becomes an easy matter, and more than one plan may be adopted. In the first place, suppose it is desired to transfer into a skep a swarm from a wooden hive, for sending to a distance. The preliminary operations are as follows: Towards evening, remove the stock a few yards from its stand, and have ready the skep on a wide board, and propped up two or three inches in front. Next puff smoke into the midst of the bees, to quiet them, and to 
induce them to fill their honey-bags. Then lift the frames one after another, and search for the queen till found. Take her gently between the first finger and thumb, seizing her by the wings, place her at the entrance of the skep, and see that she runs in. Shake on to the board, close to the skep, the bees from the frame on which the queen is found, and, after replacing it in its own hive, take out and shake off bees from other frames in succession, till a sufficient amount to make a swarm has been let run into the skep. They, with their sovereign, will ascend to the crown of their abode, and then may be secured by tying a cloth over the open part of the straw hive, and despatched to their destination. Of course the frames must be replaced in the stock hive as they are cleared. The remaining bees will soon make a new queen for themselves, and will care for the developing brood. Judgment must be exercised, so as not to weaken too greatly the population of the parent-hive.

Another method, still simpler, is to begin operations in the morning of a bright day, and to shake off the queen and bees from two frames only, and put the colony on to the old stand, removing the stock to a distance of a few yards. The bees abroad for supplies will, on their return, remain with their queen, and make up a sufficiently strong community; while the young, and those who prefer the old stock, will be sufficient to meet its requirements.

A third plan is to take the frame on which the queen is, with bees and brood, and place it, with two or three other frames from the same stock in another hive, which should be placed on the old stand. 
Foragers returning from the fields will, as in the preceding case, reinforce the new colony, while the stock, moved to a little distance, will soon repair the loss of their queen, and hatch out young bees in place of those transferred to another home.

A fourth method is to take two combs from each of several strong stocks, brushing off all bees with a feather or goose-wing. Then placing the hive thus filled with comb and brood, on the stand of a strong stock, the returning bees will take to the home thus presented to them, and will speedily raise a queen for themselves from one of the many eggs contained in the brood cells. The displaced hive must, as in previous instances, be removed a few yards from its old position. The reason for filling the abode of the new community with frames of workerbrood, is to prevent the bees from building dronecomb, and raising males only, as they are apt to do when they have to manufacture a queen, at least till she is not only hatched but begins to lay eggs.

There are three or four important precautions which are to be remernbered when making artificial swarms. Firstly-swarming should not be artificially attempted till drones are tolerably numerous, unless a fertile queen is to be given to the new colony Secondly-honey should be abundant when the. swarm is made, unless a good deal is stored in the combs removed. If syrup, however, be supplied, all danger from scanty sources outside will be removed. Thirdly-swarms should be taken only from the strongest stocks, otherwise both old and new communities will be, perhaps irretrievably, ruined. Fourthly-it is an immense advantage to introduce 
a queen into the hive that has been deprived of its mother-bee; and with suitable precautions, especially that of caging the supplied sovereign for thirtysix hours in a receptacle made for the purpose, there is usually little difficulty in getting the substitute amicably received by the mourning workers. This plan not only prevents the loss of two or three weeks of very valuable time in the rearing and fertilising of a queen, but obviates the danger of the young queen, when raised, perishing on her weddingflight, through being snapped up by a bird, or mistaking the entrance of her hive on her return.

Various modifications of the above plans may be found in Langstroth, but enough has been said to indicate the ordinary and simplest modes of procedure. 


\section{CHAPTER XX.}

QUEEN REARING.

Protection of Queen-cclls-Nucleus Hives-Various Methods of Queen Rearing-American Plan-Introduction of Stranger QueensDifficulties.

THE breeding of queens can only be done with ease and complete success in bar-frame hives. If, on examination of the frames of a stock, queen-cells with brood in them are found, these may be protected by means of little wire cages from the animosity of the mother-bee, and in due course the princesses, as they hatch out, may be transferred to a small box, with a piece of comb and a few bees belonging to the hive. Care must be taken not to let the cage touch the cell over which it is placed, and it should be thrust into the comb only to the base of one set of cells. The best time for thus affording protection is when the larva is six or seven days old.

A second plan is to take from a hive, late in the afternoon, a comb containing worker-eggs, with brood in more advanced stages, and a sufficient number of bees to keep up warmth enough to promote the development of the larvæ. These must all be put into a very small hive, and a supply of honey 
and water should be given. In the course of a few days a queen-cell, or cells, will be formed, workereggs transferred into them, and these, in process of time, will come forth as princesses. When fertilised they will be ready for using in other hives.

A third method is to set a small empty hive over a full stock, and, when the bees using the entrance of

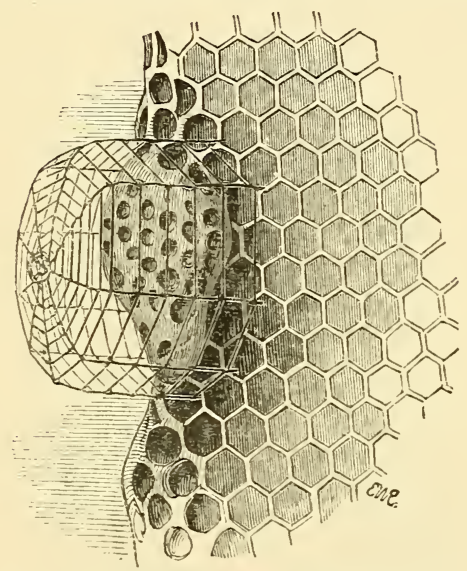

Fig. 64.-Queen Cage over Sealed Cell.

the upper one are sufficiently numerous, a broodcomb with eggs and adhering bees may be placed in the top hive. Then, in a day or two, the aperture between the two may be closed, and the nucleus being removed, another can be put in its place, and the process repeated till as many queens as are required have been raised.

Fourthly. Two or three combs with brood and honey may be taken from a hive, and having cut out a nearly triangular piece of comb, a queencell with comb, nearly equal in size to the hole, may 
be inserted, as shown in the figure. This will expedite the rearing of the princess. The bees will soon fill up the intervening spaces, and the daily emerging young bees will make subjects enough for the young monarch, till she is needed for the sovereignty of a larger population. If the miniature stock should dwindle before the young queen lays and replenishes the numbers, young bees, which have never flown, may be introduced from other hives, and these will

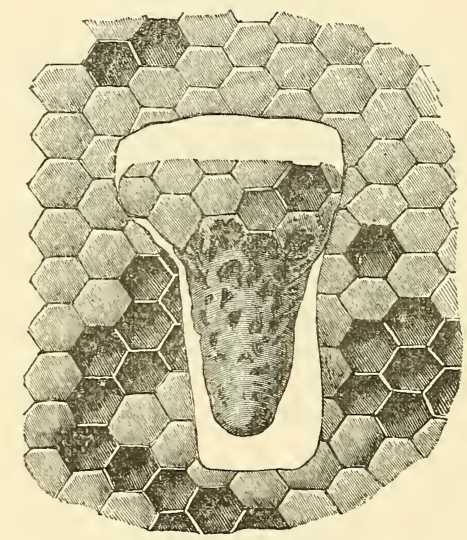

Fig. 65.-Inserted Queen Cell.

be received with pleasure by the remaining workers. Or another frame with plenty of bees may be exchanged for one of the empty ones. This latter plan involves some danger of fighting, which is avoided by supplying the newly-hatched young.

The American bee-keepers manage, it is said, to hatch royal larvæ and pupæ in little boxes heated carefully by a small lamp. We have not heard of any English apiarians who have pursued this method; 
and the probability is that the difficulty of regulating the warmth accurately, makes the results so uncertain and disappointing as not to tend to the adoption of the method among us. Like the "incubators" for the artificial hatching of poultry, so many circumstances combine to mar hopes cherished in the use of them, that it is altogether more satisfactory to rely on natural processes for the production of the young of both fowls and bees.

In all the processes of queen rearing described, we cannot but be struck with the inextinguishable love shown to the undeveloped young, and the passionate yearning for a mother-bee displayed by the workers. It matters not whether the brood presented to them be taken from their own stock or from another community; they will at once cluster upon the cells containing larvæ, and devotedly tend them till they come forth as perfect insects. The emerging progeny may even belong to another variety, Ligurian, Cyprian, or Carniolan; still the same complete devotion will be displayed. Nor is the willingness of a colony to receive an introduced queen affected by the fact of her belonging to a different race from the subjects to whom she is given. Yet, we do observe strange differences in the readiness with which a stranger sovereign is acknowledged. In some instances there is no hostility manifested to an uncaged queen, who is allowed to run down among the combs of a community which is without a mother. This is especially the case with a stock just mourning its discovered loss. At other times, even with careful introduction, and caging for from twenty-four to forty-eight hours, so unamiable a 
temper is displayed, that the supplied queen is refused; and she is either stung, or, more frequently, is so thickly clustered around and upon as to be suffocated. Occasionally, indeed, such a resolute determination is shown to have no monarch but one of their own raising, that the only course is to supply brood-comb with eggs to such a community, or to unite them with another stock which has a queen. We can no more account for these vagaries of socalled instinct, than we can for those displayed among human beings endowed with what we consider the higher faculty of reason. 


\section{CHAPTER XXI.}

\section{FEEDING.}

Troughs-Dangers of this Method-Bottle Feeders-Cheshire's Feeding Stage-Neighbour's Can Feeder-The "Round Feeder "-Autumn Feeding-Spring Feeding-Uses of Precautions-Summer Feeding of Swarms-Flour-cake-Barley-sugar or Sugar-cake-Mrr. Hunter's Recipe.

We have already spoken of the advantages consequent on feeding swarms for a few days after they emerge, especially if the weather should be wet, cold, or dull. It is even more important to see that in spring and autumn, if the stocks require food, it is given to them. With the old-fashioned skep there are difficulties in the successful supply of nourishment. The ordinary plan used to be to take a piece of elder-wood, and having cut it down the middle, and having removed the pith, to stop the open ends, or manage to have a knot at each, and then, having filled these long narrow troughs with syrup, to insert them into the hive by the entrance hole. Several disadvantages attend this plan. Firstly, there is the danger of spilling some of the liquid, and so inducing visits of bees from near hives, and setting up "robbing," with its disasters. Next, it is almost impossible, without constant attention, to 
give a proper amount of food thus. Thirdly, the bees being attracted to the floor of the hive, often become numbed in cold weather, and perish. Fourthly, where considerable feeding is necessary, and has to be rapidly done, it is impossible to accomplish it by this method, except at the cost of immense trouble.

Skeps which have a flat or broad top, with a hole fitted with a cork, can be supplied in a much better manner by one of the various kinds of apparatus we shall now describe.

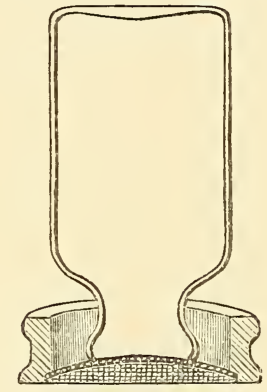

Fig. 66.-Bottle Feeder.

First, the "bottle feeder" consists of a glass jar (such as pickles, French plums, jams, marmalade, \&c., are sold in), resting on a block, square or round, as may be convenient, and having a hole cut to receive the neck of the bottle. Over the hole is fastened a piece of perforated zinc with very fine meshes. Over the mouth of the bottle a piece of fine net or muslin should be secured by a band round the neck, after the syrup has been poured in. Then the block having been put over the hole in the top of the hive, the bottle of syrup may be inverted and stood in 
the hollow prepared for it. The bees will soon become aware of the fact that food is within their reach, and poking their tongues through the zinc and muslin, they will draw what supplies they need. As no air can get through the syrup, the liquid will run only as fast as it is imbibed by the bees, unless, through sun-heat, the bottle should become so warmed as to cause the air inside to expand, and thrust out the food faster than it can be drunk.

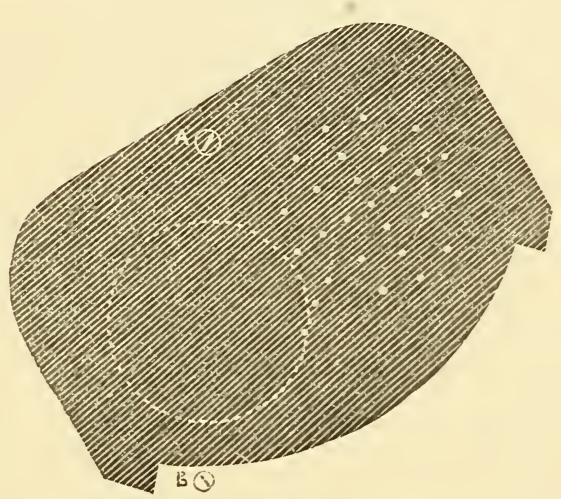

Fig. 67.-Cheshire's Feeding Stage.

It is easy to avoid this danger by properly covering the bottle. Another, and still more important, reason for protecting it is to prevent any bees from another hive getting at it ; for should they do so, robbing is very likely to ensue, stolen sweets having a most demoralising effect on bees, as well as on human beings; and this trouble once started, it is difficult to stop it before all the weak stocks have been plundered and destroyed by their stronger neighbours.

In order to regulate precisely the quantity of food it may be desirable to give to a stock, Mr. Cheshire 
has devised, instead of the muslin cover, a piece of vulcanite pierced with holes in a particular pattern, and rotating round a screw in such a way that one, two, three, or any required number of holes may be open at the same time. He also uses, and recommends, a small shovel, in which the bottle of syrup is first inverted. Then, when placed just over the vulcanite plate, the shovel is quickly withdrawn without the loss of any of the liquid.

This matter of carefully controlling the quantity of food allowed, is very important in the spring, when it is desired not only to save impoverished stocks from dying of hunger, but to stimulate well-doing stocks to early breeding. For, if too abundant supplies of syrup are given, the bees, in their determination not to miss any opportunity of storing at a time when there is no honey to be got out of doors, will fill the middle cells which are nearest the bottle, instead of leaving them for the queen to deposit eggs in, as she would naturally do, to secure them the full warmth of the cluster of her subjects.

Another method of supplying food is by means of a tin bottle or can. Mr. Neighbour describes the one invented by him for continuous supply, as "six inches wide by six high, with five small holes at the bottom, and closed by a sliding valve and a screw-top. The can is filled from the top, with the valve closed, and when the screw-top is made firm, this valve is drawn back by moving the pin in front. The can is placed over the feeding-hole at the top of the stock hive, and the bees have access to it by small holes. The can is on the principle of a fountain; the screw-top rendering it air-tight, the liquid only 
cscapes as drawn down by the probosces of the bees. A glass side is let in, to show when the feeder is empty. It need not be removed for refilling. The capacity of the vessel is over a quart." The advantages of this apparatus are, its security against

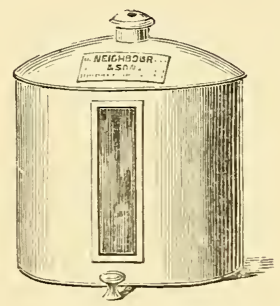

FIG. 68.-CAN FEEDER.

robber-bees; the fact that it can be filled in situ, thus avoiding all escape of warm air in cold weather, and chilling of the brood; and the facility with which its condition can be inspected and its store replenished, In addition, it is strong and not likely to get out of order.

The "round feeder" is made of zinc or earthenware, eight inches across, and three deep. It is

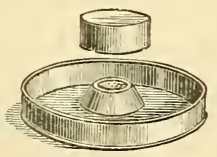

Fig. 69.-Round Tin Feeder.

filled by a sloping aperture from the outside. The bees come up through an opening in the crown of the hives on to a piece of wood, under a close-fitting tin cap, which keeps in the heat, and the bees are 
able to feed without the possibility of being drowned. The outer lid has to be raised; the liquid food is then poured into the trough, and is gradually drawn in and consumed. There is a danger in open troughs or pans, especially of zinc, which must not be overlooked, and that is the turning acid of the food by great exposure to the air, and the difficulty of thorough cleanliness without the waste of a good deal of food.

Of these various plans, the bottle is by far the cheapest, and, with a little care, it is quite effectual. Various makers of bee-apparatus have introduced slight modifications in their method, tending to convenience and safety.

The two special seasons when it may be advisable to give supplies, are the spring and autumn. When, at the end of February or early in March, some warm days have promoted activity in the hive, and its inhabitants are coming forth for flight after their long winter imprisonment, and are going in search of pollen and other food, it is desirable to examine the internal condition of affairs, so as to ascertain whether unwonted activity means scantiness of stores, and the need of searching outside for food. Should the supply of sealed honey be almost exhausted, it will be necessary to give a moderate, but continuous, quantity of syrup to avert starvation. For the reason previously mentioned, it is well not to err on the side of too great liberality. Let the bees have little more than enough for their probable daily wantssay, for a strong stock, about three ounces a day.

It is also important not to fill large bottles with syrup, otherwise there will be danger of the liquid 
running too freely, if a very warm day succeed a cold night, as the air in the bottle will expand too rapidly from the heat, and force out the syrup, to the imminent danger of the bees.

But, it is not only starving or much impoverished stocks which may be advantageously supplied with food early in the spring. If left to themselves, the wise insects will not promote breeding, till they can see their way to a constant in-flow of new nourishment for the rearing of the young. If, then, the queen is encouraged to lay, by an artificial supply, she will begin depositing her eggs much earlier than she otherwise would. Moreover, if the mass of the population are induced to remain at home, instead of going out for honey and pollen, the warmth of the hive will be better maintained, and the developing young will have more attendants about them. The most experienced apiarians, therefore, strongly recommend careful spring feeding; and one point in the carefulness is the constancy of the supply once begun, unless there is plenty of honey in the hive. In cases where this precaution is overlooked, the hungry workers will consume hundreds of newly-laid eggs, and will drag the young larvæ from the cells, thinking that their coming to maturity would involve a general starvation. On the other hand, it is necessary to see that no storage is going on in the brood part of the combs, through too liberal feeding. In points of this kind experience is the best teacher, and here the skilfulness of the bee-master is shown.

Another matter of great importance in spring feeding, is to see that the syrup supplied is not too thin, otherwise there will be danger of dysentery. 
Again, it must be well boiled and properly prepared, or what happens to be deposited in the cells will crystallise, and become worse than useless, as the bees can only with great difficulty consume or remove it in that state. The following is the proper method of preparation: Take of loaf sugar $3 \frac{1}{2} \mathrm{lbs}$., and boil in a quart of water. While boiling, add a table-spoonful of vinegar, and continue the boiling for ten minutes more. Strain the liquid, and it is ready for use. It may, with advantage, be supplied to the bees while it is lukewarm. The addition of the vinegar is an important point, as it converts the cane-sugar into glucose, or grape-sugar, which is much less liable to crystallisation.

In bad weather throughout the spring, the watchful apiarian will give his bees some artificial food, unless they have abundant stores in their hives.

Nor must it be forgotten that, if the production of brood is to be stimulated, some nitrogenous food will be necessary. When crocuses and willow-blossom are plentiful in the early spring, the bees will collect sufficient pollen from these sources, to provide for their wants in the above respect. But, failing a natural supply of such azotised material, pea-meal forms a good substitute, and is readily made use of by the workers.

In summer, it is only swarms or casts, as a.rule, that ought to be in any need of this kind of help; but, as autumn comes on, especially if the bees have been seriously deprived of their hardly-earned supplies, it will be necessary to make up to them some of that of which they have been denuded. With skeps, the only guide as to the condition of food 
stores is the weighing-machine. If this indicates a less total than from twenty-five to thirty pounds, it will be advisable to supply syrup till the requisite weight is attained. With bar-frame hives an examination of the state of affairs is perfectly easy, and there is no difficulty in removing combs which are quite empty, and are not needed for the clustering of the bees. Those which are left should each contain six or seven inches square of sealed honey, some two square feet, as a total, being considered about the proper quantity for a fairly strong stock to winter on.

For ascertaining the state of the hives in autumn, there should be an inspection of them about the middle of September; and, if necessary, the feeding should then be begun. It may be continued through October, but not later; otherwise there are dangers to be incurred. The first is, lest the evaporation of a certain amount of water from the stored syrup should not take place, and consequently, being left unsealed in the cells, it should ferment, and produce dysentery among the bees. The second is, lest there should not be sufficient warmth in the hive for the elaboration of the wax needed for sealing the filled cells; in which case, also, dysentery is likely to occur, when the immatured syrup is consumed.

Syrup given in autumn must be thicker than that supplied in spring, and should be made of five pounds of sugar to one quart of water, a tablespoonful of vinegar being added, and the mixture well, but carefully, boiled.

Sometimes, when bee-keepers have neglected the feeding of their stocks till late in autumn, they 
try to atone for their remissness by giving a supply of flour-cake-a baked mixture of sugar and peameal-on the top of the frames. This practice is not advisable, as the nitrogenous food is almost certain to stimulate breeding; and if this happens when the temperature is too low for the development of eggs and larvæ, great mischief may be done. The danger from this source will be very much in proportion to the weakness of the stock.

If proper attention has been given to the bees in autumn, they should be left quite undisturbed during the winter; for each time of excitement causes a considerable consumption of honey, to make up for the exertion to which the insects have been aroused. There is, also, the risk of chilling the hive, and lowering the temperature to a point fatal to many of its inhabitants. If, however, it becomes known to the bee-keeper that any stock is in a starving condition, no liquid food must be given, but barleysugar, or sugar-cake, may be laid on the frames. One evil of the former of these is, that it is apt to deliquesce faster than the bees can consume it, and running down the combs, makes a mess; while, if supplied too sparingly, it will not afford enough nourishment to the whole population to avert their starving. To obviate these dangers, it has been recommended to let it liquefy to a condition of toughness, and then, having put it into a bottle tied over the mouth with close canvas, to supply it in the same way as syrup.

Mr. Hunter gives the following directions for making sugar-cake, of a kind superior to barleysugar of the shops for bee-feeding purposes:- 
"Break up three pounds of loaf-sugar, place it in a saucepan or preserving-pan and pour half a pint of cold water upon it and half a wine-glass of vinegar. These are all the ingredients required. Prepare a fire in a grate, the top bar of which will let down in a similar way to that in an ordinary kitchen grate, taking care, however, that, at the commencement of the operation, the bar is up in its place, and the grate full to the top with glowing cinders or wood embers, so that a great heat may be obtained without any flame. Place upon the fire the saucepan containing the sugar, and stir it without ceasing. In a few minutes it will begin to assume the character of dirty broth, which will have anything but a nice appearance, but presently a thick scum will rise, and the mass will try to boil over. As soon as this is observed the saucepan should be removed from the fire, until the ingredients have cooled a little, when it should be set on the grate again, in such a way that only a small part of it is over the fire. The boiling will then go on on the exposed side, and as the ebullition takes place the scum will be forced to the side not over the fire, whence it may easily be removed with a spoon. Thus, the saucepan is held in the left hand, the spoon in the right, and the saucepan being on the left-hand side of the grate, with its right side exposed to the action of the fire, the scum will retreat to the left or cooler side, and will be in the handiest position for removal, as will be evident in a few minutes to any one trying it. After a quarter of an hour of this treatment the mixture will have become in a great degree clarified, when it should be removed from the fire while the 
top bar of the grate is let down, so as to permit of its nearer approach to a greater heat. Should there be any irregularity of the fire, it should now be corrected, but flame should be prevented, as the mixture, having parted with its water, will be liable to take fire if brought into contact with flame. It will be well here to remark that so long as the scum remains on the syrup there was a tendency in the whole to boil over, since the water evolved in the form of steam while the boiling was going on, accumulating in a body, would lift the scum above the saucepan to enable it to escape, but when the scum was gone the water would be evolved in bubbles of steam, which would crackle but not boil over unless a very intense heat were applied. The duration of the boiling of the clarified syrup, before it becomes liquid barley-sugar, will depend upon the amount of heat and the consequent evolution of water to which it is subjected; but trials may from time to time be made by dropping a little on some cold surfaces, to see if it becomes brittle, and when that state is arrived at it is done. Pour it into a tin dish, set it in a dry cool place until it becomes hard, and then, by striking the tin on its under side, the whole of the barley-sugar will be splintered into fragments, when it may be placed in bottles and corked up for use as required."

We have thought it advisable to quote these directions in extenso, as the feeding material thus made is cheaper-by about half the cost-than what is bought in shops, and being, moreover, not twisted like ordinary barley-sugar, it can more conveniently be placed on the top of frames, or over the feedinghole of a skep. 
The deliquescence of solid sugar-food is a source of some trouble. It may, in part, be obviated by laying the cake on coarse canvas, which will keep pieces from falling between the combs, and will help to delay liquid drops till the bees can consume them. But the most effectual plan to be rid of all these inconveniences, is to see to the proper amount of food being stored in the hives by the end of October. 


\section{CHAPTER XXII.}

W I N TERING BEES.

False and True Hybernation-Temperature of Hive in Winter-Necessity for Quiet during Winter-Structure and Winter-packing of Bar-frame Hives-Prevention of Draught and Condensation of Vapour-Supply of Water.

THE honey-bee differs from nearly all the wild varieties, as well as from hornets and wasps, in being adapted to live always in societies. Most other insects of the hymenopterous order become torpid in winter, or perish, with the exception of some queens, who survive to continue the race. Those which really hybernate are able to endure a considerable degree of cold; and, thawing under the influence of warmth, they can resume the functions of life. It is not so, however, with bees. Queens alone would be quite unable to continue the race, as they could neither build comb, nor supply food to the larvæ, nor keep up the heat required for the development of the young. For all these purposes, workers in considerable numbers are necessary. But this very concourse implies the production of heat by respiration; and, as a matter of fact, we find that all through the coldest weather of winter a temperature of over $60^{\circ}$ Fahr. is maintained in the hive. As 
a result of this, bees do not really hybernate, or even become dormant. When cold is very intense, they maintain a constant tremulous motion, as if they knew that the expenditure of muscular fibre would, by the consequent oxygenation, cause the evolution of heat; or, as if cognisant of the most modern theories of "heat as a mode of motion," they were aware that the very flapping of their wings would tend to raise the temperature of their dwelling.

A bee is chilled by a less degree of warmth than $50^{\circ}$ Fahr.; and if actually frozen, or exposed to cold at or near the freezing point of water, it cannot be revived. These facts have a very important bearing on the art of apiculture. For, in the first place, it may easily be understood that, if bees are tempted abroad by sunshine in winter, or when a bitter wind is blowing, they may perish by hundreds, through becoming torpid with cold while resting a few minutes in some shade, or by being chilled in the ungenial air. For this reason it is advisable to shelter hives from the mid-day and afternoon sun, as the danger just alluded to increases with the lateness of the hour at which the bees may be enticed abroad by the sunshine.

Then, secondly, it must be remembered that, as the bees are animate all through the winter, a constant consumption of stores is going on, and that disastrous consequences may ensue from mistaken notions as to their remaining torpid, and needing no more food than do hybernating dormice or polar bears.

Thirdly, as an easy deduction from the foregoing 
facts, everything which stirs the bees to activity, such as supplying fresh food, or disturbing the hives for any other purpose, means an increased consumption of nutriment, proportional to the activity aroused.

Fourthly, any general excitement in cold weather, leading to the wandering of individuals from the cluster, entails the risk of their being chilled, and rendered so inactive as not to be able to return to the warmest part of the hive, and consequently perishing.

These facts further suggest the importance of taking measures to prevent, as far as possible, the escape of warmth from the hive. Various precautions are adopted for this purpose. The straw skep is, in itself, a bad conductor of heat, and if made thick and strong, will usually enable the bees to maintain a sufficiently high temperature. Still, in excessively cold seasons, it is advisable to wrap straw hives round with matting, sacking, or some other material, in order still further to guard against chilling.

With bar-frame hives several points should be attended to. In the first place, it is a great advantage to have their walls double, with an air-space between them. It is even better to fill this space with cork-dust, saw-dust, bran, or chaff, to prevent any circulation of air between the outer and inner walls.

Then, it is important to remove empty combs at the beginning of the cold season, and to confine the bees in as small a space as possible, so that their number, constantly diminishing in winter, may suffice to keep up the necessary temperature. 
Again, it is of some moment to see that there are no considerable apertures in the coverings of the frames, or in the corners of the hive, by which a current of warm air out of, and cold air into, the hive may be set up.

Once more, if cushions of chaff be placed behind the frames, to fill up some of the empty parts of the hive, an additional security will be furnished against the lowering of the temperature.

In order still further to prevent separation from the cluster, and unnecessary activity, the most skilled apiarians recommend that, in autumn, holes should be made through the combs, near their tops, to serve as passages from one to another, as they are emptied of honey, without the necessity of the bees going down to the bottoms of the combs, in order to reach the other sides or different combs.

Another point of great importance in wintering bees, is the prevention of the moisture, produced by their breathing, from condensing in the hive. It should either be allowed to escape by upward ventilation, as strongly recommended by Langstroth, or by laying over the frames of wooden hives a porous material, which at the same time prevents the escape If heat. Light matting, covered with thicknesses of I suse-flannel or old blanketing, will answer the $\mathrm{p}$ rpose very well. The constant evaporation from th upper surface will prevent dampness to any ser sus degree in the lower thicknesses of material. For ourselves, we prefer the method which most effectually prevents the escape of heat, while also securing that vapour shall not be unduly condensed.

The question of ventilation, especially in winter, 
is still under debate. It is alleged, on the one hand, that it must be of advantage to get rid of all products of respiration, and that this can only be done effectually, by leaving a passage for the air supposed to be vitiated by the breathing of the bees. On the other hand, it is asserted, and the fact is incontrovertible, that the insects themselves most sedulously stop every crack and cranny, above all, in the tops of their hives; and seem to strive, by all means in their power, to prevent the escape of air, which would carry away warmth. The argument is that their natural instinct is certain to be right-that it can only have arisen, or been bestowed, for the benefit of the bees. We must acknowledge there is great force in this reasoning; and we prefer, therefore, to secure both the theoretical point relating to sufficient ventilation, and the practical recognition of the preference of the bees for complete coverings, by using the materials we have recommended above, leaving no apertures for the direct escape of air and warmth at the top of the hives.

The German apiarians lay considerable stress on the necessity of supplying the stocks with water so long as any breeding is going on. Von Berlepsch and G. Eberhardt, in an article in the Bienenzeitung, write as follows: "The Creator has given the bee an instinct to store up honey and pollen, which are not always to be procured, but not water, which is always accessible in her native regions. In northern latitudes, when confined to the hive, often for months together, they can obtain the water they need only from the watery particles contained in the honey, the perspiration which condenses on the colder parts of 
the hive, or the humidity of the air which enters their hives.

"Vital energy in the bee is at its lowest point in November and December. If, at this time, an unusual degree of cold does not force her to resort to muscular action, she remains almost motionless, a deathlike silence prevailing in the hive ; and we know by actual experiment, that much less food is consumed than at any other time. Breeding having ceased, the weather-bound bees have no demands made on their vital action, and we have never known them at this time suffer from want of water. As soon, however, as the queen begins to lay, which occurs in many colonies early in January, and in some by Christmas, the workers must eat more freely, both of honey and pollen, to supply jelly for the larvæ, and wax for sealing their cells. Much more water is needed for these purposes than when they can procure the fresh nectar of flowers, and the want of it begins to be felt about the middle of January. The mnnistakable signs of the dearth of water in a colony, are found in the granules of candied honey on the bottom of the hive." These authors go on further to say: "After protracted and severe winters, of every six bees that perish, five die for want of water, and not, as was hitherto supposed, from undue accumulation of fæces. Dysentery is one of the direct consequences of water-dearth, the bees in dire need of water consuming honey immoderately, and taking cold by roaming about the combs."

In our climate there is, usually, throughout the winter such an abundance of moisture in the air, that the point of complete saturation is often reached, 
and, except in very exceptional seasons, there will be little need to supply water to the hive before March. As a precautionary measure, however, we see no reason why some may not be given earlier, if great care is taken against its escape among the combs. For safety on this point, it would be best to give it in shallow troughs or pans at the bottom of the hive. 


\title{
CHAPTER XXIII.
}

\author{
BEE-STINGS.
}

Gentleness necessary in Manipulation-Causes of Irritation of BeesExamination of Stocks-Treatment of Stings-Remedies-Effects of Stings-Inoculation-Bee Dress-Smoke and its Uses.

THERE are some personal requisites, in addition to what is called "bee-dress," if immunity from attack is to be secured. The first of these are, calmness and self-control. Many persons become so much alarmed by a single bee buzzing about them, that they begin fighting and buffeting the insect, with the idea of driving it away. No surer method can be devised for inciting its anger and its persistent efforts to wound. If, on the other hand, perfect quietness is maintained, it will rarely happen that a buzzing bee will sting. When mischief is really meant, the attack is usually delivered with great speed and directness. Even if stung, it is much the best policy to be as self-possessed as possible, lest violent movements and angry acts should invite other bees to use their weapons; and they are the more likely to do so, if the first offender be crushed; for the smell of the sting poison and of murdered comrades readily stirs the wrath of the insects. 
As a rule, those who are accustomed to manipulate hives gently and fearlessly, may do so without the protection of veil and gloves. We have, however, mentioned the exceptional cases of persons who appear to be naturally offensive to bees; and such individuals must either clothe themselves against the possibility of being stung, or altogether avoid apiculture.

It is also true that, under some circumstances, bees become, like human beings, unaccountably irritable; and then it is better to keep at a safe distance from them, or to approach them clad in bee-dress. It is especially maddening to them to become entangled in the hair of the head or face, and if one of them has unwarily thus ensnared itself, it is advisable to extricate it as speedily as possible, or it will assuredly inflict a wound.

Woollen gloves, and some kinds of leather ones, seem also to be very objectionable to the insects; anything, in fact, which obstructs their freedom of motion, immediately throws them into a passion.

One simple, but very necessary precaution, is, to avoid breathing upon them, when observing them or examining the combs of a bar-frame hive. Blowing at them infuriates them, and they will savagely fly at the face of any one attempting it. Particular electrical conditions of the atmosphere are said to make them irascible. On very hot days, also, they are liable to get out of temper ; and showery weather, which drives them frequently home from work, appears to put them in bad humour.

Again, if they have lost their queen, or if she is absent on her nuptial excursion, or if any other event 
has thrown a hive into excitement, the workers will be likely to show their feeling by some passionate onslaught on the innocent onlooker. There is no disguising the fact that they are very quick-tempered creatures, and often act with an utter want of discrimination in the matter of stinging.

The time most suitable for the examination of stocks, and for any other processes of manipulation, is when the weather is fine, without being sultry or oppressive, and when very large numbers of the older bees are out at work. It is these who are most pugnacious, the young ones being comparatively gentle.

If several, or even one, apparently intent on mischief, should angrily buzz round, the best plan is to thrust one's head into sorne bush. This, for the most part, baffles the assailant, who seems unable to find its intended victim, and very soon flies away.

When actually stung, the first thing to be done is to extract the weapon, which the unfortunate insect almost invariably tears out of its body, with the poison-bag and muscles, as it flies off. If left in the flesh, the muscles, by their automatic action, drive the barbs in deeper and deeper, the poison also flowing more copiously into the wound. Directly the sting is removed, avoid all rubbing of the part affected, but at once press upon the puncture a hollow key, taking care that the exact spot pierced comes in the centre of the opening of the key-tube. By this means the poison will be prevented from extending in the surrounding capillaries, and from being carried to the neighbouring parts. Moreover, some of the acrid matter will be squeezed out, and so comparatively little inconvenience will follow: The pain will be much 
relieved if a strong solution of ammonia be forthwith applied ; or, failing this, carbonate of soda or of potass, all of which alkaline substances will counteract the acid poison. Should none of these be at hand, bathing with cold water, after the use of the key, will wash away the liquid squeezed out, and will dilute what remains in the wound. The application of dry earth is also recommended, and may do good, both by absorbing any of the fluid expressed from the puncture, and by its alkaline reaction destroying the potency of the poison.

There is, indeed, a long catalogue of remedies vaunted by various apiarians as certain palliatives, if not absolute cures, of the pain and swelling induced by the stings of bees. Among these may be enumerated the following:- the juice of the ripe berry of the honeysuckle; the milky liquid of the white poppy stalk; the juice of tobacco; the leaves of the plantain, or of the dock, bruised and applied to the wound. Bevan recommends spirits of hartshorn, of which ammonia is the chief component. Sliced onion or leek is very strongly praised as an antidote by some writers in our bee journals.

The principles of chemistry undoubtedly point to alkaline solutions as the proper kind of application. There can be no doubt that the poison is acid in its reaction. Any one may test this by collecting a drop or two, and putting the liquid on to litmuspaper. The characteristic change of the blue colour to red will, at once, indicate the nature of the substance. Consequently, the natural neutraliser of its properties will be an alkali of some sort.

Should faintness and prostration come on in 
consequence of one or more stings, as happens in the case of certain constitutions, smelling-salts (ammonia), or other usual stimulants to the nervous system and heart-action, must be applied, and medical aid should be summoned; but the cases in which such steps become necessary are comparatively rare. Certainly not one person in a thousand need be terrified from bee-keeping by the fear of serious consequences from being stung.

It is true the effects of the poison are, in most cases, very unpleasant, severe pain being felt for a few minutes, succeeded later by swelling, smarting, and irritation; but these symptoms soon subside, and leave no ill consequences. Moreover, it is a wellascertained fact that, after numerous stings, some effect is produced on the blood-a sort of inoculation -which renders the result of the poison less and less severe. Many bee-keepers, indeed, pay almost no attention to punctures from their pets, as pain and swelling are quite insignificant in their cases. Herr Klein, in fact, recommends apiarians to get purposely stung, so that, as speedily as possible, they may secure to themselves this immunity from discomfort. IVe doubt whether many persons will have the hardihood to accept his advice, or will consider such a violently homœopathic remedy less objectionable than an occasional attack of the malady. ${ }^{1}$

Our advice, on the contrary, is that the bee-keeper, especially if timid about being stung, should take all reasonable precautions against attack. For this

1 We may remark in passing that we have been informed the poison of the bee is used under the name of $A$ pis as a recognised and potent medicine by homœopathic practitiorers. 
purpose he should provide himself with a bee-dress, consisting of a sort of bag of black net, which will slip over the head and shoulders, and may be fastened round the waist by an elastic band. It should be large enough to admit of wearing a hat with a tolerably broad brim. This will cause the veil to stand away from the face sufficiently to prevent any angry bee from getting at the flesh. Sleeves of black calico should be attached to it, and may be secured at the wrists by tying, or by elastic bands. Such a dress is best worn without a coat but over a waistcoat, as greater coolness and freedom of movement will thus be attained. The hands may be protected by cotton or india-rubber gloves, and the sleeves should be fastened over these round the wrists. If, in conducting any extensive manipulations, bees, half-stupefied or weak from their youthfulness, are likely to be crawling about the ground, it is advisable to tuck the trousers inside the boots, or to tie them round the ankles, or in some way to prevent the ascent of any insects beneath the clothes.

Thus protected, the novice may, with perfect confidence, conduct such operations among his hives as he may deem necessary. He should be careful, however, not to let his security induce any roughness or carelessness in handling the insects or their combs and hive-frames. As much quietness and gentle treatment should be used, as if freedom from attack depended entirely on such methods; for, it is certain that by great tenderness in handling, bees become accustomed to those who have to do with them; whereas, a hive once enraged by accidental or rough 
manipulation will remain ill-tempered and passionate for a long period, and will consequently become very difficult to deal with. If, by any means, a stock has thus been excited, it is advisable to leave it alone, and let it quiet down as speedily and thoroughly as possible.

The use of smoke must not be forgotten, as one of the most potent means of controlling the passion of bees, and causing them to gorge themselves, in which condition of repletion they are much better-tempered than under any other circumstances.

Various kinds of "smokers" are in use among apiarians, and different substances to be burnt for producing the smoke are recommended. Among the former we may mention the apparatus of Messrs. Abbott of Southall, Neighbour of London, and Blow of Welwyn, Herts: while brown paper, old sacking, touchwood, puff-ball, rags moistened with a solution of nitre and dried, will afford sufficiently satisfactory means of fumigating stocks. Bee-keepers will find a few vigorous puffs of tobacco very effectual in alarming the bees, and driving them to fill their honey-bags. There will, however, be some risk of being stung, as one cannot conveniently smoke with a veil on, and where lengthened manipulations are required, it is often necessary to repeat the fumigating process, if the bees seem recovering from their first dose, or if many, absent at its administration, have returned to their homes while these are being disturbed. We recommend, therefore, the presence of some kind of fumigating apparatus in every apiary, and in the selection of one it will be found very convenient to have amongst its advantages the ability 
of retaining in a smouldering condition, by a gentle through-draught, the materials inserted for burning. The "smoker" should always be properly filled with the stuff from which smoke is to be generated, and smouldering should go on continuously in the material when laid aside in the intervals of more active use. Great trouble and inconvenience arise from having repeatedly to re-light the paper, rag, or other articles used. One means of obviating this, is to stand the apparatus point upwards, when the funnel will act as a chimney, and aid in keeping up a quiet current of air. 


\section{CHAPTER XXIV.}

PASSIONS AND EMOTIONS OF BEES.

Affecti in for Queen and Bro od-Recognition of Friends and Strangers

-Fear-Angar-Covetousness-Benevolence-Remorse-Hope Instinctive or Sense-action.

CERTAIN difficulties surround the question of the emotions exhibited by the lower orders of animals; since it is easy for imagination, or, at least, the interpretative faculty of observers, to lend so special a colouring to actions, that the significance given to appearances will vary exceedingly, according to the subjectivity of the individual recording and explaining phenomena. There can, however, be little doubt that a feeling of affection exists between the workers and the queen, and is reciprocally manifested. The symptoms of distress at the loss of the hive-mother; the reverent attention paid to her by her special attendants; the joy at her restoration after temporary removal; resentment shown to a substitute while any hope of recovering their rightful monarch remains; the devoted following of her when a swarm issues, all tend unmistakably, we think, to show that genuine love is the bond between the undeveloped females and the one fully developed in the 
community. As to the drones, we can give credit to one only-the royal spouse-for any share in this emotion, and, indeed, we should be inclined to place the one exception in a different category.

As to affection for all belonging to one community, the facts are very conflicting. In the first place, drones appear to have the entrée of any stock. We can see that the obvious benefit of cross-breeding is thus more likely to be secured; but it is impossible to imagine this advantage to influence the bees. Again, the manifest hostility shown by one colony of workers to individuals from any other, is doubtless the result of the fear of stores being robbed; while drones are allowed free passage, because they do not transfer honey from one hive to another, and take no more than suffices for their personal needs. But, while there is no doubt of exclusiveness being shown by the workers towards other workers, we have little evidence of any actual affection existing among the members of the same community. It is true that the crushing of one bee enrages others who become aware of the circumstance, but the anger is probably the result of fear of further destruction, rather than grief at the loss of a friend. The death of individuals in the ordinary course of nature, does not seem to excite any emotion beyond the desire to get rid of the body, which is unceremoniously taken in the jaws, aided by the legs, of some enterprising survivor, carried to a distance from the hive, and then let fall. Bees never attempt to extricate co-workers from imprisonment in spider-webs, or from any other difficulty into which they have fallen.

We must, however, acknowledge that an intense 
affection for the developing brood is shown by the workers. It matters not whether the combs containing it belong to their own hives or to others. They will cluster upon the cells to maintain the required warmth, will supply the larvæ with food, and render every attention required by the young. When the offspring have come forth, some rather rough, but manifestly kindly meant offices, are performed, in clearing away the remains of the cocoon, combing out the imperfectly expanded wings, \&c., but loving care ceases with the need for it; and, in adult life, the most we can predicate is a placid indifference to each other's presence, unless, indeed, anger should be aroused by some accident, when a more or less serious battle will take place.

That bees are susceptible of fear we have made evident in what has been said about the effect produced on them by smoke, by drumming, and by any sharp vibration of their combs.

The passion of anger is decidedly prominent in their nature. It is, indeed, apt to rise to an uncontrollable degree on very slight provocation, particularly, as we have mentioned, under certain conditions of weather, and especially of temperature. Moreover, the exhibition of it is frequently unrestrained by the fact that the use of the sting generally means the death of the aggressor, orving to the impossibility of withdrawing the barbed weapon, without tearing away part of the vital organs also.

Covetousness is also a powerful emotion with these insects. We have already spoken of the dangers of allowing bees a taste of sweets from other hives than their own, and of the almost ineradicable longing for 
the honey stored in other communities, if once pilfering has begun. And yet we can hardly ascribe sheer selfishness as the motive for robbing. We see, in fact, that the life of the worker is one long series of labours on behalf of a progeny not its own, and for a community in which its own existence is of very short duration. While, therefore, we allow that there is shown a desire to avoid honest toil, if dishonest courses will yield supplies more readily, still we must admit that the good, not of the individual but of the state, is the actually impelling principle of the plunderer. The amount of infatuation shown in the eagerness of bees for sweets is well described by Dr. Langstroth: "No one can understand the extent of it until he has seen a confectioner's shop assailed myriads of hungry bees. I have seen thousands by strained out from the syrup in which they had perished, thousands more alighting even upon the boiling sweets, the floor covered and the windows darkened with bees, some crawling, others flying, and others still so completely besmeared as to be able neither to crawl nor fly-not one in ten able to carry home its ill-gotten spoils, and yet the air filled with new hosts of thoughtless comers." They appear, indeed, unable to perceive the disasters of companions, and rush heedlessly on to destruction, the victims of which lie all around them.

From what has been previously said, it will be seen that we cannot with any show of reason assign to bees such complex emotions as benevolence or remorse. They are incapable, on the one hand, of appreciating the combination of circumstances involved in the distress or need of a friend, and the means of aid suitable 
for relief; and, on the other, having apparently no distinct knowledge of how the doing or omission of any action will affect other individuals, they cannot be sensible of regret or satisfaction in having done, or neglected to do, any specific deed.

We might, probably, with equal assurance deny to bees the possession of hope. It is true they prepare combs, store honey and pollen, attend upon the queen when laying, and carefully nurture the larvæ, as if they anticipated the rearing of a progeny ; but it is d:fficult to conceive that these various duties are carried out with any definite notion of the future. We incline rather to the belief that a series of sensations promotes a corresponding series of actions, the combination, correspondence, and harmonising of which, for the general welfare, is wrought out by laws of which we know nothing, or, we would much rather say, by the operation of the infinite and Divine IVill, without the direct control of which we cannot imagine this complex universe could hold on its way. Nor need we hesitate to assign its working to such comparatively insignificant objects as hives of bees, when we have the emphatic declaration of our Lord that not one sparrow lights upon the ground for its food without the knowledge of God; that $\mathrm{He}$ feeds the ravens, clothes the lilies with bsauty, and numbers the very hairs of our heads. 


\section{CHAPTER XXV.}

\section{INTELLECT AND INSTINCT IN BEES.}

Intellect in Man and Animals as related to Immortality-MemoryJudgment-Instances of Attention-Prevision-Provision-Instinct -Manifestations-Bearing on Evolution.

THERE has been a singular unwillingness on the part of many religious writers to acknowledge among animals inferior to man the possession of true intellectual faculties. This has arisen, partly from the desire to keep man on a pedestal immensely exalted above the rest of the creatures more or less allied to him, and partly from the fear that the concession of high faculties might seem to imply the immortality of all living beings or of none.

The first of these reasons which have influenced writers may be dismissed with the remark, that the position of superiority which man has held, and more than ever holds, depends, not entirely upon his powers of mind, but upon a combination of faculties, physical, mental, moral, and, above all, spiritual ; so that there need be no grudging of endowments of intellect to other creatures on earth beside ourselves. As to the second point, we see no necessity to consider that it supplies a dilemma. Man and all other 
animals may be immortal, for aught we know; or man may, according to current opinion, stand alone in this respect; but the yea or nay of the question need not rest upon the foundation of the gift of intellect. We know, indeed, so little of the actual connection between mind and body, the senses and the intellect, that it becomes quite unsafe to base upon our knowledge any theories as to the conscious possession of power when the body ceases to live. The discussion of this subject must rest on other and higher grounds altogether, and so will lie outside the limits of our work. But we may well inquire how far true intellectual processes go on in bees. And the best way to do this will be to take some of the strictly intellectual faculties, and see whether they really exist among these insects.

Firstly, with regard to memory. Without entering upon theories as to the simple or complex nature of the means by which we recall feelings, events, sensations, or ideas, we may take it for granted that memory is a sign and an attribute of considerable mental endowment. Now that bees distinctly remember, there can be not the slightest doubt. Whatever may be our opinion as to the faculty by which they find their way back to their hives from long distances, there is clear evidence of their recollecting particular places, in the circumstance that, for a day or two after the securing of a swarm, certain bees will hover round the spot from which the hiving took place. Again, it is possible to train these insects to come day after day to a particular place, by supplying them with food under conditions in which their senses of sight and smell would not 
inform them of its continued presence. Moreover, after being seriously disturbed, a stock appears to remember, for many days, the molestation, and to be eager to resent further intrusion, unless peaceable behaviour is strongly enforced by smoke or an anæsthetic.

Secondly, as to judgment. This involves the previous conception of two ideas at least, the comparison of these, or their connection, at all events, and a decision founded on their connection. That these processes take place in the bee-mind, we are apparently warranted in concluding from several circumstances to which allusion has already been made. Let us recall, for instance, the fact that if, owing to an unusual influx of honey, the attachments of the combs seem insufficiently strong to bear the weight dependent on them, the workers proceed to make a new connecting layer, at the top of the hive, and of greater holding power. This they do by gnawing away the original one, and replacing it, one side at a time, by new work, the security of which is assured before the other side is proceeded with. Now, in this case there is a perception of an unusual, or, at least, an unexpected influx of stores, as well as of a certain strength being required to sustain the weight of them. Furthermore, there is a calculation, or comparison, founded on the two perceptions or conceptions, and an act of decision resulting from such comparison-apparently a clear case of judgment.

Again, let us revert to the manufacture of queens by the workers. If at the time of the removal or loss of the mother-bee in any way, there should be 
unhatched princesses in the hive, no attempt will be made to follow the course adopted in the absence of such royal progeny. In the latter case-i.e. when there is no royal brood-there must be a distinct conception, first of their bereavement; secondly, of the hopelessness of a sovereign appearing in the ordinary way. Then a judgment is formed of the proceedings necessary for making a queen, and action immediately follows. Not only so, but, as if to secure themselves against the repetition of their calamity, they prepare not one queen only, but several, so that, if the first which comes to maturity be lost, there may be others in reserve. A further act of definite judgment appears in this; for, if one only were produced and lost, they would be powerless to repeat the process, as all the rest of the worker brood would, in the mean time, have advanced far beyond the stage at which its transformation would be possible. The bees, then, with admirable prevision, forbear to risk all the future of their community on one hope of a queen.

Once more, we may notice the remarkable fact that, if a queen be removed or lost late in the summer, at the time when the destruction of the drones is drawing to a close, the males of that particular hive will be spared as long as there is any hope that a royal spouse may be needed. In this instance, too, we have what seems a distinct judgment of the necessity that there should be drones spared for the renewal of the progeny of the stock, and their consequent immunity from the death or banishment they would have undergone in a community possessing a fertile sovereign. 
Again, in the late summer, when supplies of honey from the fields begin to fail, the workers, even in a flourishing hive, will not only worry to death, or drive away to destruction, all the males which are adult, but will pull out of the cells the immature drones, and carry them from the hive. In this case we have two independent judgments. First, that, having a fertile queen, but no probability of further swarming, no raison d'être exists for the males among them; and secondly, that the unhatched males would, on emerging from the cells, be useless consumers of precious stores, and consequently are better destroyed.

Numerous other evidences of judgment might be adduced, such, for instance, as building drone-comb, i.e. cells of large size, when unusual space is required for quick storing of food, the different expedients for repairing, refixing, and giving direction to combs, in view of various difficulties to be encountered. But we have said, we believe, sufficient to make good the special point in question.

We might, perhaps, with advantage, have spoken of the faculty of attention, i.e. the direction of the mental powers to a particular end by the determinate action of the will. At every moment we may see, in a busy hive, evidences of this power. Indeed, in so complex a community, where so many operations are constantly going forward, where so many stages of social development are being passed through, where so many separate interests have to be regarded, and where the harmonious co-operation of individuals is of supreme importance to the general welfare, it is impossible that this faculty of attention should be wanting or unexercised. 
We have hinted at the prevision shown by bees. Now, if this really exists in them, we must acknowledge it to be one of the very highest endowments of intellect. It is that which in man removes him from the sport of circumstances, and gives him large control over his own earthly destinies. It is that which, when applied to events more or less unascertainable by the majority of men, proportionately awakes their astonishment, and creates a reputation for ability and high endowment. Now, that the faculty is possessed by bees is, we think, evident from many considerations. When, for instance, a hive has lost its queen, and has no hope of a successor, despair comes over the community, as the workers feel they have no longer an object in their toil. They seem to foresee the speedy end of their colony, and the consequent uselessness of collecting stores, or proceeding with comb-building.

Again, the destruction of the drones and dronebrood, when no longer of possible service, implies a knowledge that the males, if spared, will produce a scarcity of food, by uselessly consuming the stores, while the preservation, to a late period, of drones in a hive whose queen is lost near the end of summer, indicates a foresight of the possible need of males to mate with a young queen, whose advent is hoped for.

Without much risk of straining this line of argument, we might consider the storage of honey and bee-bread as a prevision, and not merely as a provision for the needs of winter. In like manner, the encasing in propolis of slugs, mice, or other intruders, when dead in the hives, may be looked upon as a 
safeguard against expected putrefaction. The cessation from grief for loss of a quẹen, when new royal cells are preparing, may be regarded as evidence of anticipated joy in a coming monarch. We acknowledge, however, that here the dividing line between reason and instinct becomes very narrow, and it is exceedingly difficult to determine the strict limits of either.

At this point, also, comes in the remarkable question of heredity. The causes and determining circumstances of this quality are at present very imperfectly understood; nor is it probable that anything like a complete explanation of the subject will be forthcoming. That it is, however, a most potent element in the subject of mental, as well as physical, characters cannot be disputed. To it, in fact, the possession of what we call instinct must be entirely referred, though it leaves untouched the actual nature of this endowment.

The definition of instinct is not a very simple matter, but we may consider it as a power, appearing in generation after generation of animals, by which, without instruction, they perform certain actions, or series of actions, tending to the welfare of the individual or of the race. We usually regard the purely intellectual operations as improvable by education. Instinct, on the other hand, neither requires, nor, in general, is aided by teaching. It is true that man has taken advantage of certain qualities, apparently instinctive, in particular animals, and has seemed to improve them by schooling them, as, for instance, in the case of pointers and setters among dogs; but it is rather, as it appears to us, the mental processes of the 
creature, which have been controlled and modified, and then the tendency to the reproduction of these has been transmitted by heredity. Pure instinct we, therefore, continue to regard as outside the plane of education.

The faculty as exhibited by bees is most astonishing. We have already enumerated many circumstances, which evidently have had their origin in this power, but we may well recall certain of these in illustration of this point.

Firstly, then, the shaping of the cells with definite and constantly repeated angles of the sides; the arrangement of them, so that the base of each is formed by the junction of the bottoms of three cells on the opposite side of the comb ; the preparation of abodes suitable in size, and in other special respects, for the larvæ of queens, drones, and workers; and the careful transition from one to the other of the last two-all these and other circumstances connected with the construction of their dwellings, attest the possession of an innate faculty needing no instruction from the elders of the hive.

Again, the gathering, in due proportion and according to varying needs, of honey, pollen, and propolis, must be attributed to this same occult endowment. The proper admixture of the different kinds of food, adapted to the varying ages of the larvæ; the preparation and administration of the "royal jelly," necessary for the development of queen-larvæ; the covering of the cells with waxen lids of different shapes, according to the nature of their contentsconvex on the male cells, nearly flat on those of workers, and somewhat concave on the honey stores- 
are other manifestations of an internal guide towards useful labour.

Once more, the series of remarkable facts connected with their respect and attention and service to their sovereign ; their treatment of queens introduced into hives possessing a queen, or without one; the permission, and even urging, of rival monarchs to fight à outrance; the expedients adopted to repair, if by any means it is possible, the loss of a queen-all these facts point, still further, to a power, by whose almost unerring operation extraordinary results are secured for the well-being and the very continuance of the race.

Nor is it easy to see how, on the principles of evolution alone, this faculty can have been acquired ; for the remarkable point, and one apparently inexplicable on the development-theory, is this, that the two portions of the community alone concerned in the actual propagation of the race are absolutely without the special endowment of which we have been speaking, at least so far as the particular directions of its manifestation just mentioned enable us to conclude. The queen among bees, unlike her representative among wasps, is quite unable to perform any of the processes preliminary to egglaying. She cannot secrete wax or build comb. She cannot fly abroad to collect honey. She has no means of gathering pollen. She can neither procure nor use propolis. So helpless, indeed, is she, that, bereft of attendants, she is unable to feed herself sufficiently to maintain life. The drones, if not so absolutely helpless, are equally incapable of all constructive work, of the power of collecting honey, 
making wax, building comb, guarding the stores against robbers, or even tending and nurturing the young brood. We see, then, the endowments of instinct in all their higher manifestations are conferred alone on the members of the community who cannot transmit them to posterity. Nor does the fact of the occasional appearance of fertile workers at all explain away the difficulty; for, as has been shown, such abnormal mothers produce only male offspring, which never inherit the special faculties of the undeveloped females, and consequently cannot transmit what they have never possessed.

If asked what solution of the difficulty we are prepared to offer, we confess, with satisfaction, to the retention of the undisproved theory that the Creator has, in His own inscrutable, but all-beneficent, way, specially gifted these insects with powers of a kind adapted to the highest welfare of their race, as we also believe $\mathrm{He}$ has given to other orders of beings, from the ant up to man, and on to angels, faculties to be used, not only for the benefit of the individual, the species, or the genus, but for the harmonious working of the universe He has called into being. To those, at least, who rejoice to believe in a personal God, who find an atheistic cosmos the most unthinkable of notions; who see a thousand mysteries inexplicable on any theory of unintelligent "natural selection," the study of the honey-bee provides reason for, and evokes the sentiment of, sublime adoration of an infinite First Cause, i.e. the Deity. 


\section{CHAPTER XXVI.}

\section{BEES IN RELATION TO FLOWERS.}

Connection of Plant-life and Insect-life-Reproduction of FlowersIntervention of Insects-Hermaphrodite Flowers-Cross-fertilisation-Cucumbers, Melons, \&c.-Poplars-Firs-Epilobium or Willow Herb-Cinerarias-Darwin's Experiments-NasturtiumFoxglove - Figwort - Salvia - Heath - Strawberry, Raspberry, and Blackberry-Apple and Pear-Altruism of Bees.

THE connection between insects and the plant-world, and the mutual benefits they render, have long been known to man. While the one kingdom is almost entirely dependent on the other for sustenance, and this, not only as regards food, but for dwelling-places also: the organic, but (so far as we can judge) inanimate, one of the two, requires the aid of the animate for the continued reproduction of many of its members.

It would lead us too far from the subject of this book to enter at all fully into the question of the complete interaction of plant-life and insect-life. In dealing with the relations of bees to flowers we shall, therefore, confine our remarks almost entirely to the important part played by these creatures in the reproduction of certain kinds of plants. 
It may, perhaps, be necessary, previously to entering on this subject, to say that in flowers we have organs analogous to, though widely differing from, those indicative of sex in the animal world. The functions, at least, are the same; and the combined action of the two sets is essential to the propagation of the race by seed. Unless pollen from the anthers is conveyed to the pistil, and, germinating there, imparts to the ovules vivifying nourishment, no seed will come to perfection, or will be capable of growing. While most flowers are hermaphrodite, i.e. produce both stamens (or anther-bearers) and pistils, it happens, in not a few instances, that certain flowers have anthers, and no pistils: while others, on the same plant, have pistils, but no anthers. Again, the antheriferous and pistiliferous flowers, in certain species, are found on different individual plants, so that, unless some agency were provided for the transference of the pollen, these species would inevitabiy die out. Now, the two means for this conveyance are the wind and insects. It is evident that the former can have only a very limited action, and would need for its effective service a great abundance of any particular flower, lest the fructifying grains should become the mere sport of the breezes, and fail to reach their all-important goal, and accomplish their all-needful function.

Moreover, in many cases, the position of the anthers in the flower entirely excludes the possibility of any currents of air assisting in the carrying of the pollen-dust to the pistil of the same or of different flowers. Hence there is a necessity for the intervention of insects; and that they may be induced to 
visit such flowers, and unconsciously effect the essential operation of fertilising them, nectar is secreted near the base of the stamens or the ovary, or in some position which will involve, in the gathering of it, the brushing off and conveying away of some of the pollen-grains. It is, indeed, a remarkable fact that fragrance and honey-bearing are scarcely ever associated with plants which can easily be wind-fertilised. Such flowers are, also, for the most part, inconspicuous; while those which need the agency of insects to aid in their reproduction are bright in colour, sweet in perfume, and more or less prolific in honey.

It must not be supposed, however, that even the hermaphrodite, or double-sexed, flowers are independent of the visits of bees and other insects. In ail of them cross-fertilisation, as Darwin has abundantly proved, ${ }^{1}$ is a most important factor in the continued vitality of any species, and cross-breeding gives an immense advantage in "the struggle for existence," where the conditions of life are not wholly favourable. Indeed, in many instances, special provision has been made by the Creator against selffertilisation : in some cases, by the anthers and pistil coming to maturity, in the same flower, at different times; in others, by the placing of the stamens in such a position relatively to the stigma (or top of the pistil) that it is not possible for the pollen-grains of the one set of organs to fall on the surface of the other. It cannot but be interesting to give examples of these various facts, and so to show the marvellous

1 For full and most interesting information on this point, vide Cross and Self-Fertllisation of Plants, by Charles Darwin. Murray. 
and necessary connection between the two kingdoms of nature.

Firstly, then, as well-known instances of pistilbearing and stamen-bearing flowers occurring separately on the same plant, we may mention cucumbers, melons, marrows, et hoc genus omne. Now, when these vegetables are grown under glass, whether in greenhouses or in pits, to which bees and other insects have little or no access, gardeners find it necessary themselves to apply the pollen-bearing portions of the one kind of flower to the pistil of the other. If this is neglected to be done, the fruit makes no progress, turns yellow, and dies. Where, however, the plants are grown in the open air, or are not so shut up as to exclude insects, they will be fertilised without the intervention of man; for bees of various kinds will certainly visit the flowers, and carry the life-giving dust where it is needed. In fact, we believe it might be asserted with confidence, that in all plants, where this separation of, what we may call, the sexes takes place, the flowers possess special attractiveness to the tenants of our hives; and it is well that this is the case, otherwise the continued existence of such plants would be seriously endangered.

As examples of diœcious genera, or those having pollen-bearing flowers on one plant and pistiliferous flowers on another, we may note the willows, the poplars, and the firs; and it is remarkable that these all are special favourites with bees. In the early spring, when breeding has been going on in the hives, and when the demands of the advancing larvæ require considerable supplies of pollen, the catkins 
of the willow are abundantly visited, and the diffusion of their fertilising powder is thus greatly promoted. The same may be said about the poplar, and, in all probability, the gathering of propolis from trees of the fir-tribe makes the bee the unconscious, but useful, instrument of carrying pollen from the catkins to the cones, though, from the abundance of the powder, and the openness of the scales of the cones, the wind is a sufficiently effective agent for its conveyance in this order of trees.

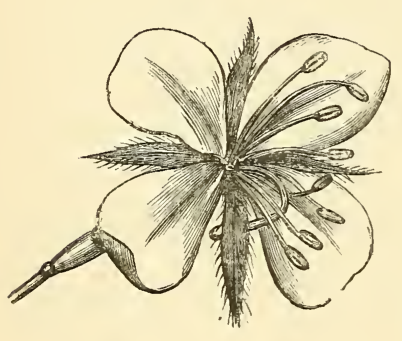

Fig. 70.-Epilobium Angustifolium. (Young bloom.)

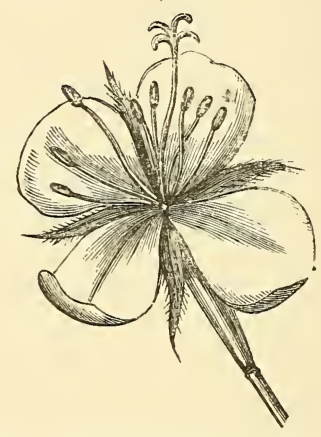

Fig. 7x.-Epilobium Angustifolium. (Old bloom.)

Passing next to cases in which the stamens and pistils of the same flower come to maturity at different times, so as to make cross-breeding a necessity, we may mention first some plants in which the pollen ripens before the stigma is ready to receive it. We have such a condition of things in the willowherb, or epilobium tribe. The pretty pink blossoms of a large variety of this genus are to be found, in summer, along the banks of brooks and running ditches. We will confine our remarks to the species 
distinguished by its narrow leaves, and hence named angustifolium. When the flower has fully opened, the eight stamens spread out, and their anthers shed the pollen. Bees visit the blossoms, and getting dusted with the grains, carry these away to other flowers of the same kind. And here, in passing, we may recall the fact of bees keeping to one species of plant during the whole of any one journey from the hive. The importance of this can be now better appreciated, when its influence on the fructification of blossoms is observed. But to return, the pistil of the willowherb remains, till the stamens have withered, curved round ou' of the way, and unable to receive any of their pollen. Then, after they are dead, it comes into such a position that it can take what pollen may be brought to it from younger flowers. For the conveyance of this it is dependent chiefly on bees, who do not fail to carry enough for the required purpose. In this way each blossom, by the agency of these insects, both gives and gets what is necessary for the continued life of the species; and without these unconsciously conferred benefits from insect life, no seeds of this kind of epilobium would mature.

Another instance, equally interesting, is seen in the well-known cineraria tribe. The plants of this genus belong to the composite order, in which what is usually called the blossom, consists of many flowers, grouped together on one head. In the example before us, there are nearly 200 thus aggregated. These florets separately open at different times, those of the outer circles coming before those nearer the centre. The pollen-tube of each is formed by five anthers, fastened together at their edges, and discharging their 
pollen into the space between them. At the lower part of this inclosure the pistil is growing, but is not in a condition to receive usefully the fertilising powder. It, however, as it advances, sweeps out, and carries up with it, the pollen-grains, so that they may be conveyed to other florets of the same or other blossoms, to effect their vitalising work. At length the pistil, with its brush on its summit, comes

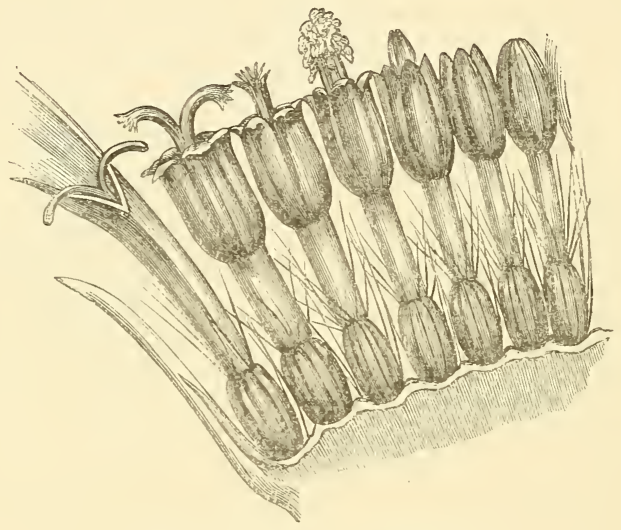

Fig. 72.-Cineraria. (Magnified.)

into view, but, even yet, is not sufficiently developed for fertilisation. In due course, however, the upper end splits, and exposes the surface of the stigma ready for the pollen, which must be brought from some other floret, and probably from some other blossom. Thus cross-breeding is effectually secured.

Another point for attaining this end is worthy of remark. The outer ring of florets is distinguished by long, coloured petals, which make up, in common parlance, the flower of the cineraria. These serve 
to render the composite head conspicuous, and attractive to insects. Some varieties, moreover, emit fragrant odours, and thus present further inducements for visitation. It is remarkable that, in these florets of the outer edge, the gay-coloured petals are developed at the expense of the anthers. Consequently, they produce no pollen, and their pistils have no brushes, as there would be no office for them to perform. The bright rays have accomplished their own special purpose, and the florets may well depend on others for pollen.

Now, as to the great importance of cross-fertilisation in this species, we may quote the experiments made by Dr. Darwin. ${ }^{1}$ He says: "Two purpleflowered varieties (of cineraria) were placed under a net in the greenhouse, and four corymbs (or bunches of flowers) on each were repeatedly brushed with flowers from the other plant, so that their stigmas were well covered with each other's pollen. Two of the eight corymbs thus treated produced very few seeds, but the other six produced on an average $4 \mathrm{I}^{\prime} 3$ seeds per corymb, and these germinated well. The stigmas on four other corymbs on both plants were well smeared with pollen from the flowers on their own corymbs; these eight corymbs produced altogether ten extremely poor seeds, which proved incapable of germinating. I examined many flowers on both plants, and found the stigmas spontaneously covered with pollen; but they produced not a single seed. These plants were afterwards left uncovered in the same house, where many other cinerarias were in flower; and the flowers were

${ }^{1}$ See Cross and Self-Fertilisation of Plants, p. 335. 
frequently visited by bees. They then produced plenty of seed, but one of the two plants less than the other, as this species shows some tendency to be diœcious.

"The trial was repeated on another variety with white petals tipped with red. Many stigmas on two corymbs were covered with pollen from the foregoing purple variety, and these produced eleven and twenty-two seeds, which germinated well. A large number of the stigmas on several of the other

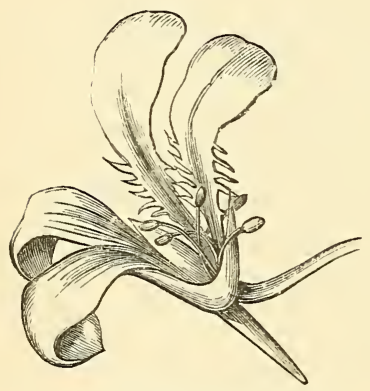

Fig. 73.-Tropeolum Majus. (Young bloom.)

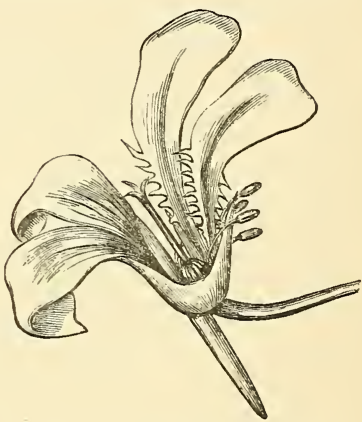

Fig. 74. - Tropeolum Majus. (Old bloom.)

corymbs were repeatedly smeared with pollen from their own corymb; but they yielded only five very poor seeds, which were incapable of germination. Therefore the above three plants, belonging to two varieties, though growing vigorously and fertile with pollen from either of the other two plants, were utterly sterile with pollen from other flowers on the same plant."

A condition similar to that described in the cineraria is found in the nasturtium (Tropocolum majus). In the young blossom may be observed the 
five stamens fully developed, while the stigma remain s quite out of their reach. Later, when all the pollen is discharged from the anthers, the pistil throws up its style and stigma, now ready for fertilisation, which must be effected by the transfer of pollen from some other blossom of the same or another plant of the species. This transfer is effected, usually, by the bees.

Another example of this non-coincidence in the times of development of the stamens and pistil is found in the foxglove (Digitalis purpurea), but the fertilisation is effected by the larger humble-bees. The two upper and longer stamens shed their pollen before the two lower and shorter ones. This arrangement partly avoids the risk of self-fertilisation, while their position, which changes just when the anthers, are ripe, enables them to smear the under side of any entering bee; while they also shed their pollen abundantly on the thickly-set hairs lining the mouth of the corolla. A second use is served by these hairs, viz., that of obstructing the entrance of the smaller kinds of bees, which could not so effectually fertilise the ovules. The larger sorts, in their raids upon the nectar, carry pollen from flower to flower, thus in the best manner bringing about the most desirable result of cross-breeding.

Passing now to plants in which the pistil develops earlier than the stamens, we may note the knotted figwort (Scrophularia nodosa). On making a section of a recently opened flower, the style, with its stigma, may be observed protruding just beyond the lip of the corolla, while the stamens are hiding away, as it were, in a little pouch below the entrance of the 
blossom. When fertilisation by pollen from another flower has taken place, the pistil droops and withers; while the anthers grow upwards to the mouth of the corolla, and present their nectar to the honey-seekers, for conveyance to other flowers of the species.

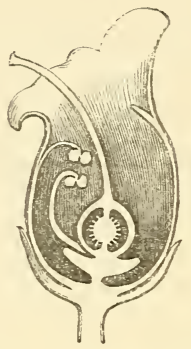

Fig. 75.-Section of Scrophularia Nodosa.

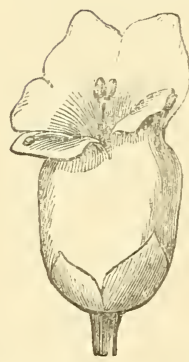

Fig. 76.-Scrophularia Nodosa. (Young bloom.)

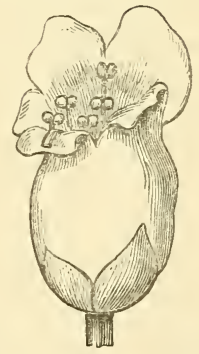

Fig. 77.-Scrophularia Nodosa. (Old bloom.)

In the common sage (Salvia officinalis) we find a very remarkble contrivance, by means of which the anthers, through a sort of hinge-like connective, are brought down on the back of a bee entering the flower. The pollen thus discharged is carried by the insect to other blossoms, in which the place of the withered stamens has been occupied by the stigma 
now ready to receive the grains. Thus again interbreeding is secured.

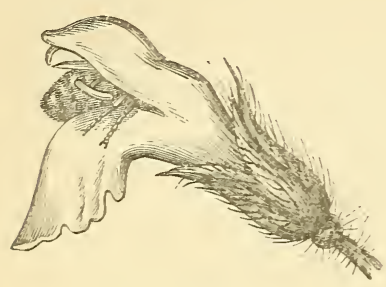

Fig. 73.-Salvia Officinalis. (New bloom.)

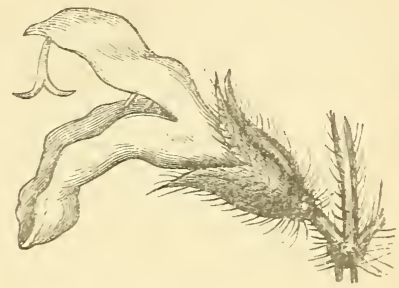

Fig. 79.-Salvia Officinalis. (Old bloom.)

The next figure represents the very curious arrangement of the stamens in the Erica tetralix, or common heath. These, eight in number, are seen standing round the style, at about half its length.

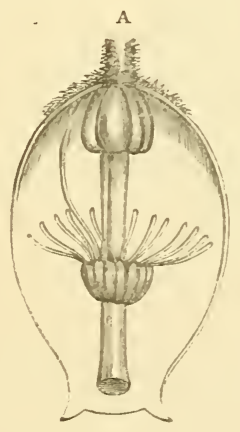

Fig. 80.-A. ERICA 1ETRALIX.

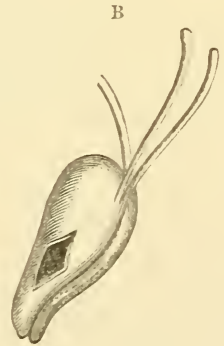

B. ANither of Tetralix.

Each is held by a long filament (only one of which is shown in the figure), and is armed with a horn-like process. When the anthers are ripe, the pollen would escape from openings in their sides, were it not that the little slits abut on each other. When, 
however, a bee visits the flower, and thrusts up her proboscis, this strikes against one of the little horns, and pulls apart its anther from the rest. Pollen then drops on the bee's head, to be carried by it to other blossoms, which, while receiving a portion brought to them, in their turn give the bee a supply to carry to other flowers. It is a very salutary thing for the propagation of the heath that bees have such a strong liking for its nectar, and are thus induced to perform, albeit unconsciously, the process of fertilisation.

In the strawberry the stigmas are ripe long before the pollen is ready; and hence we understand why

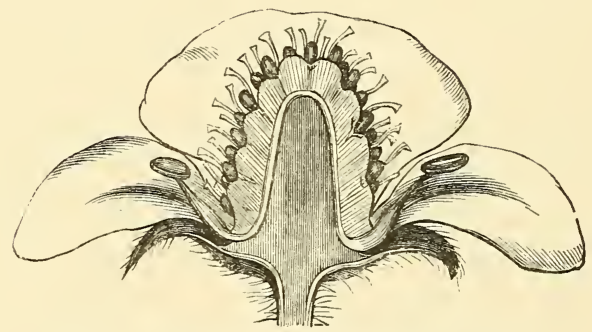

Fig. 8r.-Section of Strawberry Blojm.

the Creator has arranged that the nectar of these blossoms should be so attractive to the bees, whose visits are so necessary for the development of the fruit. When fertilisation takes place, growth proceeds in the ordinary manner, and with results so satisfactory to mankind. Where pollen fails to fall on any of the multitudinous stigmas, we have a shrunken, hard, greenish mass. Any dish of strawberries will show where this has happened. It is said that to 
produce one perfect specimen of the fruit, from 100

to 300 separate fertilisations must be effected.

In the raspberry and blackberry again, each drupel, or little fleshy portion, of which very many make up one so-called berry, has had its own stigma, which an insect has visited; and hence again, we understand how it is that the flowers have been so largely endowed with nectar, as to entice the bees most freely to visit them.

In apple and pear blossoms we have other instances of the stigmas coming to maturity before the anthers ;

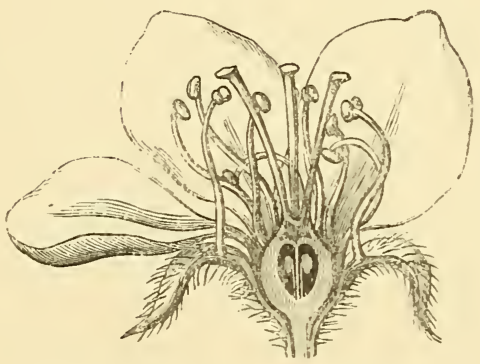

Fig. 82.-Section of Apple Bloom.

and, therefore, they require the intervention of bees for their fertilisation. Peaches, apricots, nectarines, plums, greengages, and, we might almost venture to assert, all our choicest and most valuable fruits, are dependent for their perfection upon the busy searchers after honey; and many a market-gardener would greatly increase his chances of good crops of fruit, were he to maintain a few stocks of bees in his orchards, and allow access for the active workers to his trees blossoming under glass-houses. 
From the vegetable world we might adduce many other evidences of the marvellous interdependence of the two great kingdoms of organic nature. Enough, however, has been said to illustrate this point, and we trust that some of our readers may be led to further investigation in this field, which opens up such wonders, and such pleasurable surprises, for all who care to trace evidences of the Creator's infinite resources, wisdom, and care for all that $\mathrm{He}$ has made.

Everywhere, also, on earth may be seen at work the grand law of self-sacrifice for others' needs. Very many facts which we have detailed in the natural history of bees, illustrate this most thoroughly. We may, indeed, say that the life of a worker, who will neither have progeny of her own, nor see many of the race for whom she spends her powers, is one continued offering of herself for the welfare of the community. "As the Latin poet says, Sic vos non vobis, mellificatis apes; and thus these unselfish toilers, beside teaching us many another lesson, seem to foreshadow, and to lead our thoughts to, the infinite gift of Him "who gave Himself for us" that we in and through Him might have life.

God has written tokens of $\mathrm{His}$ wisdom and love around us everywhere. None who reverently observe any of $\mathrm{His}$ works can fail to see His attributes embodied throughout all nature. 


\section{CHAPTER XXVII.}

SUPERSTITIONS CONNECTED WITH BEES.

Superstitions likely to gather around Bees-Unlucky to Buy BeesIll Omen for a Swarm to Settle on a Dry Stick-"Have the Bees been told ?"-Turning Hives on the Death of the Owner-Probable Origin of these Errors.

ON a priori grounds it is only to be expected that various superstitions would arise at different times and in various countries with regard to bees. Insects displaying such marvellous instincts, such apparent adaptation of means to ends, such indications of reasoning and special intelligence, were sure to be credited with powers beyond those generally recognised in them. Hence we may account for some of the curious ideas about bees which have prevailed in certain localities.

There are other notions, however, the origin of which is more difficult to discover. Such, for instance, is the prejudice among ignorant beekeepers against selling for coin swarms or stocks. A purchase thus made is supposed to be likely to lead to misfortune for one of the two parties concerned. By some occult process, lying outside the 
range of reason or imagination, ill luck is thought to be attracted by bargains of this sort.

A correspondent of the Journal of Horticulture thus narrates the following incidents: "Last August I purchased a swarm, for which I paid ten shillings. So far as I could judge from my limited experience with bees, for the first fortnight they appeared to be doing well, but one night, about eight o'clock, I found they had deserted the hive, and were on the ground in a cluster the size of a large plate. I gently lifted the hive and placed it over the cluster. About ten o'clock I found most of the bees had gone up into the hive, which I then returned to its stand. For a short time the bees appeared to work, but one day, thinking they appeared very quiet, I lifted the hive, and discovered that it was quite empty of bees. There were three nice pieces of empty comb. I think the bees were teased by wasps. Our parishioners tell me I did two things wrong, and that in consequence my bees could not thrive. One was to give money for them, which is always unlucky; the other was, that I did not have them at the right time of the year. I ought to have had them on Old Christmas Day. Is there anything in these ideas?"

The correspondent signed herself "A Clergyman's Wife," and the explanation of her want of success was not far to seek. She had been taken in by the vendor of her bees. A poor swarm had been palmed off upon her, and one so manifestly weak, and having, so late in the comb-making and honey-gathering time as August, only three small combs, was doomed to perish with cold and starvation. The poor insects, 
as a forlorn hope, had deserted their hive for what they trusted might be better quarters. The fallacy of the coin having had anything to do with their destruction, takes rank with the disinclination of some people to accept from a friend the present of a pocketknife, unless the donor will take a halfpenny in exchange; or with the old saying "Helping to salt is helping to sorrow." We can hardly suppose that the kindly sort of freemasonry, which now exists among bee-keepers, has ever proceeded so far as to make any one always willing to give his swarms or stocks to another. If so, the benevolence once current has degenerated into a willingness, even among the devotees to the supersition of which we are speaking, to accept full value in the way of barter if not in cash. Whatever its origin, we feel satisfied the days of this prejudice are numbered. With the immense spread of apiculture now taking place experience and common sense will sweep away this psychological cobweb, as so many others have been made to disappear under the same powerful agencies.

As to the other superstition about "Old Christmas Day" being the proper time for procuring a stock, the probability is that seasons sacred to the memory of events in the life of our Lord Jesus Christ would have special attributes of good fortune attributed to them. But the actual reason why stocks purchased at the above-named period would be pretty sure to do well is, that by Old Christmas Day they would have passed the perils of early winter, and would be hardly likely to find a buyer unless their weight indicated that they had food supplies sufficient to last till the flowers came again. 
A second notion of this kind is, that if a swarm settles on a dry stick or dead tree, the bees will not long survive. Doubtless, many persons could be found to state that in their own apiaries they had seen instances in which the one event had followed the other. We, indeed, have had one such coincidence - a case in which a swarm settled on a stake supporting an espalier apple-tree, and died during the ensuing winter. Still, we are unable to believe that there is any real connection between the incidents. Living trees offer so many inducements to a swarm on the wing for settling-the benefit of shade above all-that it is not to be wondered at that branches with foliage are, if accessible, almost always chosen by the insects for alighting on. It is just possible that an old and feeble queen may occasionally, when heading a swarm, be unable to fly farther than a very short distance, and, through fatigue, may settle on a post or other leafless wood. Of course such a queen would be likely to die within a few months at most, and thus involve the loss of the colony during the next winter. Hence the idea we are speaking of may have arisen.

We come now to a notion more widely prevalent than either of the preceding, and perhaps even more absurd. We allude to the supposed necessity of informing the bees of the death of their owner or of any member of his family. So strongly is this fallacy held, that in many country districts, especially among the cottagers, the question after a decease in the household "Have the bees been told?" is almost as much a matter of course as an inquiry whether the undertaker has been sent for. Even in the depth of winter, it is thought by believers in this superstition 
needful to "wake the bees," albeit we know that they are not asleep, and tell them of the sad event, in which they are supposed to have so profound an interest. In Maude's Antiquities we read of the following case in point: "A gentleman at a dinner table happened to mention that he was surprised, on the death of a relative, by his servant inquiring whether his master would inform the bees of the event, or whether he should do so. On asking the meaning of so strange a question, the servant assured him that bees ought always to be informed of a death in the family, or they would resent the neglect by deserting the hive. This gentleman resides in the Isle of Ely, and the anecdote was told in Suffolk. One of the party present, a few days afterwards took the opportunity of testing the prevalence of this strange notion, by inquiring of a cottager, who had lately lost a relative, and happened to complain of the loss of her bees, whether she had told them all she ought to do. She immediately replied, 'Oh! yes, when my aunt died I told every skep myself, and put them into mourning.' I have since ascertained the existence of the same superstition in Cornwall, Devonshire, Gloucestershire (where I have seen black crape put round the hive or on a small stick by its side), and Yorkshire. There are many other singular notions afloat as to these insects. In Oxfordshire I was told that, if man and wife quarrelled, the bees would leave them.

"In the Living Librairie, Englished by John Molle, I62I, page 283, we read, "Who would beleeve without superstition (if experience did not make it credible) that most commonly all the bees die in 
their hives if the master or mistress of the house chance to die, except the hives be presently removed into some other place? And yet I know this hath hapned to folke no way stained with superstition.' A vulgar prejudice prevails in many places of England that, when bees remove or go away from their hives, the owner of them will die soon after."

A correspondent of The Bee Journal writes under the head of "Norfolk Bee-Superstition": "A neighbour of mine had bought a hive of bees at an auction of the goods of a farmer, who had recently died. The bees seemed very sickly, and not likely to thrive; when my neighbour's servant bethought him they had never been put in mourning for their late master. On this he got a piece of crape and tied it to a stick, which he fastened to a hive. After this the bees recovered; and when I saw them they were in a very flourishing state-a result which was unhesitatingly attibuted to their having been put into mourning."

It is more difficult to suggest the possible origin of these curious fancies than to explain those previously mentioned. We may, perhaps, be on the right track in supposing that it has often happened, when the master or mistress of the bees has been ill or has died, the insects have missed, especially in autumn or early spring, the attention required for their welfare, and have, in consequence, perished. Then other persons of the household, unacquainted with the actual connection-in many instances a vital connection-between the bees and their owner, have attributed to them a bond not actually existing; and so, being led to the silly notion of the insects grieving, or needing to be informed, and to have their 
hive put in mourning, they have easily diffused a superstition in which each favouring coincidence would tell widely for its extended belief.

In the Norfolk case, narrated in The Bee Joumal, several possible explanations suggest themselves. In the first place, if the deceased farmer was an inhabitant of the same village as the buyer of his bees, and the hives were removed to a new home near their old one, most of the bees which had previously flown would return to their accustomed spot, and perish, not knowing their way to their changed abode. Then, in the course of a fortnight or three weeks, a good number of freshly-hatched insects would have strengthened the community, and these, naturally, would return with their supplies to the fresh domicile, and soon put matters into a flourishing condition.

Again, if dull gloomy weather followed the purchase of the bees, and was succeeded by brighter days, coincidently with the fastening of the stick and crape to the hives, the improved appearances would, of course, be due to warmer temperature and sunnier hours, without any change in the feelings of the insects from their abode being duly adorned with the emblems of mourning.

Lastly, the explanation may be simply that, when the stock was bought it was in poor condition, but that in two or three weeks, by the hatching of brood in the natural course of events, a greatly improved condition of affairs had come about. The first of these explanations, however, is probably the correct one.

One more superstitious custom is said to prevail in Devonshire, viz., at the funeral of a deceased bee 
keeper, the turning round of every hive that belonged to the departed, and this just at the moment the corpse is being carried out of the house. We do not pretend to explain this curious fancy. It may have originated in an experiment to avert the supposed disastrous connection between the bees and the death of their owner. Anything would seem to do for a charm to minds imbued with superstition.

Borlase, in his Antiquities of Cornwall, mentions one other superstition of apiarians of that county. He says: "The Cornish to this day invoke the spirit Browny when their bees swarm; and think that their crying 'Browny, Browny, will prevent their returning to their former hive, and make them pitch and form a new colony."

It is not wonderful that the many extraordinary facts connected with bees, coming at various times under human observation, should have led to notions of marvels, founded, not on observation, but on fancy. There is a strong tendency in the human mind to desire explanations of phenomena, and where there has been no scientific training in observation, false deductions are easily arrived at, or guesses as to causes are made, which have no foundation in fact. Bee-keeping has, for the most part, till in quite recent times, been chiefly in the hands of people of the more ignorant classes, among whom wonderful stories easily arise, are rapidly propagated, and tenaciously believed. Any circumstances seeming to support a previously established fancy would serve to increase the strength of superstition; while any number of instances not corroborating prevailing ideas would be disregarded. But, 
when once the spirit of sound investigation is applied to these vulgar errors, they become so manifestly absurd, that the marvel is how they can possibly have arisen.

Without doubt, there are many extraordinary facts connected with bees still awaiting the observation and the explanation of explorers in this department of natural history. Problems connected with the working of mind in the lower animals; the relations between reason and instinct; the functions of particular organs in these and other insects; the transmission of faculties not possessed by either parent in particular races; the direction and variation in the working of inherent faculties, through the agency of man, are subjects opening up most interesting fields of inquiry, which we would point out to those who have the inclination, leisure, and opportunities for pursuing investigations. We are satisfied that efforts and time thus devoted will be well repaid by the pleasure which springs from knowledge, and will lead in all devout minds to enlarged admiration of the wisdom and beneficence of $\mathrm{Him}$, from whose creative power the varied structures of animal life have come, and from whose infinite resources have been bestowed all those faculties which call forth our astonishment and delight as we study the facts of insect life. The deepest impression on mind and heart will be that embodied in the exclamation of the ancient Hebrew poet, "O Lord, how manifold are Thy works: in wisdom hast Thou made them all." 


\section{CHAPTER XXVIII.}

THE PROFITS OF BEE-KEEPING.

Methods of Honey-taking - Straw-Caps - Bell-Glasses - Sections Frames-Extractors-Run Honey-Average Returns of Hives.

IN our introduction, reference was made to the money-returns likely to be derived from bee-keeping by persons of ordinary good sense, who learn to manage their hives according to modern methods. Some few facts relating to this point may be advantageously added.

With the different straw-skeps in use, three methods of honey-taking may be adopted, without killing the bees. Among cottagers the usual plan is to put on to the stock-hive a "cap" or smaller straw-hive, and to remove this when full. Others, more wisely, induce their bees to work in bell-glasses of various sizes and these, when nicely filled, are very saleable, at a shilling or fifteen pence per lb. A third plan is to fit a certain number of the "sections" described in Chapter XVII. into a box or crate, and to place these on a strong stock. In the height of a good season, 
from $\mathrm{I} 2 \mathrm{lbs}$. to I $5 \mathrm{lbs}$. of the purest honey ought to be gathered in three or four weeks, by any of these methods.

With the bar-frame hives, either bell-glasses, or "sections," may be still more advantageously filled; because, by judicious examination and treatment of the stocks, these may be strengthened and helped, so as to be in the most favourable condition for storing honey in large quantities. It is no uncommon thing for $40 \mathrm{lbs}$. or $50 \mathrm{lbs}$. to be taken in "sections" from a single flourishing hive; and, in an ordinary season, the average amount from each stock ought not to be less than $20 \mathrm{lbs}$. Much, however, will depend on the control exercised over swarming. Of course the more numerous the population is kept, the greater will be the quantity of stores secured. If colony after colony is allowed to be sent off, the less will be the strength of the parent-community for food-gathering. Still, one swarm and $20 \mathrm{lbs}$. of honey in the season is not an unreasonable amount to expect from a really good hive.

Again, from the modern wooden hives, frames of well-filled and sealed comb may be taken, and after this has been cut out, the frames may be put back into their places, having been first supplied with "foundation," to give help and direction to the bees in working out new combs for refilling. One such frame of sealed honey should weigh 5 lbs. or $6 \mathrm{lbs}$.

Another plan, yielding by far the largest results, is to throw out the honey from the combs as they are filled. By means of "extractors," of which there are several kinds, the operation is very easy. The sealed cells of one side must be uncapped, and the 
frame then subjected to rapid rotation, which will cause the liquid to fly out through centrifugal tendency. Having cleared one side, the other must be operated upon in the same manner, and then the emptied combs should be put back into the hive, in the same order as that in which they have been taken out. In this way very large quantities of honey may be obtained; for the bees, having no fresh comb to make, throw all their energies into repairing and refilling the cells from which their stores have been extracted. The liquid from the unsealed portions of the comb is apt to be thin, and is then called "unripe." It requires to have some of its water evaporated, either by exposure to the air or to heat. If this precaution is neglected, this dilute honey is liable to ferment and turn sour. The bees never seal any in the cells till it is of the proper consistency for keeping. It is curious they should know when it is in suitable condition for covering up from the air.

Marvellous accounts are received from time to time of the quantities of honey obtained by bee-keepers who make free use of the "extractor." Single hives have been known to yield in one season over $80 \mathrm{lbs}$. in weight. The most satisfactory results are, probably, secured by a selection of one of the various methods of honey-taking to which we have alluded. The nature of the hive; the strength of the stock; the prevention of swarming, or its permission; the supply of food required for the honeyless part of the year,-all have to be taken into consideration in deciding upon the method of removing honey, and the amount which shall be abstracted. 
For ordinary home use, run honey is most serviceable. As it can be sold, moreover, at only a less price than that in sections or frames, there is this further inducement for its consumption rather than its sale. Ordinarily, not more than tenpence or a shilling a pound, at most, can be obtained for it; while sealed honey in sections, or in frames, is worth considerably more.

We need hardly say that the weather is a most important factor in the success or failure of beekeeping, in any particular year. Apiculturists, like agriculturists, are subject to many and great alternations of hope and fear. The brightest prospects of a bountiful honey-harvest are often blighted by rainy or ungenial days in May and June; and if these are succeeded by a cloudy, cold July, the bees will not only not store any more honey than they will themselves require, but may very possibly need liberal supplies of syrup in the autumn to carry them through the winter.

Speaking in general terms of the profit to be made by amateur bee-keepers, we may safely say that, in a series of years, the average returns ought to be sufficient to pay the expenses of maintenance, and to yield, in addition, swarms and honey to the value of, at least, Il. per hive. Such results will, of course, not be attained without patient and careful attention to the apiary; but such attention will be further rewarded by the pleasures derivable from a knowledge of the habits of the wonderful insects; from the successful pursuit of a rational and inexpensive hobby; from the ability to interest and instruct other people in this department of natural history; and lastly, but 
not least, from enlarged conceptions of the attributes of the Creator, whose almighty power and wisdom are proclaimed alike by "sun and moon, and stars of light; mountains and all hills; fruitful trees and all cedars; beasts and all cattle ; creeping things and flying fowl."

THE END. 





\title{
Boston Public Library
}

\section{Central Library, Copley Square}

\author{
Division of \\ Reference and Research Services
}

The Date Due Card in the pocket indicates the date on or before which this book should be returned to the Library. Please do not remove cards from this pocket. 


\section{B. P. L. Bindery, juil $\approx 21904$}

$$
\begin{aligned}
& 26 \cdots \\
& 4 \%
\end{aligned}
$$


